UNIVERSIDADE DE SÃO PAULO

INSTITUTO DE FÍSICA DE SÃO CARLOS

DEPARTAMENTO DE FÍSICA E CIÊNCIA DOS MATERIAIS

\title{
APLICAÇÃO DA TÉCNICA DE \\ VARREDURA-Z PARA A DETERMINAÇÃO DE \\ PARÂMETROS TÉRMICOS
}

Fernando Fuzinatto Dall'Agnol

ok

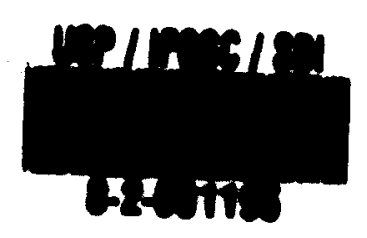

Dissertação apresentada ao Instituto de Física de São Carlos, da Universidade de São Paulo, para obtenção do título de Mestre em Ciências: Física Básica

Orientador: Prof. Dr. Sérgio Carlos Zilio

São Carlos -SP

1998 
Dall'Agnol, Fernando Fuzinatto

Aplicação da técnica de varredura-z para a determinação de parâmetros térmicos/ Fernando Fuzinatto Dall'Agnol.--São Carlos, 1998.

$90 \mathrm{p}$.

Dissertação (Mestrado)-Instituto de Física de São Carlos, 1998.

Orientador: Prof. Dr. Sérgio Carlos Zilio.

I. Título.

1. Varredura-z. 2. Efeitos térmicos. 3. Meios Opacos. 
UNIVERSIDADE DE SÃO PAULO

Instituto de Física de São Carlos

Av. Dr. Carlos Botelho, 1465

CEP 13560-250 - São Carlos - SP

Brasil

Fone (016) 272-6222

Fax (016) $272-2218$

MEMBROS DA COMISSÃO JULGADORA DA DISSERTAÇÃO DE MESTRADO DE FERNANDO FUZINATTO DALL'AGNOL APRESENTADA AO INSTITUTO DE FISICA DE SÃO CARLOS, DA UNIVERSIDADE DE SÃO PAULO, EM O6 DE MARÇO DE 1998.

COMISSÃO JULGADORA:

Prof. Dr. Sékgio Carlos Zilio/IFSC-USP

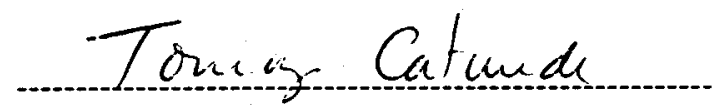

Prof. Dr. Jomaz Catunda/IFSC-USP

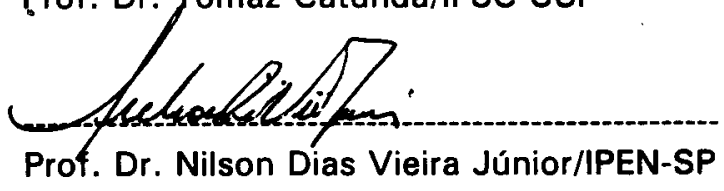

- Educação para o Brasil 
$\grave{A}$ Chê pelo amor e compreensão, e aos meus pais pela oportunidade $e$ sacrificios. 


\section{Agradecimentos}

- Ao professor Sérgio Carlos Zilio pela valiosa orientação, paciência, apoio, amizade, confiança, ajuda e discussões teóricas durante a realização deste trabalho.

- Aos meus professores, tanto do mestrado quanto da graduação, que tanto contribuiram e ainda contribuem para minha formação e da formação de meus colegas

- A todos os meus amigos de graduação e de mestrado pelos anos de amizade e cooperação. Em especial ao Jabah, meu fiel parceiro de escalada e de república

- Aos meus companheiros de experimento Cleber Renato Mendonça, Daniel Varela Magalhães e Lino Misoguti pela ajuda e discussões.

- A todos os outros amigos do grupo André, Andrea, Aparecida, Débora, Flávinho, Gugs, Humb, Joatan, Kilvia, Liliane, Marcassa, Marilia, Patricia, Rick, Serginho, Sergião, Vanderlei e Viviane pela agradável convivência

- Ao Gilberto e Rui pelo apoio técnico e à Bel pelo apoio administrativo.

- Aos técnicos da oficina do óptica e mecânica pelo apoio técnico.

- Ao Mauro pela preparação das amostras de poliestireno dopadas com DR1 


\section{Índice}

Lista de figuras........................................................................................i

Lista de tabelas.....................................................................................iii

Lista de Símbolos.........................................................................iv

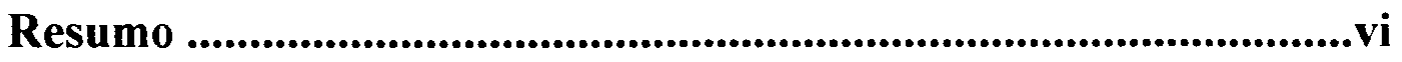

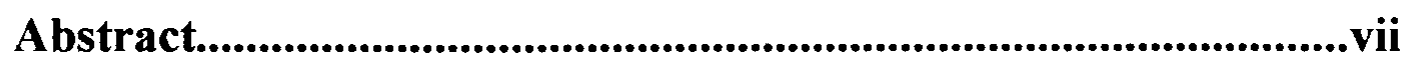

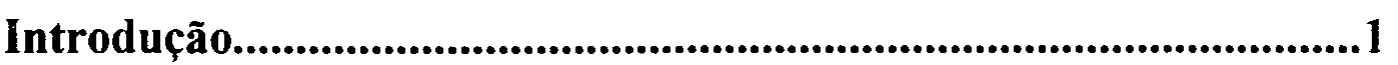

I. Auto-Modulação de Fase por Efeitos Térmicos....................................5

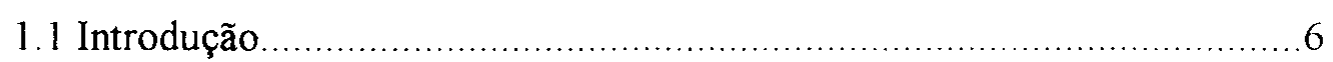

1.2 Auto-modulação de fase na transmissão...............................................

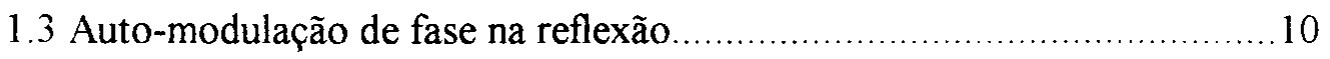

1.4 Auto-modulação de fase por efeitos térmicos ........................................11

1.4.1 Equação de Navier-Stokes (ENS) .............................................11

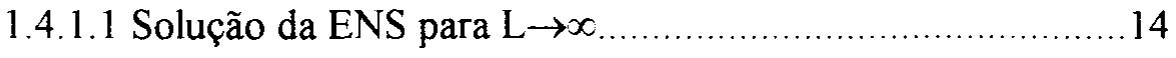

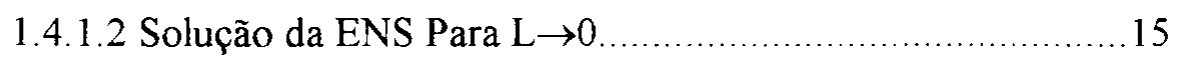

1.4.2 Características das amostras..................................................... 16

1.4.3 Auto-modulaçâo de fase em liquidos .......................................17

II A Técnica de Varredura-Z........................................................18

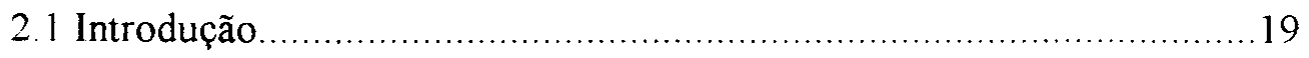

2.2 Descrição experimental da técnica de varredura-z …...........................20

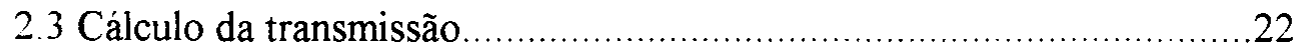

2.3.1 Integral de difração de Fresnel-Kirchhoff ..................................23

2.3.2 Adequação experimental para simplificar a integral de difração..27

2.4 Variações experimentais da técnica de varredura-z ............................28

2.4.1 Técnica de varredura-z resolvida no tempo...........................29

2.4.1.1 Cálculo da transmitância para amostras transparentes....30

2.4.2 Técnica de varredura-z resolvida em freqüência .....................32

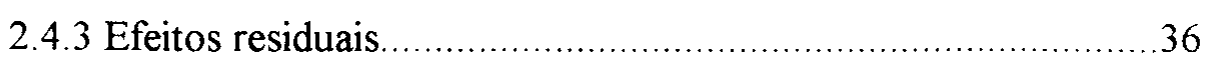


III Técnica de Varredura-Z por Reflexão.......................................38

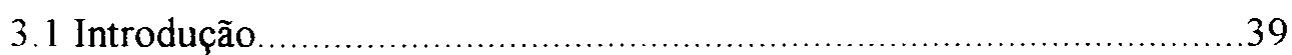

3.2 Descrição experimental da técnica de varredura-z por reflexão.............39

3.3 Transmitância pela abertura para amostras grossas $(\mathrm{L} \rightarrow \infty) \ldots \ldots \ldots \ldots \ldots . . . . .40$

3.3.1 Propriedades da transmitância para amostras grossas devido ao termo linear no tempo

3.3.2 Propriedades da transmitância para amostras grossas devido ao

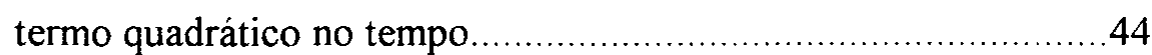

3.4 Transmitância pela abertura para amostras finas $(\mathrm{L} \rightarrow 0) \ldots \ldots \ldots \ldots \ldots \ldots \ldots . . . .45$

3.4.1 Propriedades da transmitância devido aos termos linear e quadrático no tempo para amostras finas .......................................46

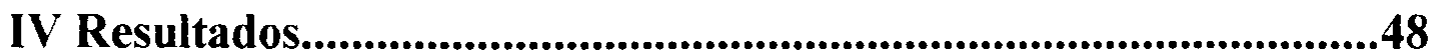

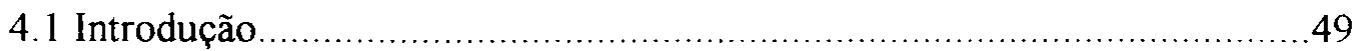

4.2 Medidas por transmissão na água........................................................ 49

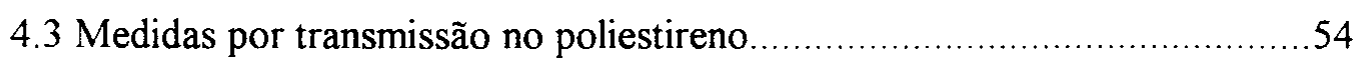

4.4 Medidas em vidros dopados com semicondutor (VDS) ...........................55

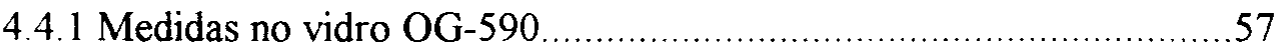

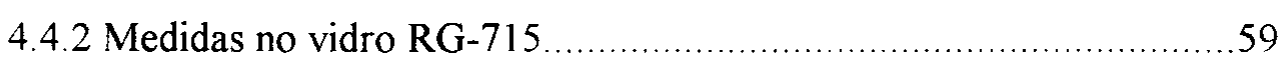

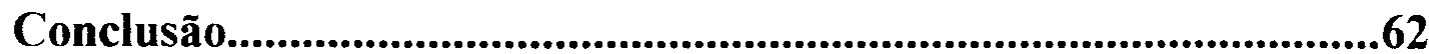

Apêndice A- Cálculo da Temperatura nas Amostras........................65

A1-Distribuição de temperatura em meios semi-infinitos .....................................66

A2-Distribuição de temperatura em duas dimensões para meios infinitos............70

Apêndice B- Cálculo da Deformação na Superfície..............................72

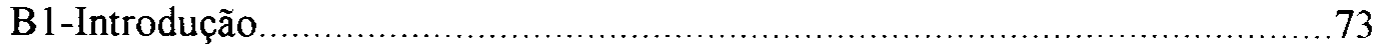

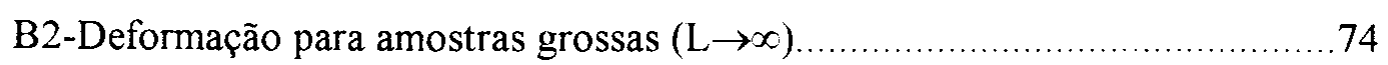

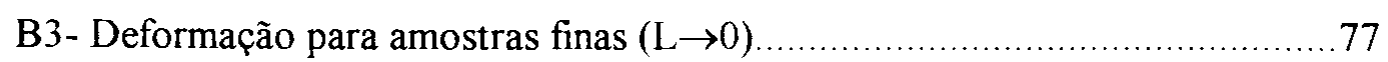

Apêndice C- Decomposição Espectral do Sinal..................................80

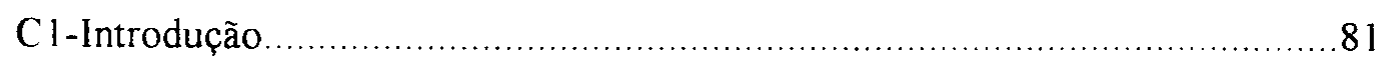

C2-Análise espectral do sinal para frequeências suficientemente altas..................81

C3-Análise espectral do sinal para frequências moderadamente altas.................85

C4-Análise espectral para freqüências baixas ..............................................87

Referências.........................................................................................888 


\section{Lista de figuras}

Figura 1.1 Comportamento do campo elétrico da luz ao longo de dois meios refringentes.

Figura 1.2 Modulação de fase dentro de duas amostras com nãolinearidades de sinais contrários.

Figura 1.3 Representação da variação de temperatura em $(R, Z)$ devido a uma quantidade $\mathrm{dQ}$ de calor depositada no volume $d X^{\prime} \times d Y^{\prime} \times d Z^{\prime}$ em $\left(X^{\prime}, Y^{\prime}, Z^{\prime}\right)$

Figura 2.1 Arranjo experimental utilizado na técnica de varreduraZ.

Figura 2.2 Representação esquemática do efeito de uma não-linearidade positiva $\left(\mathrm{n}_{2}>0\right)$ na técnica de varredura- $\mathrm{z}$

Figura 2.3 Transmissão normalizada em função da posição da amostra

Figura 2.4 Diagrama para calcular o campo em $\mathrm{P}_{1}$ devido à amostra $\mathrm{S}$, em função da fonte do campo em $\mathrm{P}_{\mathrm{s}}$

Figura 2.5 Evolução temporal da transmitância assistida num osciloscópio para uma não- linearidade positiva ................................ 30

Figura 2.6 Variação $\mathrm{de} \mathrm{dn} / \mathrm{d} \theta$ com a temperatura para a água................... 32

Figura 2.7 Representação da transmitância com os termos linear e quadrático no tempo.

Figura 2.8 Variação teórica de $\mathcal{R}$ em função da frequêencia graficada com o termo linear no tempo (curva cheia), e com o termo quadrático (curva pontilhada) para uma amostra fictícia.

Figura 2.9 Representação de f. $\Delta \mathbb{Z}($ f) em função de $f$.

Figura 2.10 f. $\Delta R$ em função de $f$ para o vidro dopado com semicondutor $\mathrm{RG}-715$.......

Figura 3.1 Montagem experimental da técnica de varredura-z por reflexão. 40

Figura 4.1 Evolução temporal da transmitância para a água numa dada posição. 
Figura 4.2 Representação da modulação da luz com duty cycle" de $92 \%$ utilizada na técnica de varredura-z resolvida no tempo............. 51

Figura 4.3 Medidas resolvidas no tempo na água ............................... 51

Figura 4.4 Medida resolvida em frequência na água................................ 53

Figura 4.5 Medidas resolvidas no tempo no poliestireno......................... 54

Figura 4.6 Variação dos coeficientes linear e quadrático no tempo medidos no filtro OG-590 com a técnica RT

Figura 4.7 Medida no vidro OG-590 com a técnica de varredura-z resolvida em frequência.

Figura 4.8 Gráficos de $T^{(1)}(Z)$ e $T^{(2)}(Z)$ para medidas resolvidas no tempo 59 para o vidro $\mathrm{RG}-715$

Figura 4.9 Medida resolvida em freqüência no vidro RG-715.

Figura A1 Representação da variação de temperatura em torno de $(R, Z)$ devido a uma quantidade $\mathrm{dQ}$ de calor depositada no volume $d X^{\prime} \times d Y^{\prime} \times d Z^{\prime}$ em $\left(X^{\prime}, Y^{\prime}, Z^{\prime}\right)$..

Figura A2 Representação da variação da intensidade com a profundidade em um elemento de volume devido a um feixe gaussiano atenuado exponencialmente......

Figura A3 O comportamento da difusão de calor num meio semi-infinito a partir de uma fonte puntual é idêntico ao de um meio infinito com duas fontes puntuais simétricas em relação à interface........

Figura C1 Representação esquemática de um periodo do sinal visto no osciloscópio

Figura C2 Gráfico da expressão (C9) conforme acrescentamos termos à somatória.

Figura C3 Gráfico da função (C13) com 100 termos. A curvatura da evolução temporal é devida ao termo $\mathrm{T}^{(2)}(Z)$ que leva em conta a difusão de calor. 


\section{Lista de Tabelas}

Tabela 3.1 $\Delta Z_{p v}{ }^{(1)}$ em função de $A_{0}$

Tabela 4.1 Comparação entre os valores medidos pela técnica de varredura-z resolvida no tempo e valores tabelados para a água.

Tabela 4.2 Parâmetros térmicos tabelados para a água.

Tabela 4.3 Comparação entre os valores medidos pela técnica de varredura-z resolvida no tempo e valores tabelados para o poliestireno.

Tabela 4.4 $\alpha_{\mathrm{ab}}$ em função do comprimento de onda para os vidros OG-590 e RG-715.

Tabela 4.5 Valores obtidos para o vidro OG-590 pela técnica RT

Tabela 4.6 Valores obtidos para o vidro RG-715 pela técnica resolvida no tempo

Tabela 4.7 Comparação entre os valores de $\alpha_{\text {ter }}(1+v) /\left(\rho C_{p}\right)$ para os vidros OG590 e RG-715 usando as técnicas de varredura-z RT e RF. 


\section{Lista de Símbolos}

k

módulo do vetor de onda.

L

comprimento da amostra.

$\mathrm{dn} / \mathrm{d} \theta$

variação do índice de refração com a temperatura.

$\Delta \theta$

variação de temperatura

$\Delta \mathrm{T}^{(1)}$

amplitude do coeficiente do termo linear no tempo.

$\Delta \mathrm{T}^{(2)}$

amplitude do coeficiente do termo quadrático no tempo.

w raio do feixe gaussiano.

u(r) módulo da deformação superficial.

v módulo de Poisson.

$\mathrm{k}_{\mathrm{ter}} \quad$ condutividade térmica.

$\rho C_{p} \quad$ capacidade térmica por unidade de volume

D difusividade térmica.

$\mathrm{R}$ coordenada radial em unidades do raio do feixe do laser $\mathrm{R}=\mathrm{r} / \mathrm{W}$.

$\mathbb{F}(Z) \quad$ razão entre as primeiras duas componentes de Fourier do sinal.

$\mathrm{X}, \mathrm{Y}, \mathrm{Z}, \mathrm{X}^{\prime}, \mathrm{Y}^{\prime}, \mathrm{Z}^{\prime} \quad$ coordenadas cartesianas em unidades do raio do feixe do laser.

Z (Capitulo II em diante) posição da amostra em unidades do parâmetro confocal do feixe $\left(\mathrm{Z}=\mathrm{z} / \mathrm{z}_{0}\right)$

$T^{(1)}(Z) \quad$ coeficiente do termo linear no tempo em função da posição

$T^{(2)}(Z) \quad$ coeficiente do termo quadrático no tempo em função da posição.

$P \quad$ potência incidente na amòstra.

$\mathbf{P}_{\mathrm{ab}} \quad$ potência absorvida pela amostra.

$\alpha_{\text {ter }} \quad$ coeficiente de dilatação térmica da amostra.

$\mathrm{A}_{0} \quad$ coeficiente de absorção em unidades de $\mathrm{w}_{0}{ }^{-1}\left(\mathrm{~A}_{n}=\alpha_{\mathrm{ab}} \mathrm{W}_{0}\right)$.

A coeficiente de absorção em unidades de $W^{-1}\left(A=\alpha_{\text {ter }}\right)$

f freqüência, variável de integração

fi variável de integração.

K variável de integração.

$\alpha_{\mathrm{ab}} \quad$ coeficiente de absorção da amostra. 
$\Delta Z_{\mathrm{pv}} \quad$ separação entre o pico e o vale.

$\Delta \mathrm{T}_{\mathrm{pv}} \quad$ amplitude do sinal entre o pico e o vale

$\Delta R$

$\phi_{\mathrm{L}}$

$\phi_{\mathrm{NL}}$

$\mathrm{n}_{2}$

amplitude da variação de $\mathbb{R ( Z )}$.

fase linear.

fase não-linear

indice de refração não-linear. 


\section{Resumo}

A técnica de varredura-z tem sido bastante utilizada para a determinação do índice de refração não-linear $\left(\mathrm{n}_{2}\right)$ em meios transparentes. Apresentamos neste trabalho uma análise teórica e resultados da técnica de varredura-z por reflexão, visando o estudo de efeitos térmicos em amostras que possuem coeficientes de absorção muito grandes. Extensões à técnica, tais como: a varredura-z resolvida no tempo e varredura-z resolvida em freqüência puderam ser aplicadas para medir efeitos térmicos, pois estes são relativamente lentos nos materiais que medimos (água, polímero e vidro). Das componentes linear e quadrática da evolução temporal da transmitância, ou, da segunda componente de Fourier de curvas obtidas em duas frequências, pode-se extrair parâmetros térmicos como: a capacidade térmica por unidade de massa e a difusividade térmica. Propriedades térmicas são de grande interesse na usinagem de peças, e em estudos sobre tensões estruturais e novos materiais. Pela teoria aqui desenvolvida, dada as constantes térmicas, é possivel distinguir os efeitos térmicos e eletrônicos nas amostras que apresentam os dois. 


\begin{abstract}
The Z-Scan technique is the most popular one for the determination of the nonlinear index of refraction $\left(\mathrm{n}_{2}\right)$ of transparent media. In this work we present a theoretical analysis and results of the reflection z-scan technique, aiming the research of thermal effects in highly absorbing materials. Extensions of the technique, such as the timeresolved z-scan and the frequency resolved z-scan could be applied to measure thermal effects because they are relatively slow in the materials that we have measured (water, polystyrene and glass). From the linear and quadratic terms of the transmittance time evolution, or, from the second Fourier component of curves obtained in two frequencies, one can extract thermal parameters like: the heat capacity per unit mass and the thermal diffusion coefficient. Thermal properties are of great interest in the manufacture of pieces, and in the study of structure strains and new materials. By the theory presented here, if thermal constants are given, one can distinguish between thermal and electronic effects in samples that presents both.
\end{abstract}


Introdução 
A óptica não-linear (ONL) trata de fenômenos que só podem ser compreendidos quando incluímos na polarização do meio onde a luz atua, termos de ordem superior ao linear. A polarização para meios transparentes é usualmente expressa como [1]:

$$
\mathbf{P}=\chi^{(1)} \mathbf{E}+\chi^{(2)}: \mathbf{E E}+\chi^{(3)}: \mathbf{E} \mathbf{E E}+\ldots
$$

Os coeficientes $\chi^{(1)}, \chi^{(2)}$ e $\chi^{(3)}$ são denominados susceptibilidades de primeira, segunda e terceira ordem, respectivamente. Com estes três termos apenas, pode-se explicar a maioria dos fenômenos de ONL. Termos de ordens maiores são muito fracos e pouco estudados.

A óptica não-linear surgiu com a invenção do laser. Antes, não havia fontes monocromáticas suficientemente intensas para se observar estes fenômenos. A primeira observação de óptica não-linear foi feita em cristais de quartzo [2] com a geração de segundo-harmônico, onde parte da radiação em $694 \mathrm{~nm}$ de um laser de rubi era convertida em $347 \mathrm{~nm}$.

A técnica de varredura-z $[3,4]$, utilizada inicialmente para medir a susceptibilidade de terceira ordem $\chi^{(3)}$, tornou-se muito popular devido à sua precisão e simplicidade. Seguiram-se a ela, várias outras técnicas complementares para adequá-la a diferentes situações fisicas. As complementações utilizadas neste trabalho visam medir, não mais efeitos eletrônicos, mas efeitos térmicos, de cujos gráficos extraímos os parâmetros térmicos das amostras (difusividade, condutividade térmica e calor específico). Efeitos térmicos devido à difusão de calor, provocam na luz uma modulação de fase que ao contrário dos efeitos eletrônicos, não acompanham o perfil do feixe de 
laser. Cada material possui um conjunto único de parâmetros térmicos que são de extrema importância no cálculo de tensões internas e deformações estruturais devidas à inomogenidade da temperatura nestas estruturas. Estes estudos são importantes em processos de modelamento de peças de precisão e no desenvolvimento de novos materiais.

Fizemos medidas em várias classes de materiais como polímeros (poliestireno dopado com DR1), vidros dopados com semicondutores (filtros ópticos) e líquidos (água), que possuem parâmetros térmicos bem diferentes. Para o estudo de materiais opacos, desenvolvemos um aparato experimental para medidas por reflexão. Uma técnica semelhante já havia sido proposta por D. V. Petrov et al. [5], mas nela tem-se o inconveniente da linha de base do sinal normalizado variar segundo a função $1 / z^{2}$. Na montagem aqui apresentada a linha de base permanece constante. Também apresentamos uma teoria mais completa para descrever a difusão de calor. Entre as implementações à técnica de varredura-z, utilizamos a técnica resolvida no tempo [6] e a resolvida em freqüência [7]. A primeira nos permite fazer um acompanhamento temporal através de um osciloscópio de memória, de onde extraimos os parâmetros térmicos. Na segunda, a evolução temporal é decomposta em componentes de Fourier que são aquisicionadas por lock-ins. No capitulo I explicaremos como ocorre a auto-modulação de fase quando a luz atravessa um meio não-linear eletrônico ( $\chi^{(3)}$ apreciável), estendendo posteriormente a idéia para meios não-lineares térmicos, calculando a fase não-linear induzida. No capítulo II descreveremos a técnica de varredura-z e as implementações utilizadas. O capítulo III é dedicado a detalhar a técnica de varredura-z por reflexão que foi desenvolvida neste trabalho. No capítulo IV mostraremos os resultados obtidos com 
água, poliestireno e vidros dopados com semicondutores. Por fim, concluiremos discutindo a aplicabilidade da técnica e proporemos trabalhos futuros baseados no presente. 


\subsection{Introdução}

A incidência de luz sobre um dado material pode alterar seu índice de refração de uma maneira que depende da intensidade da onda eletromagnética. Tal variação pode ser originada por efeitos eletrônicos ou térmicos. Os efeitos térmicos não são locais, pois induzidos num ponto qualquer afetam toda a amostra, como veremos posteriormente. Esta não localidade gera dificuldades no tratamento matemático do problema. Embora estejamos interessados apenas no estudo dos efeitos térmicos, exporemos também a teoria sobre os efeitos eletrônicos, não só para completeza do trabalho, mas também para facilitar a introdução de conceitos e técnicas.

Não-linearidades eletrônicas têm sua origem fisica na oscilação não harmônica das nuvens eletrônicas dos átomos do meio quando submetidos ao campo elétrico da luz. Para tanto, este campo deve ser comparável ao campo interatômico. Nestas condições, a polarização de meios transparentes pode ser descrita em termos de uma série de potências do campo elétrico [1]:

$$
\mathbf{P}=\chi^{(1)} \mathbf{E}+\chi^{(2)} \mathbf{E} \mathbf{E}+\chi^{(3)} \mathbf{E E E}+\ldots
$$

Efeitos de variação do índice de refração estão ligados ao coeficiente do terceiro termo, $\chi^{(3)}$, da expansão da polarizzação do meio. Nestes materiais o índice de refração pode ser escrito como:

$$
\mathrm{n}=\mathrm{n}_{0}+\mathrm{n}_{2} \mathrm{I}(\mathrm{r})
$$

onde $\mathrm{n}_{0}$ é o indice para baixa intensidade, $\mathrm{n}_{2}$ é o índice não-linear e $\mathrm{I}(\mathrm{r})$ é a intensidade da luz dependente da posição radial. Todo meio que exibe um comportamento descrito pela expressão (1.2) é denominado de meio tipo Kerr, em analogia ao efeito Kerr eletro-óptico, no qual o índice de refração é modificado por um campo elétrico 
externo, induzindo uma birrefringência no material [8]. A diferença aqui é que o campo elétrico externo é o da luz e sua intensidade modula o índice de refração. A relação entre $n_{2}$ e $\chi^{(3)}$ é dada por [9]:

$$
n_{2}=\frac{3}{4} \frac{\chi^{(3)}}{4 n^{2} \varepsilon_{0}^{2} c}
$$

A polarização também pode ser modificada por transições eletrônicas. Neste caso, ao invés de uma simples deformação na nuvem eletrônica, tem-se a modificação completa do orbital atômico. $\mathrm{O}$ átomo excitado tem polarização diferente do átomo no estado fundamental, e como consequência, diferente índice de refração. Quando o efeito eletrônico é populacional, a expansão da polarização só é válida se a frequência da luz não estiver muito próxima de ressonâncias, ou seja, se o efeito for pequeno.

\subsection{Auto-modulação de fase na transmissão}

Para uma onda propagando-se num meio refringente, a velocidade é inversamente proporcional ao índice de refração e a frequência é constante. Desta forma, onde o índice de refração é maior, o número de oscilações por unidade de comprimento também o é (figura 1.1). Num meiọ tipo Kerr, o feixe sofre um número de oscilações por unidade de comprimento que é função da intensidade. Assim, podemos dizer que a fase da onda em dada posição radial é modulada pela intensidade do próprio feixe. A este efeito denominamos auto-modulação de fase. Para exemplificar, suponha uma onda com perfil gaussiano de intensidade, incidindo sobre um meio com índice não-linear positivo $\left(\mathrm{n}_{2}>0\right)$. No centro do feixe, a intensidade é maior e, portanto o índice de refração sentido pela luz é maior. A intensidade do feixe 
modula o índice de refração, que por sua vez modula a velocidade do feixe segundo a relação $v=\mathrm{c} / \mathrm{n}(\mathrm{I})$. Nas bordas, o feixe se adianta em relação ao centro, como mostra a figura 1.2. Na saída da amostra, os pontos de equifase não estão mais sobre um plano, como quando entraram no meio. Como os pontos de equifase definem a frente de onda, esta ganha uma curvatura côncava, neste exemplo. O feixe tende a convergir para o centro de curvatura segundo o princípio de Huygens [no qual, cada ponto da frente de onda se comporta como uma fonte de ondas independente, mas em fase com todos os outros pontos desta frente]. Para um índice não-linear negativo $\left(\mathrm{n}_{2}<0\right)$, o feixe diverge (figura 1.2).

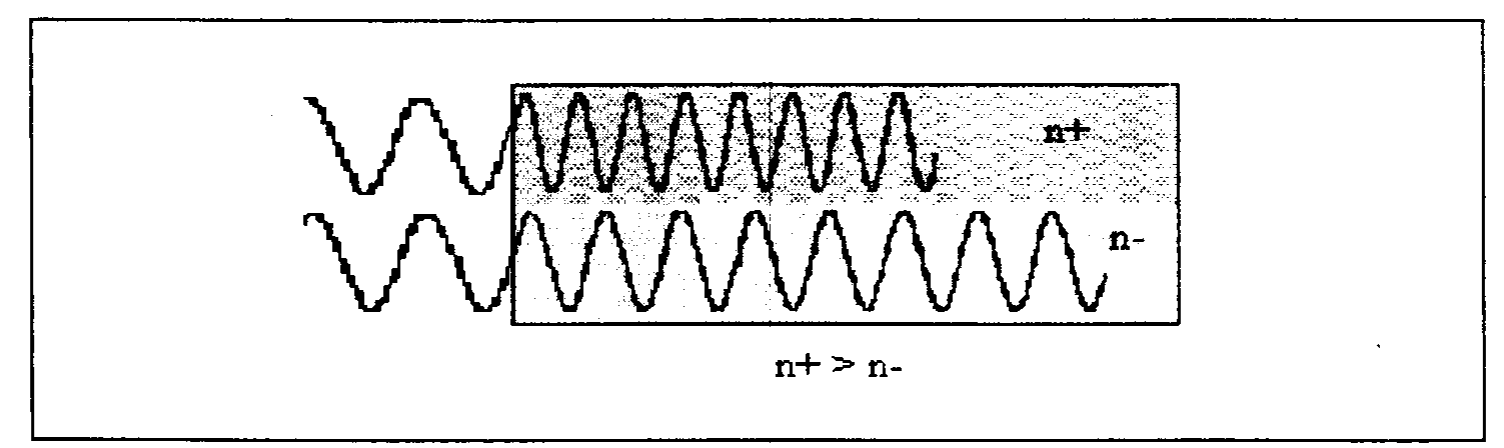

Figura 1.1: Comportamento do campo elétrico da luz ao longo de dois meios refringentes.

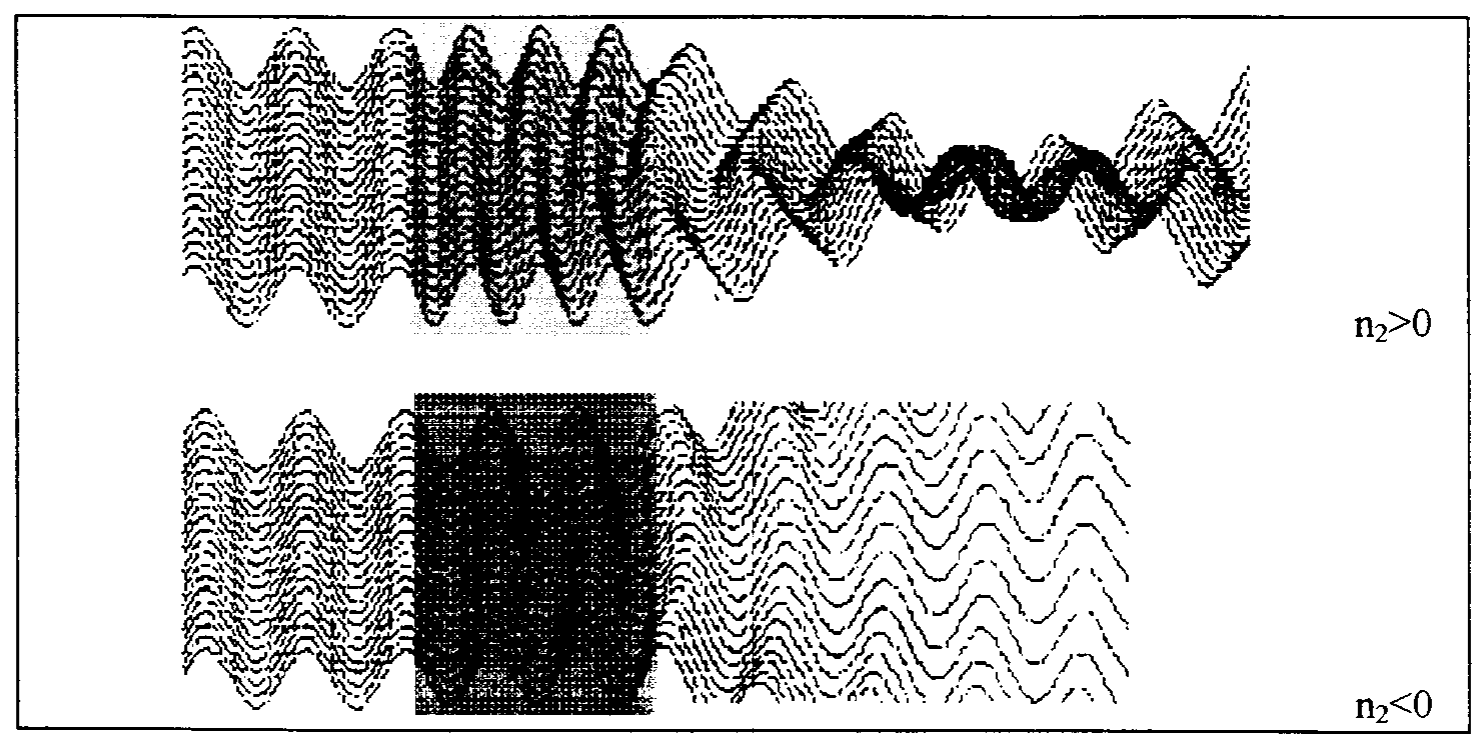

Figura 1.2: Modulação de fase dentro de duas amostras com não-linearidades de sinais contrários. 
Modulação de fase de feixes luminosos é um fenômeno comum na natureza. $\mathrm{O}$ piscar das estrelas numa noite de atmosfera turbulenta deve-se a flutuações na densidade do ar, e consequentes flutuações no índice de refração. Ora as flutuações levam à convergência da luz no observador, ora à divergência, resultando em cintilações. Fenômenos de convergência e divergência por modulação de fase podem ser observados próximos de superficies aquecidas, como na sombra de um isqueiro aceso. Na óptica fisica linear, os efeitos de convergência ou divergência por lentes são descritos em termos de modulação de fase [10]. A modulação de fase nestes exemplos é induzida por algum fator externo. Quando há auto-modulação, é a própria luz que induz sua modulação de fase

Baseado nas figuras 1.1 e 1.2 vemos que a fase não-linear é dada pelo módulo do vetor de onda no vácuo vezes a diferença de caminho óptico entre os pontos da coordenada radial do feixe. Quando a não-linearidade é térmica, a fase não-linear em meios transparentes é dada por:

$$
\phi_{N L}=k L \frac{d n}{d \theta} \Delta \theta
$$

onde $\mathrm{k}$ é o módulo do vetor de onda no vácuo, $\mathrm{dn} / \mathrm{d} \theta$ é a variação do índice de refração com a temperatura, $\Delta \theta$ é a variação de temperatura induzida pelo feixe e $\mathrm{L}$ é o comprimento do meio

Quando o efeito é eletrônico a variação de fase é dada por:

$$
\phi_{N L}=k n_{2} I(r) L
$$

onde I(r) é a intensidade em dada posição radial do feixe. 


\subsection{Auto-modulação de fase na reflexão}

Um feixe de ondas planas tem sua fase mudada de $\pi$ quando incide numa interface refletora. Se a interface for plana, toda a frente de onda tem sua fase mudada pelo mesmo fator e a onda refletida continua plana. Porém, em interfaces que apresentam uma curvatura, além da mudança de $\pi$, o feixe tem sua fase radial modulada pela curvatura, por percorrer distâncias diferentes até ser refletido. Como vimos na seção anterior, isto gera uma curvatura na frente de onda que leva o feixe a convergir ou divergir e, a menos do fator $\pi$, o tratamento matemático é idêntico. Dizemos que a luz é auto-modulada se a curvatura da interface é induzida pela própria luz. Neste caso, haverá uma fase não-linear, que para incidência normal fica [5]:

$$
\phi_{N L}(r)=2 k u(r)
$$

onde u(r) é altura da deformação induzida pela luz na superficie. O fator 2 leva em conta que as ondas que incidem sobre a deformação e as que incidem fora dela percorrem distâncias cuja diferença é o dobro do valor da deformação na superficie. É importante notar que só a deformação induzida pela luz contribuirá para a fase nãolinear. A equação (1.6) não leva em conta a variação do índice de refração com a intensidade que altera a refletividade ao longo da coordenada radial do feixe. Geralmente este efeito é desprezivel só sendo observado com laser pulsado de alta intensidade [11]. Nas amostras com que trabalhamos a fase não-linear é observada com baixa intensidade, de onde se conclui que só o efeito de dilatação térmica é importante. 


\subsection{Auto-modulação de fase por efeitos térmicos}

Em muitos casos a auto-modulação de fase, tanto por transmissão como por reflexão num meio refringente, são gerados pelo aquecimento destes meios. No primeiro caso, a passagem da luz aquece o meio alterando seu índice de refração, bem como o comprimento devido à dilatação térmica. No segundo caso quando a luz incidente é absorvida pelo meio, a dilatação térmica produz uma curvatura na superficie. Em ambos os casos, a luz sofre modulação de fase como visto nas seções anteriores

\subsubsection{A equação de Navier-Stokes (ENS)}

A fase não-linear induzida por uma interface refletora depende da deformação na superficie. Portanto devemos calcular como o meio se expande quando aquecido para compreendermos quantitativamente o valor desta deformação.

Quando se aquece um meio de forma inomogênea, cada ponto tende a dilatarse de acordo com a temperatura local. Se o meio for rígido, surgirão tensões internas que alterarão a dilatação de todo meio, e não somente do ponto considerado. A equação de Navier-Stokes descreve o comportamento do meio para uma dada distribuição de temperatura em função do módulo de Poisson $(v)$, onde entra a contribuição devido à rigidez estrutural da amostra. A ENS para um meio qualquer pode ser escrita como [12]:

$$
(1-2 v) \nabla^{2} \vec{u}+\nabla(\nabla . \vec{u})=2(1+v) \alpha_{t e r} \nabla \theta
$$

onde u é o vetor deslocamento de um elemento de volume em relação a sua posição inicial, $v$ é o módulo de Poisson, $\alpha_{\text {ter }}$ é o coeficiente de expansão térmica e $\theta$ é a 
temperatura. A temperatura, por sua vez, é encontrada resolvendo-se a equação diferencial de difusão de calor [13]:

$$
k_{t e r} \nabla^{2} \theta-\rho C p\left(\frac{\partial}{\partial}\right) \theta=-\frac{d Q}{d t}\left(X^{\prime}, Y^{\prime}, Z^{\prime}\right)
$$

onde $\mathrm{k}_{\mathrm{ter}}$ é a condutividade térmica, $\rho \mathrm{Cp}$ é a capacidade térmica por unidade de volume e $d \Omega / d t\left(X^{\prime}, Y^{\prime}, Z^{\prime}\right)$ é a taxa de calor por unidade de volume gerada no ponto $\left(X^{\prime}, Y^{\prime}, Z^{\prime}\right)$ do meio.

Definimos as variáveis $\mathrm{X}^{\prime}, \mathrm{Y}^{\prime}$ e $\mathrm{Z}^{\prime}$ como as coordenadas $\mathrm{x}, \mathrm{y}, \mathrm{z}$ normalizadas ao raio do feixe gaussiano (w) que aquece o meio. As variáveis $X^{\prime}, Y^{\prime}, Z^{\prime}, R$ e $Z$ são adimensionais e estão definidas na figura 1.3. Apesar da simetria cilindrica dada pelo feixe, optaremos por trabalhar com coordenadas cartesianas para facilitar o cálculo das integrais

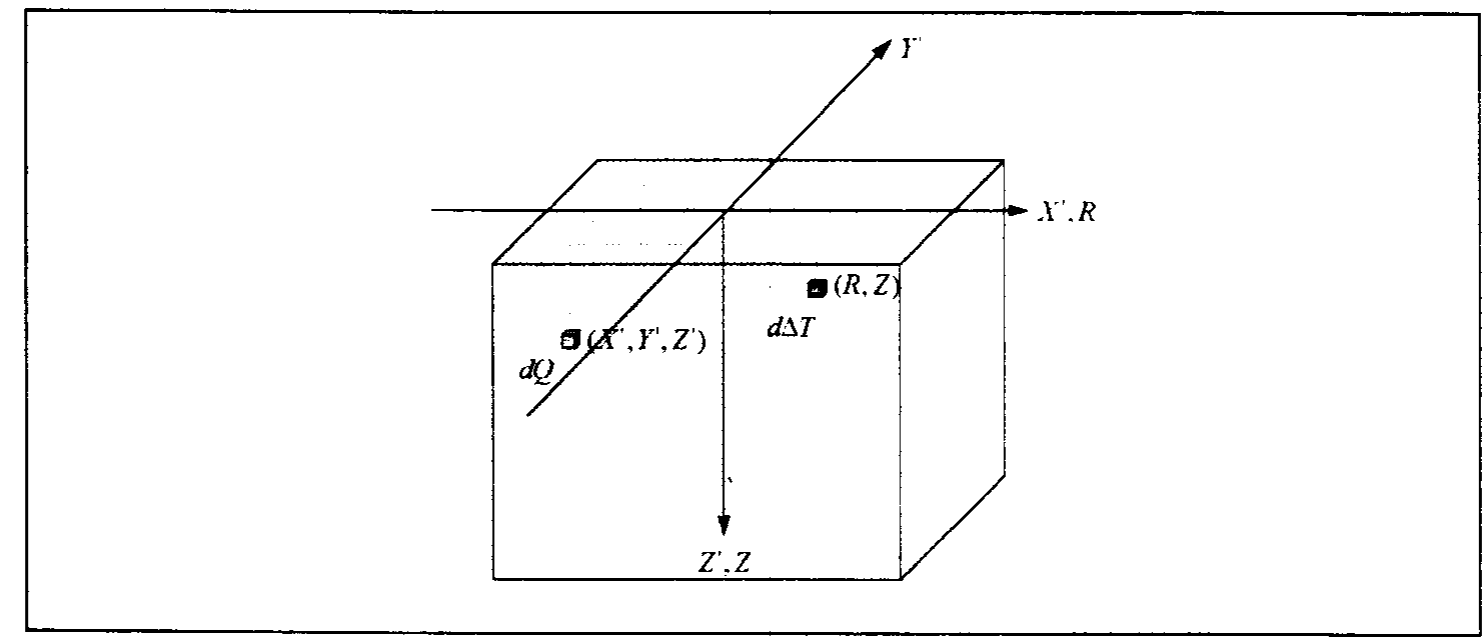

Figura 1.3: Representação da variação de temperatura em $(R, Z)$ devido a uma quantidade dQ de calor depositada no volume $d X^{\prime} \times d Y^{\prime} \times d Z^{\prime}$ em $\left(X^{\prime}, Y^{\prime}, Z^{\prime}\right)$.

Para um meio infinito, podemos obter uma solução particular importante de (1.8), que dá a variação de temperatura, $\Delta \theta$, num ponto $(R, Z)$ e tempo $t$, devido a um 
incremento de calor depositado em (X', Y', Z) e tempo t'. Esta solução é dada por [13]:

$$
d \Delta \theta(R, Z, t)=\frac{d Q\left(X^{\prime}, Y^{\prime}, Z\right)}{8 \rho C p\left[\pi D\left(t-t^{\prime}\right)\right]^{3 / 2}} e^{\frac{w^{2}}{4 D\left(t-t^{\prime}\right)}\left[\left(R-X^{\prime}\right)^{2}+Y^{2}+\left(Z-Z^{\prime}\right)^{2}\right]}
$$

onde $\mathrm{D}=\mathrm{k}_{\mathrm{tet}} /(\rho \mathrm{Cp})$ é a difusividade térmica, $\mathrm{t}$ é o tempo em que se observa a variação de temperatura, $\mathrm{t}^{\prime}$ é o tempo no qual meio recebeu o pulso de calor $d Q\left(t^{\prime} \leq t\right), Z$ é a profundidade da amostra em unidades de w e R é a coordenada radial em unidades de w. A temperatura é obtida integrando (1.9) no volume e no tempo. Ou seja, (1.9) é a função de Green da temperatura.

No caso que trataremos, o calor depositado na amostra segue um perfil radial gaussiano, atenuado exponencialmente ao longo da profundidade. Assim, $\mathrm{dQ}\left(\mathrm{X}^{\prime}, \mathrm{Y}^{\prime}, \mathrm{Z}^{\prime}\right)$ é dado por:

$$
d Q=\frac{2 P_{a b} A}{\pi} d t \exp \left[-2\left(X^{\prime 2}+Y^{\prime 2}\right)-A Z^{\prime}\right] d X^{\prime} d Y^{\prime} d Z^{\prime}
$$

onde $\mathrm{P}_{\mathrm{ab}}$ é a potência absorvida pela amostra e $\mathrm{A}$ é o coeficiente de absorção em unidades de $\mathrm{w}^{-1}$.

As soluções para a temperatura e para o deslocamento na superficie dependerão das condições de contorno dadas pela forma da amostra. A amostra que trataremos possui uma espessura $\mathrm{L}$ com interfaces planas, paralelas e infinitas. A solução geral para a temperatura e para o vetor deslocamento é extremamente complexa. Extrair qualquer parâmetro delas levaria muito tempo de processamento nos computadores atuais. Assim sendo, somos obrigados a buscar casos limites para a teoria, tratando de duas situações importantes para as quais poderemos facilmente 
adequar o experimento. Especificamente, consideramos os casos limites de amostra grossa $(\mathrm{L} \rightarrow \infty)$ e amostra fina $(\mathrm{L} \rightarrow 0)$.

\subsubsection{Solução da ENS para $L \rightarrow \infty$}

Podemos considerar a espessura da amostra infinita se ela for muito maior que a profundidade de penetração da luz e do comprimento de difusão térmico. Seu cálculo envolve a integração da função de Green da temperatura [expressão (1.9)] no volume e no tempo. A expressão para o acréscimo de temperatura no ponto $(R, Z)$, deduzida detalhadamente no apêndice A, fica:

$$
\begin{aligned}
& \Delta \theta=\frac{P_{a b} A}{8 \pi k_{t e r} w} \int_{\frac{w^{2}}{8 D t}}^{\infty} \frac{e^{\frac{-2 f}{1+f} R^{2}-2 f Z^{2}}}{f(1+f)} \times \\
& {\left[e^{\left(\frac{A-4 f Z}{\sqrt{8 f}}\right)^{2}} \operatorname{erfc}\left(\frac{A-4 f Z}{\sqrt{8 f}}\right)+e^{\left(\frac{A+4 f Z}{\sqrt{8 f}}\right)^{2}} \operatorname{erfc}\left(\frac{A+4 f Z}{\sqrt{8 f}}\right)\right] d f}
\end{aligned}
$$

O cálculo do deslocamento na superficie, detalhado no apêndice $B$, é obtido substituindo-se (1.11) na solução de (1.7) . Desta forma obtém-se:

$$
\begin{aligned}
& u(R, Z=0)=\frac{P_{a b} A \alpha_{t e r}(1+v)}{2 \pi k_{t e r}} \int_{0}^{\infty} K e^{\frac{-K^{2}}{8}} J_{0}(K R) \times \\
& {\left[\int_{0}^{f} \frac{e^{\left(A^{2}-K^{2}\right) f i e r f d}(A \sqrt{f i})+e r f d(K \sqrt{f i})}{A+K}-\right.} \\
& \left.\frac{e^{\left(A^{2}-K^{2}\right) f i e r f d}(A \sqrt{f i})-\operatorname{erfd}(K \sqrt{f i})}{A-K} d f i\right] d K
\end{aligned}
$$


onde fi é o tempo em unidades de tempo característico: $\mathrm{fi}=\mathrm{Dt} / \mathrm{w}^{2}$. A resolução das integrais nos cálculos intermediários é feita no "software" Mathematica. As integrais que aparecem nas expressões finais mostradas em (1.11) e (1.12) ou não são analíticas, ou a solução analítica é mais complicada que a própria integral.

As equações (1.11) e (1.12) ainda são bastante complicadas. Devemos fazer outras considerações para simplificar mais o problema. Estas considerações estão relacionadas com a técnica experimental e, portanto serão discutidas no próximo capítulo.

\subsubsection{Solução da ENS para $L \rightarrow 0$}

A amostra pode ser considerada fina se for muito menor que a profundidade de penetração e o comprimento de difusão térmico. Nestas condições, a absorção e a variação de temperatura podem ser consideradas uniformes na profundidade, dependendo apenas da posição radial e do tempo. O cálculo da temperatura e do deslocamento na superfície, é feito como para o caso da seção 1.4.1.1 (amostras grossas), integrando-se a função de Green no espaço e no tempo. Aqui, no entanto, a função de Green para temperatura é bidimensional, pois não depende da profundidade, e é dada por:

$$
d \Delta \theta=\frac{d Q / L}{4 \pi \rho C_{p} D\left(t-t^{\prime}\right)} e^{\frac{-\varkappa^{2}}{4 D\left(t-t^{\prime}\right)}\left[\left(X^{\prime}-R\right)^{2}+Y^{\prime} 2\right]}
$$

com

$$
\frac{d Q}{L}=\frac{2 P \alpha_{a b}}{\pi} d t^{\prime} e^{-2\left(X^{\prime} 2+Y^{\prime}\right)} d X^{\prime} d Y^{\prime}
$$


A variação de temperatura e o deslocamento na superficie ficam:

$$
\Delta \theta=\frac{P \alpha_{a b}}{4 \pi k_{t e r}}\left\lfloor E i\left(-2 R^{2}\right)-E t\left(\frac{-2 R^{2}}{1+\frac{8 D t}{w^{2}}}\right)\right\rfloor
$$

e

$$
u(R, 0)=\frac{P \alpha_{a b} \alpha_{t e r} L}{4 \pi k_{t e r}}(1+v) \int_{0}^{\infty} \frac{J_{0}(K R)}{K} e^{\frac{-K^{2}}{8}}\left(1-e^{\frac{-K^{2} D t}{w^{2}}}\right) d K
$$

onde $\alpha_{\mathrm{ab}}$ é o coeficiente de absorção da amostra, $\mathrm{P}$ é a potência do laser incidente na amostra e Ei(x) é a exponencial integral de $\mathrm{x}$ definida como:

$$
E i(x)=-\int_{-x}^{\infty} \frac{e^{-\varepsilon}}{\varepsilon} d \varepsilon
$$

A dedução das equações (1.15) e (1.16) estão detalhadas nos apêndices A e B. Como para o caso anterior (amostras grossas), discutiremos outras simplificações no futuro.

\subsubsection{Características das amostras}

Para as medidas por reflexão, a amostra deve ter uma superficie com boa qualidade óptica, além de ser homogênea nas regiões de absorção e difusão de calor. $\mathrm{Na}$ aproximação de amostra grossa, a profundidade de penetração da luz deve ser muito menor que a espessura. Pode-se adaptar as amostras a estas características necessárias de várias formas. Quando não se tem boa qualidade óptica convém fazer a medida por transmissão com a amostra fina, quando for possivel torná-la fina o 
suficiente. Ou ainda, usar um feixe de diâmetro grande para amenizar as imperfeições da superficie. Pode-se conseguir variar o coeficiente de absorção dos materiais várias ordens de grandeza através da escolha conveniente da frequência e/ou dopando-se o material com substâncias que aumentam seu coeficiente de absorção, sem alterar seus parâmetros térmicos.

\subsubsection{Auto-modulação de fase em líquidos}

Para observar efeitos térmicos em líquidos é preciso analisar a luz transmitida pelo meio, pois não há deformação na superficie e não se observa modulação de fase por reflexão. $O$ que buscamos saber neste caso é a variação do índice de refração com a temperatura, $\mathrm{dn} / \mathrm{d} \theta$, que gera a modulação de fase por diferença de caminho óptico, como explicamos na seção 1.2. Na análise de líquidos é preciso também que a espessura da cubeta que o contém seja suficientemente fina para que a absorção seja uniforme na profundidade. A temperatura em função da coordenada radial e do tempo é a mesma obtida para amostras finas, mostrada na equação (1.15). A fase não-linear neste caso fica:

$$
\phi_{N L}=k L \frac{d n}{d T} \Delta \theta(R)
$$

A fase não-linear gera uma curvatura na frente de onda que é detectada pela técnica de medida que será vista no próximo capítulo. 


\section{Capítulo II}

A Técnica de Varredura-Z 


\subsection{Introdução}

Em 1989, Sheik-Bahae et al. [3] propuseram uma técnica denominada técnica de varredura-z (Z-scan) para medir o índice de refração não-linear com um aparato experimental simples e preciso. As técnicas anteriores a esta, e ainda utilizadas, tais como: interferometria não-linear [14], mistura degenerada de quatro ondas [15], e mistura quase degenerada de duas ondas [16], exigem um aparato experimental complexo. Outras técnicas requerem um aparato experimental simples, porém pecam na sensibilidade ou requerem uma análise detalhada da propagação do feixe no interior do meio, tais como: rotação elipsoidal [17] e medida da distorção do feixe [18]. A técnica de varredura-z baseia-se na distorção espacial do feixe devido à automodulação de fase pela amostra. Uma de suas principais características é a possibilidade de se estimar o índice não-linear $\left(\mathrm{n}_{2}\right)$ através de uma relação linear simples entre a variação observada na transmitância e a distorção de fase induzida. A transmitância normalizada é a quantidade que se mede num experimento de varredura-z e é dada pela razão entre as potências transmitida por uma abertura quando o meio manifesta e quando não manifesta efeitos não-lineares. Esta manifestação depende da posição da amostra em relação ao foco do feixe gaussiano, sendo que, próximo dele a intensidade é grande e portanto o efeito também o é. Longe do foco o efeito induzido é predominantemente linear.

Desde que foi criada, esta técnica tem sido modificada, quer para aumentar sua sensibilidade, quer para adequar o experimento a diferentes situações físicas. Neste trabalho utilizamos várias destas implementações, por exemplo, varredura-z resolvida no tempo, varredura-z resolvida em frequência e varredura-z por reflexão. 
Por hora, a técnica será descrita como proposta originalmente por Sheik-Bahae et al. [3].

\subsection{Descrição experimental da técnica de varredura-z}

A técnica de varredura-z utiliza um feixe de laser gaussiano focalizado numa região do espaço em torno do qual a amostra translada, como mostra a figura 2.1. O laser passa pela amostra e se propaga até ser transmitido por uma iris, que deixa passar apenas a porção central do feixe. Logo atrás da íris posiciona-se um detetor, D1, que mede a luz transmitida em função da posição da amostra. Uma fração do feixe é desviada para um outro detetor, D2, que monitora as flutuações de potência do laser, corrigindo assim tais flutuações. Para a normalização do sinal, a potência transmitida com a amostra numa dada posição $\mathrm{z}$ é dividida pela potência transmitida quando a amostra esta longe do foco. Obtemos assim a transmitância normalizada em função da posição.

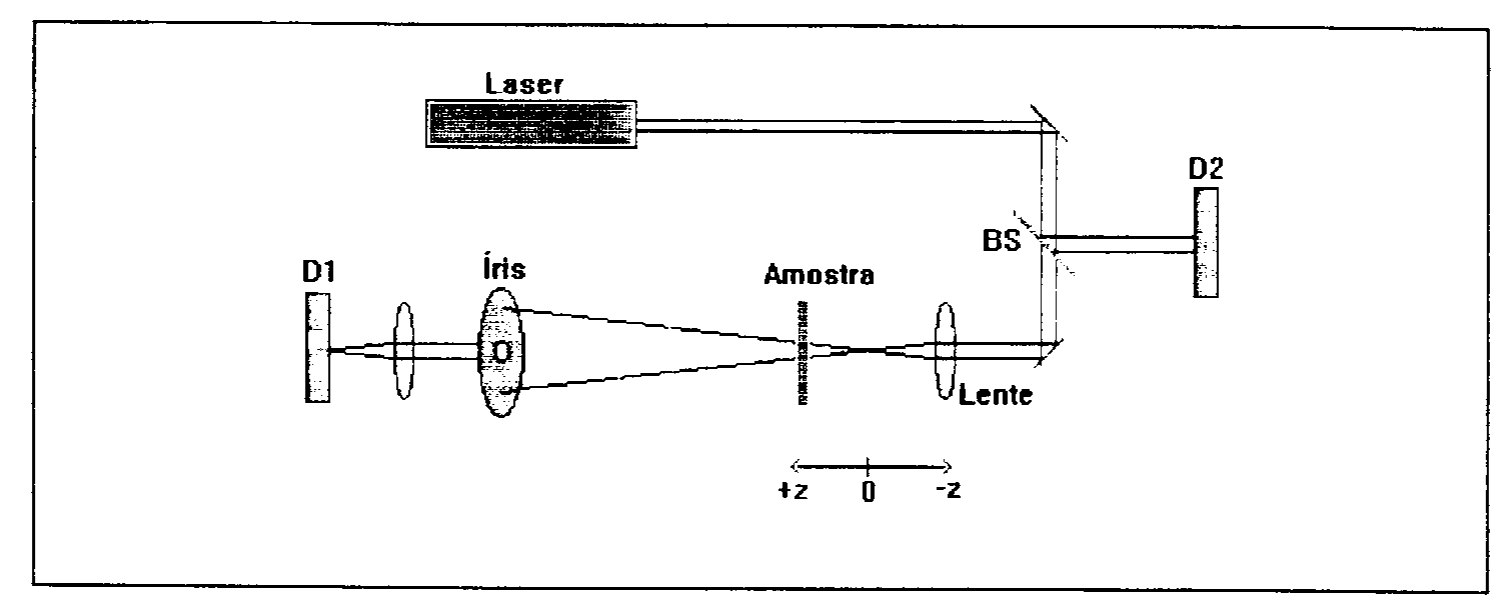

Figura 2.1: Arranjo experimental utilizado na técnica de varredura-z

Pela notação do artigo de Sheik-Bahae et al. [3], convenciona-se que o foco seja a posição $z=0$, entre o foco e a lente seja a região $z<0$, e entre o foco e a íris, a região $z>0$. Longe do foco, a intensidade é relativamente baixa, o efeito não-linear é 
desprezível, e nenhuma modificação no campo da luz é observado. O detetor recebe a mesma potência através da íris, para qualquer valor de $\mathrm{z}$ grande em módulo (figura 2.2a). Próximo do foco porém, onde a intensidade é maior, o efeito não-linear gera a auto-modulação de fase. Para um indice não-linear positivo $\left(\mathrm{n}_{2}>0\right)$, o meio se comporta como uma lente convergente como visto na seção 1.2. A amostra antes do foco $(z<0)$ produz uma convergência adicional no feixe, espalhando mais luz na posição da íris, chegando menos luz no detetor (figura 2.2b). Depois do foco $(z>0), o$ meio compensa em parte a divergência do feixe nesta posição e mais luz passa pela íris, aumentando o sinal no detetor (figura 2.2c). Este sinal como função da posição, apresentar-se-á como uma curva de dispersão (figura 2.3). Para um índice não-linear negativo $\left(\mathrm{n}_{2}<0\right)$, a amostra se comporta como uma lente divergente e a curva de transmitância terá o pico e o vale invertidos.

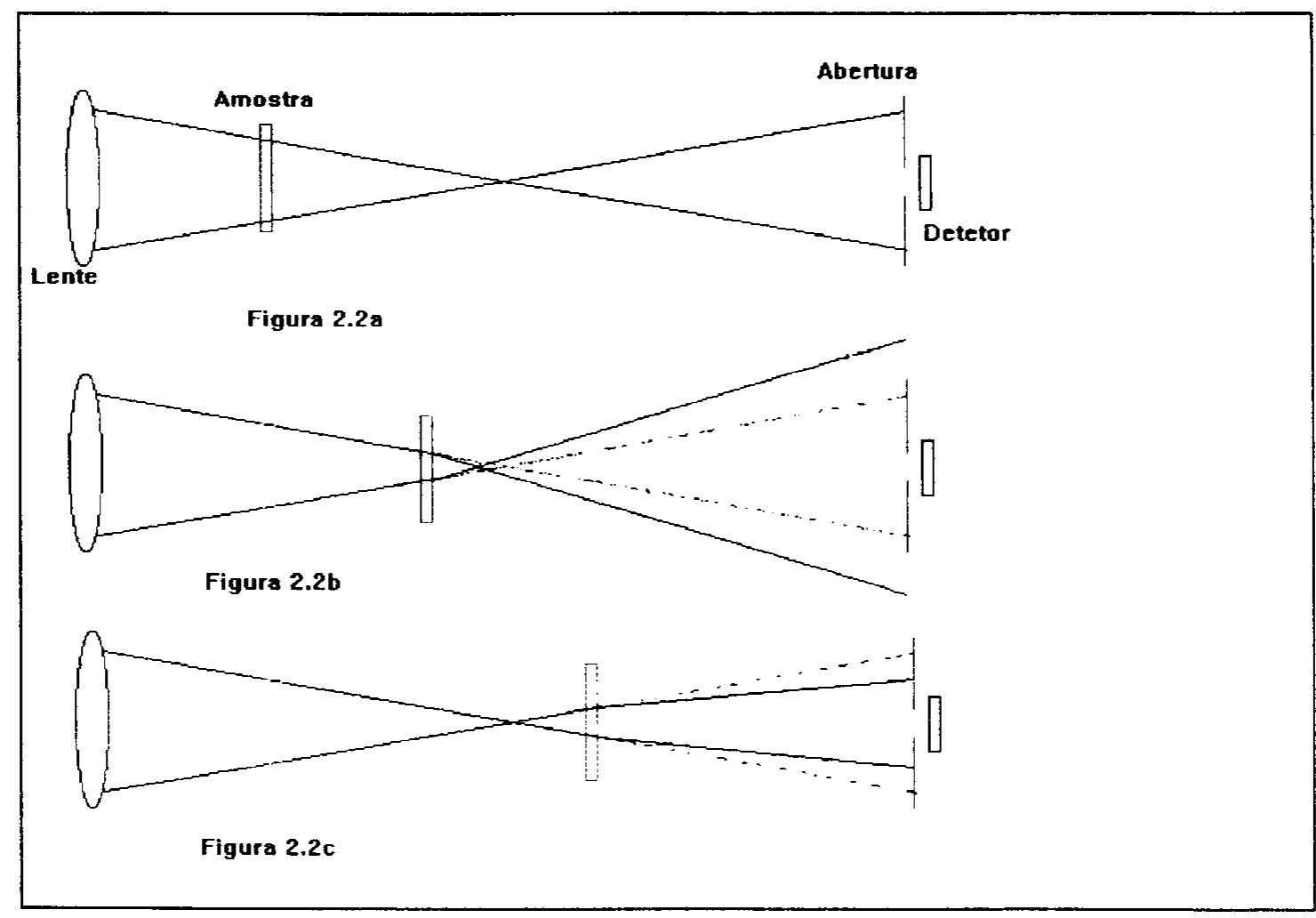

Figura 2.2: Representação esquemática do efeito de uma não-linearidade positiva $n_{2}>0$. Na técnica de varredura-z a modulação de fase faz variar a intensidade detectada na abertura. a) Amostra longe do foco, b) amostra próxima e antes do foco e c) amostra próxima e depois do foco. 


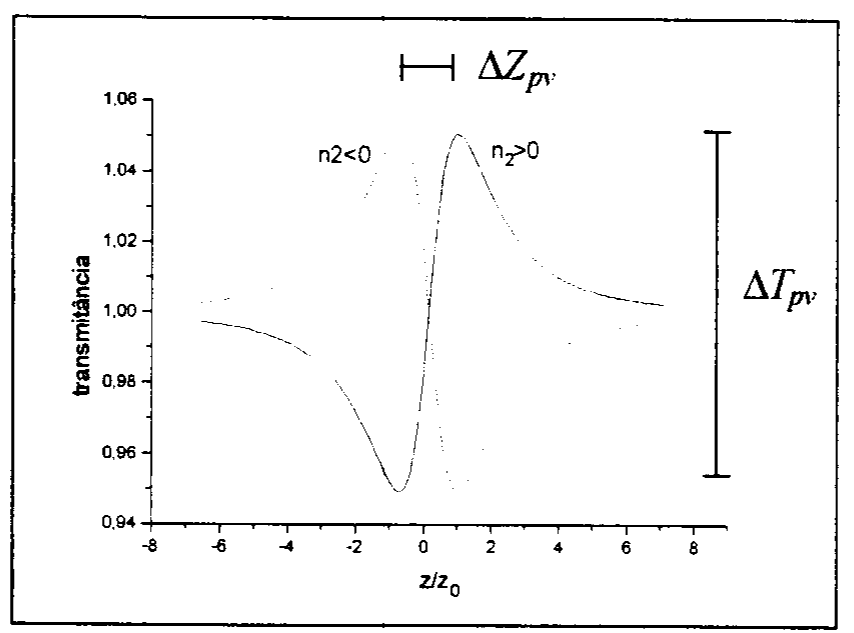

Figura 2.3: Transmissão normalizada em função da posição da amostra.

\subsection{Cálculo da transmissão}

O cálculo da transmissão pode ser feito de duas formas. Uma delas é o método de decomposição gaussiana (MDG), através do qual, o fator de fase nãolinear, $e^{i \phi N L}$ é decomposta em série de potências. Neste método interpretamos cada termo da série como um feixe gaussiano independente que se propaga até a abertura com parâmetro confocal e posição de foco próprios. Estes feixes interferem-se na abertura, modulando a transmissão. Este método, no entanto, só se aplica se o perfil da fase não-linear for gaussiano. Se, por exemplo, o meio for um absorvedor saturável ou apresentar efeitos térmicos, este perfil não é gaussiano e devemos recorrer a uma teoria mais geral, que é descrita a seguir.

A integral de difração de Fresnel-Kirchhoff [19] descreve matematicamente o princípio de Huygens, dando o padrão de campo em qualquer ponto do espaço a partir das condições iniciais de fase e intensidade da onda, quaisquer que sejam elas. Esta integral, por basear-se num principio fundamental, pode descrever qualquer fenômeno ondulatório desde que levemos em conta a ação do meio sobre a fase da onda em função da posição e do tempo. A integral de difração de Fresnel-Kirchhoff é 
a forma mais adequada de descrever o campo modificado por efeitos térmicos. A partir deste campo, calculamos a transmissão que por sua vez está relacionada com os parâmetros térmicos como veremos no capítulo seguinte.

\subsubsection{Integral de difração de Fresnel-Kirchhoff}

A integral de difração para o campo elétrico está mostrada na equação (2.1). Ela descreve o campo num ponto $P_{1}\left(x_{1}, y_{1}, z_{1}\right)$ em função da distribuição do campo no plano da amostra como esquematizado na figura 2.4. Explicitamente,

$$
E\left(x_{1}, y_{1}, z_{1}\right)=\frac{i}{\lambda} \iint_{S} E\left(x_{0}, y_{0}\right) \frac{e^{-i k r_{01}}}{r_{01}}\left(\frac{\cos \alpha+\cos \beta}{2}\right) d x_{0} d y_{0}
$$

onde $\alpha$ é o ângulo entre a onda incidente no plano de $\mathrm{S}$ com a normal, $\mathbf{n}$, e $\beta$ é o ângulo entre a onda difratada e a normal e onde $\mathrm{P}_{0}\left(\mathrm{x}_{0}, \mathrm{y}_{0}\right)$ corresponde a um ponto localizado no plano da amostra.

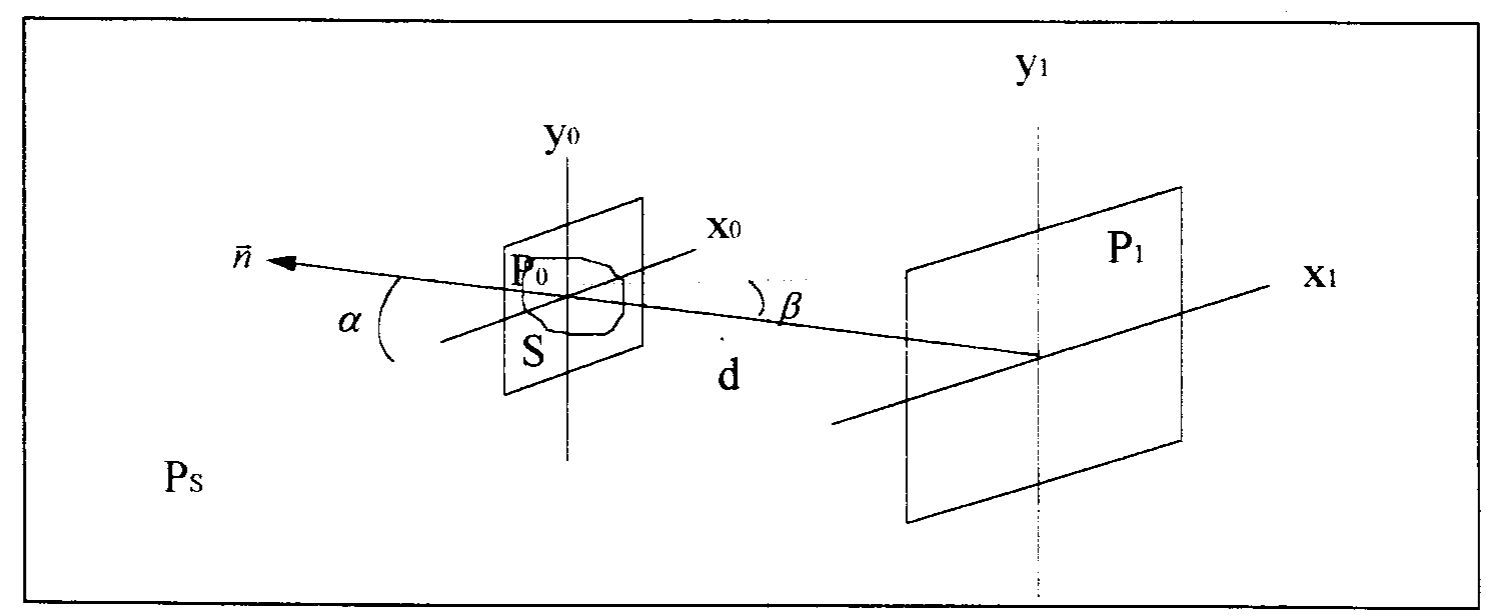

Figura 2.4: Diagrama para calcular o campo em $P_{1}$ devido à amostra $S$, em funçāo da fonte do campo em $P_{s}$

Podemos simplificar a equação (2.1) considerando: (i) uma fonte perpendicular ao plano da amostra com raios para-axiais, o que acarreta em $\cos (\alpha)=$ 
$\cos (\beta)=1$, (ii) a distância d entre o plano da amostra e o plano de observação muito maior que o raio de iluminação da amostra. Assim podemos substituir $\mathrm{r}_{01}$ por $\mathrm{d}$ no denominador de (2.1) (porém não podemos fazer a mesma substituição na exponencial, pois este termo é oscilatório e não converge para d grande) e (iii) apenas o primeiro termo da expansão de:

$$
r_{01}=d \sqrt{1+\frac{\left(x_{0}-x_{1}\right)^{2}+\left(y_{0}-y_{1}\right)^{2}}{d^{2}}}
$$

o que resulta em:

$$
r_{01}=d+\frac{x_{1}^{2}+y_{1}^{2}}{2 d}-\frac{x_{1} x_{0}+y_{1} y_{0}}{d}+\frac{x_{0}^{2}+y_{0}^{2}}{2 d}
$$

Vamos considerar também que o campo incidindo sobre a amostra possui um perfil gaussiano. Devido à simetria cilíndrica, convém fazer uma mudança para coordenadas polares de acordo com:

$$
\begin{array}{ll}
\mathrm{x}_{0}=\mathrm{r} \cos (\psi), & x_{1}=r_{a}^{\prime} \cos (\phi) \\
\mathrm{y}_{0}=\mathrm{r} \operatorname{sen}(\psi), & y_{1}=r_{a}^{\prime} \operatorname{sen}(\phi)
\end{array}
$$

onde $(r, \psi)$ são as coordenadas dos pontos localizados na amostra e $\left(r_{a}^{\prime}, \phi\right)$ são as coordenadas dos pontos no plano de observação. Substituindo (2.5) em (2.3) e esta em (2.1), podemos resolver a integral na nova variável $\psi$ observando a definição da função de Bessel de ordem zero:

$$
J_{0}(x)=\frac{1}{2 \pi} \int_{0}^{2 \pi} e^{i x \cos (v)} d v
$$


e assim obtemos o campo no plano de observação como:

$$
E\left(r_{a}^{\prime}, \phi\right)=\frac{i}{\lambda Z} e^{-i k\left(d+\frac{r_{a}^{\prime 2}}{2 d}\right)} \int_{0}^{\infty} e^{-\frac{i k r^{2}}{2 d}} E(r, \Psi) J_{0}\left(\frac{k r_{a}^{\prime} r}{d}\right) r d r
$$

Em experimentos de varredura-z, devemos introduzir uma fase não-linear que é função da coordenada radial $r$ e levar em conta o perfil transversal do feixe gaussiano. Desta forma obtemos:

$$
\vec{E}\left(r_{a}^{\prime}\right) \propto \frac{i}{\lambda z_{a}} w_{0} E_{0} \int_{0}^{\infty} R J_{0}\left(\frac{k w r_{a}^{\prime} R}{z_{a}-z}\right) e^{-i\left(\phi_{L}+\phi_{N L}\right)-R^{2}} d R
$$

onde $\lambda$ é o comprimento de onda da luz, $z_{a}$ é a distância entre o foco e o plano de observação, z é a posição da amostra, $r_{a}$ ' é a coordenada radial da abertura e a integração é feita sobre a coordenada radial da amostra em unidades de w $(R=r / w)$. De acordo com o tratamento padrão para feixes gaussianos [10], a fase linear é dada por:

$$
\phi_{L}=\frac{k w^{2}}{2}\left(\frac{1}{z_{a}-z}+\frac{1}{2\left(1+\frac{z_{0}^{2}}{z^{2}}\right)}\right) R^{2}
$$

A expressão para a fase não-linear dependerá de como é feita a medida (transmissão ou reflexão) e das características da amostra (absorvedor saturavel, meio não-linear eletrônico ou térmico). Para medidas por reflexão em meios térmicos a fase não-linear é dada pela equação (1.6). 
$\mathrm{O}$ raio do feixe gaussiano é uma função de $\mathrm{z}$ com a seguinte dependência [10]:

$$
w(Z)=w_{0} \sqrt{1+Z^{2}}
$$

onde $\mathrm{Z}$ é a coordenada axial em unidades de $\mathrm{z}_{0}\left(\mathrm{Z}=\mathrm{Z} / \mathrm{z}_{0}\right), \mathrm{z}_{0}=\mathrm{kw}_{0}{ }^{2} / 2$ é o parâmetro confocal do feixe e $\mathrm{w}_{0}$ é o raio na posição focal.

O sistema de aquisição mede a potência transmitida pela íris para a amostra numa posição $\mathrm{z}$, normalizada pela potência com a amostra longe do foco. Obtemos a potência transmitida pela integração do campo na abertura da íris:

$$
P_{T} \propto \int_{0}^{r_{a}} r_{a}^{\prime}\left|E\left(r_{a}^{\prime}\right)\right|^{2} d r_{a}^{\prime}
$$

onde $r_{a}$ é o raio da abertura. A transmitância normalizada é dada por:

$$
T(Z)=\frac{P_{T}(Z)}{P_{T}(Z \rightarrow \infty)}
$$

É a partir da curva de transmitância que se determina os parâmetros nãolineares da amostra. Entretanto, há muitas integrais envolvidas no seu cálculo. A integral de difração como escrita em (2.8) não é analitica nem para o caso trivial $\left(\phi_{\mathrm{NL}}=0\right)$. Faz-se necessário simplificar as equações acima utilizando o aparato experimental de forma que alguns termos possam ser desprezados ou que possam ser tratados na forma de série de potências. 


\subsubsection{Adequação experimental para simplificar a integral de}

\section{difração}

A integral de difração como escrita em (2.8) vale para um caso muito geral mas não é analítica. Podemos simplificar bastante as equações de (2.8) a (2.12), realizando o experimento numa configuração adequada. Podemos fazer $z_{a} \rightarrow \infty$ em (2.9), quando a abertura é colocada bem distante da amostra. Em (2.11) podemos fazer $r_{a} \rightarrow 0$ pela escolha de uma íris suficientemente pequena. Também podemos expandir a função $\mathbf{e}^{i \phi_{\mathrm{NL}}}$ da equação (2.8) em série de potências se $\phi_{\mathrm{NL}}$ for pequeno, o que sempre ocorre se a potência utilizada for suficientemente pequena. Com as aproximações citadas acima podemos re-escrever a equação (2.8) como

$$
E\left(r_{a}^{\prime}=0\right) \propto \int_{0}^{\propto} \operatorname{Re}^{-i \phi L-R^{2}}\left(1-i \phi_{N L}\right) d R
$$

onde

$$
\phi_{L}=Z R^{2}
$$

$\mathrm{Na}$ equação (2.13), os fatores da integral que apareciam em (2.8) foram incorporados na proporcionalidade. A equação (2.14) foi obtida tomando-se $z_{a} \rightarrow x$ em (2.9) e usando $\mathrm{z}_{0}=\mathrm{kw}_{0}{ }^{2} / 2$. Substituindo as expressões simplificadas (2.13) e (2.14) na transmitância pela abertura [equação (2.12)] obtemos: 


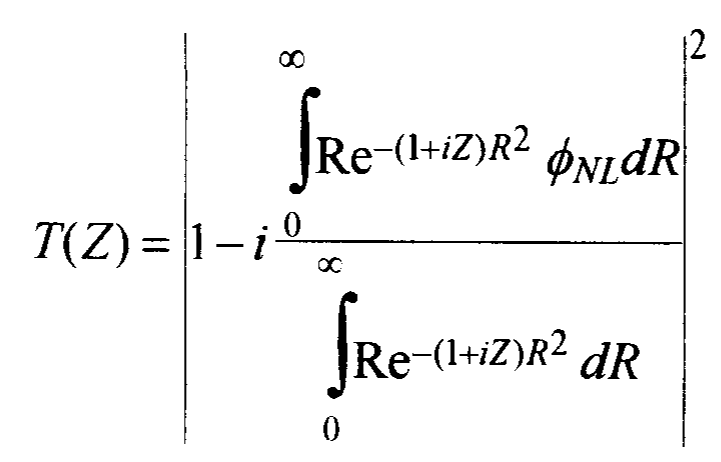

A integral no denominador de (2.15) é analítica. Ela provém do cálculo da potência transmitida pela abertura, $\mathrm{P}_{\mathrm{T}}$, quando a amostra está longe do foco $(\mathrm{Z} \rightarrow \infty)$ onde a fase não-linear é desprezivel. Isto normaliza teoricamente a transmissão, fazendo-a variar em torno de 1. Experimentalmente, a normalização pode ser feita de várias formas. Nos artigos de Sheik-Bahae et al. $[3,4]$ normaliza-se todos os pontos da curva dividindo-se seus valores pelo valor do sinal com a amostra longe do foco. Nas implementações da técnica de varredura-z, que serão descritas a seguir, a normalização do sinal é feita de formas mais eficientes.

\subsection{Variações experimentais da técnica de varredura-z}

Desde que foi criada, a técnica de varredura-z tem sido modificada, quer para aumentar sua sensibilidade, quer para adequar o experimento a diversas situações fisicas. Descreveremos detalhadamente nas subseções seguintes as extensões à técnica que utilizamos neste trabalho. Para citar brevemente algumas outras temos:

Técnica de duas cores [20], consistindo de dois feixes, um de bombeio e outro de prova. Ambos seguem co-propagantes, sendo que o feixe de bombeio, que gera o efeito não-linear é bloqueado por um filtro que só deixa passar o feixe de prova. (ii) Técnica de duas lentes [21], onde a varredura é feita pelas lentes enquanto que a amostra fica parada e (iii) Varredura-z eclipsante [22], que utiliza um disco opaco 
no lugar da abertura deixando passar apenas as bordas do feixe, sendo mais sensivel à distorção do feixe e proporcionando uma maior sensibilidade.

\subsubsection{Técnica de varredura-z resolvida no tempo (RT)}

Quando o tempo de resposta da amostra é lento, é possivel fazer um acompanhamento temporal da evolução do sinal modulando-se o laser através de um chopper. Logo que o chopper é aberto, ainda não houve deposição de calor na amostra e o sinal no detetor é devido a luz refletida numa interface plana. Com o decorrer do tempo, a amostra absorve parte da luz que convertida em calor provoca dilatação térmica. O sinal no detetor aumenta ou diminui conforme a amostra esteja antes ou depois do foco. A variação do sinal, pode ser acompanhada num osciloscópio, como mostrada na figura 2.5. Considerando a evolução temporal para tempos pequenos e observando apenas os termos linear e quadrático, temos informações a respeito dos parâmetros térmicos da amostra como será visto no próximo capítulo

$\mathrm{Na}$ descrição feita acima usamos como exemplo uma não-linearidade térmica, mas pode ser aplicada para qualquer meio lento. Esta técnica foi desenvolvida e aplicada por L. C. Oliveira et al. [6] para medir não-linearidades eletrônicas por transmissão. Uma vantagem importante é que se pode normalizar a transmitância em qualquer tempo pelo valor da transmitância em $\mathrm{t}=0$, eliminando-se assim qualquer efeito linear espúrio que varie com a posição da amostra, como por exemplo, espalhamento por defeitos, impurezas ou deformações permanentes na amostra. Em $\mathrm{t}=0$ a não-linearidade ainda não se manifestou sendo o sinal devido apenas a efeitos lineares 


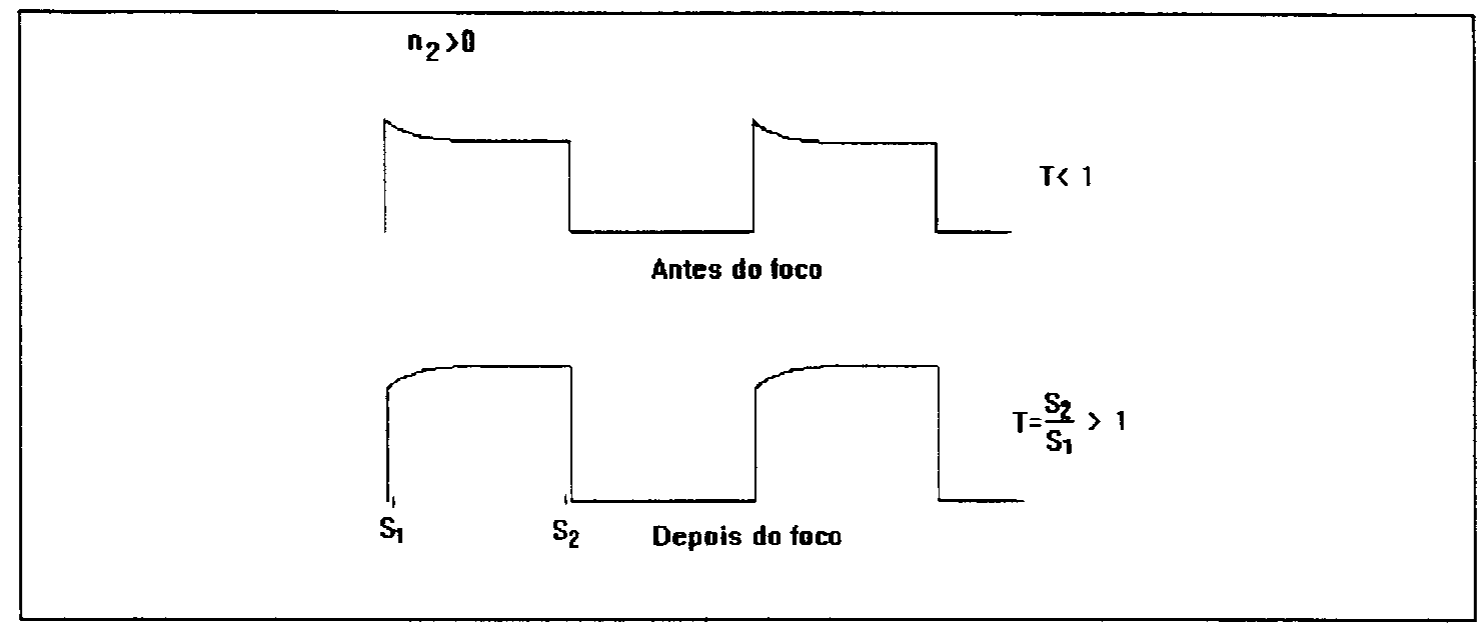

Figura 2.5: Evolução temporal da transmitância assistida num osciloscópio para uma nãolinearidade positiva. $S_{2}$ é o sinal em algum tempo durante a abertura do chopper a ser normalizado por $S_{1}$, o sinal logo após a abertura do chopper.

A transmitância normalizada é obtida dividindo-se a potência calculada pela abertura num tempo $\mathrm{t}$ pela potência transmitida em $\mathrm{t}=0$ :

$$
T(t)=\frac{P_{T}(t)}{P_{T}(t=0)}
$$

Experimentalmente, a aquisição é feita por um detetor que transforma a potência transmitida pela íris em tensão elétrica. Esta tensão é transformada em valor numérico por um conversor analógico-digital e enviado a um microcomputador. Este só adquire os sinais $S_{1}$ e $S_{2}$ (figura 2.5) nos instantes pré-determinados pelo programa feito para este fim. O microcomputador faz a razão entre os sinais nestes tempos.

\subsubsection{Cálculo da transmitância para amostras transparentes}

Nas amostras medidas com a luz transmitida por ela, temos que a fase nãolinear é dada pela equação (1.4) $\operatorname{com} \Delta \theta$ (variação de temperatura) dada por (1.15). Substituindo a fase não linear na equação (2.15) e resolvendo as integrais no "software" Mathematica obtemos: 


$$
T(Z)=1+i \Gamma \ln \left[\frac{3-i Z+(1-i Z)\left(\frac{8 D t}{w^{2}}\right)}{3+i Z+(1+i Z)\left(\frac{8 D t}{w^{2}}\right)}\left(\frac{3+i Z}{3-i Z}\right)\right]
$$

com

$$
\Gamma=\frac{k L P \alpha_{a b}}{4 \pi w_{0}^{2}}
$$

Expandindo a expressão (2.17) até o termos de segunda ordem no tempo obtemos:

$$
T(Z)=1+\frac{32 Z \Gamma}{\left(9+Z^{2}\right)\left(1+Z^{2}\right)} \frac{d n}{d \theta} \frac{1}{\rho C_{p}} t-\frac{256 Z\left(3+Z^{2}\right) \Gamma}{\left(9+Z^{2}\right)^{2}\left(1+Z^{2}\right)^{2}} \frac{d n}{d \theta} \frac{1}{\rho C_{p}} \frac{D}{w_{0}^{2}} t^{2}
$$

Se as aproximações discutidas na seção (2.3.2) forem feitas, a transmissão converge rapidamente quando expandida em série de potências no tempo, de forma que a equação (2.19) é o suficiente para representar a evolução temporal da transmitância. Como veremos adiante, o ajuste teórico será feito com os coeficientes do tempo desta equação.

A equação (2.17) para a transmissão não leva em conta que os próprios parâmetros térmicos podem variar com a temperatura. Se este for o caso, podemos representar esta variação como uma série de potências da temperatura, assim como expandir a temperatura numa série de potências do tempo. Veja, por exemplo, como varia o parâmetro $d n / d \theta(\theta)$ da água mostrada na figura 2.6. Na equação (2.18) este parâmetro é tratado como uma constante, o que pode gerar erros grandes em algumas amostras. 


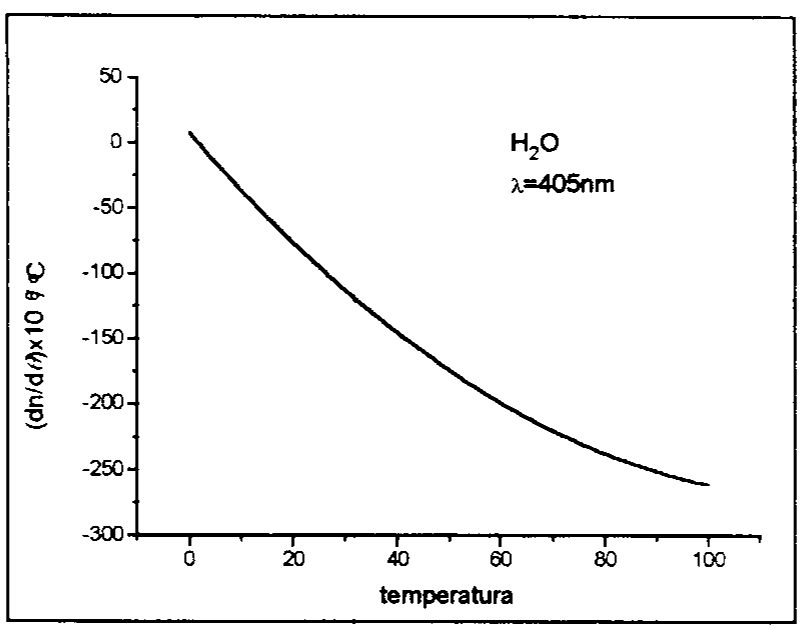

Figura 2.6: Variação de dn/d $\theta$ com a temperatura para a água

\subsubsection{Técnica de varredura-z resolvida em frequência (RF)}

A técnica de varredura-z resolvida em frequência é uma implementação muito engenhosa, desenvolvida por Mendonça et al. para medir efeitos não-lineares lentos [7]. Ela consiste de um aparato experimental de varredura-z com o feixe modulado por um chopper. O sinal no detetor consiste de uma onda quadrada mais um sinal não-linear induzido pela amostra. Dois lock-ins são usados para separar as componentes de Fourier em $\mathrm{f}$ e $2 \mathrm{f}$ do sinal. A primeira componente está ligada principalmente ao sinal linear enquanto que a segunda é devida somente ao sinal nãolinear, pois uma onda quadrada não possui componente em 2 f. A razão entre elas dá o valor normalizado e com grande precisão, graças à eliminação do ruido pelos lock-ins.

Nos nossos experimentos, para evitar que o tratamento matemático fique muito complicado, esta técnica deve ser utilizada com frequência suficientemente alta para que o sinal em cada semi-período possa ser tratado como uma função que contém apenas os termos linear e quadrático no tempo. Assim como na técnica de varredura-z resolvida no tempo, estes dois termos contém todas as informações a respeito da amostra. 
Nestas condições, um período do sinal pode ser escrito como:

$$
\begin{array}{cc}
S=0 & p / \frac{-1}{2 f}<t<0 \\
S=S_{0}\left(1+T^{(1)}(Z) t+T^{(2)}(Z) t^{2}\right) & p / 0<t<\frac{1}{2 f}
\end{array}
$$

onde $\mathrm{S}_{0}$ é o sinal linear, $\mathrm{T}^{(1)}(\mathrm{Z})$ e $\mathrm{T}^{(2)}(\mathrm{Z})$ são coeficientes que dependem dos parâmetros térmicos e podem ser obtidos da equação (2.19) no caso da varredura-z por transmissão. Estes coeficientes tem sempre sinais contrários. Um esboço da equação (2.20) é mostrado na figura 2.7 .

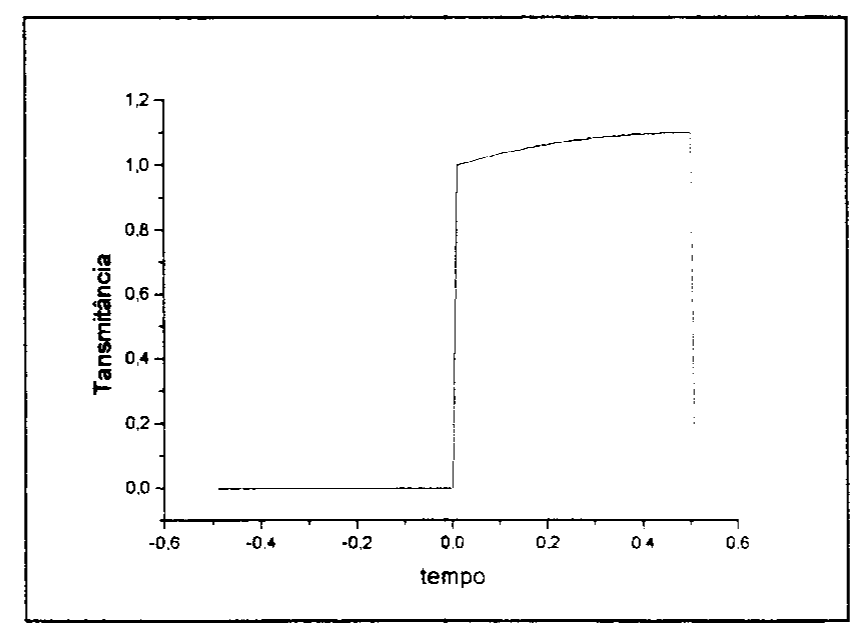

Figura 2.7: Representação da transmitância com os termos linear e quadrático no tempo.

A série de Fourier que representa a função (2.20) está mostrada no apêndice C. Desta série só estamos interessados nas duas primeiras componentes de Fourier dadas por:

$$
\begin{gathered}
c_{1}=\frac{2 S_{0}}{\pi} \\
c_{2}=\frac{S_{0}}{8 f^{2} \pi} \sqrt{\frac{T^{(2)}(Z)^{2}}{\pi^{2}}+\left[2 f T^{(1)}(Z)+T^{(2)}(Z)\right]^{2}}
\end{gathered}
$$


de cuja razão, que chamaremos de $\mathbb{Z}(Z)$, sai o sinal não-linear normalizado:

$$
R(Z)=\frac{c_{2}}{c_{1}}=\frac{1}{16 f^{2}} \sqrt{\frac{T^{(2)}(Z)^{2}}{\pi^{2}}+\left[2 f T^{(1)}(Z)+T^{(2)}(Z)\right]^{2}}
$$

Experimentalmente, as componentes $c_{1}$ e $c_{2}$ são obtidas pelos lock-ins na forma de tensão elétrica que é transformada em valor numérico por um conversor analógico-digital e a razão é feita pelo microcomputador.

Quando se fizer medidas RF é necessário saber se a frequência utilizada caracteriza-se como "suficientemente alta" ou "moderadamente alta". Fazendo varreduras-z em função da frequência, obtemos um comportamento esquematizado na figura 2.8 para uma amostra fictícia.

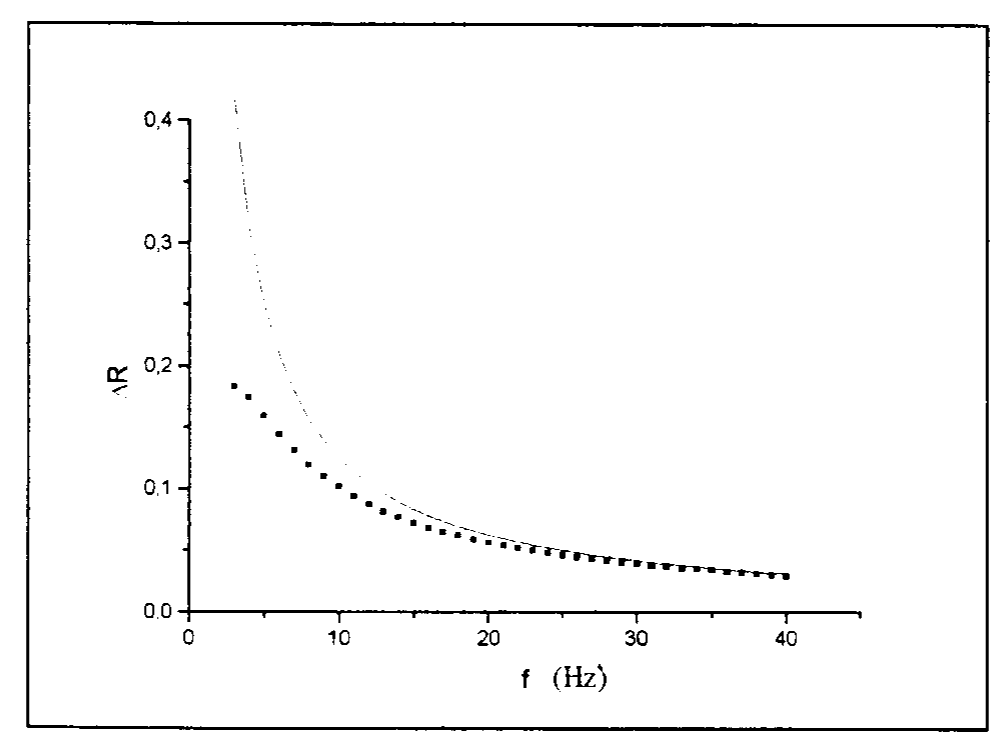

Figura 2.8: Variação teórica de $\mathcal{Z}(Z)$ em função da frequência graficada com o termo linear no tempo (curva cheia), e com os termos linear e quadrático (curva pontilhada), para uma amostra fictícia.

Deste gráfico vemos que para altas frequências a curva de $\Delta \boldsymbol{Z}$ decai com $1 /$ f, de forma que $f \times \Delta \boldsymbol{Z}(\mathrm{f})$ é constante, mudando de comportamento em frequências mais baixas onde há difusão de calor, como representado pela figura 2.9 . 


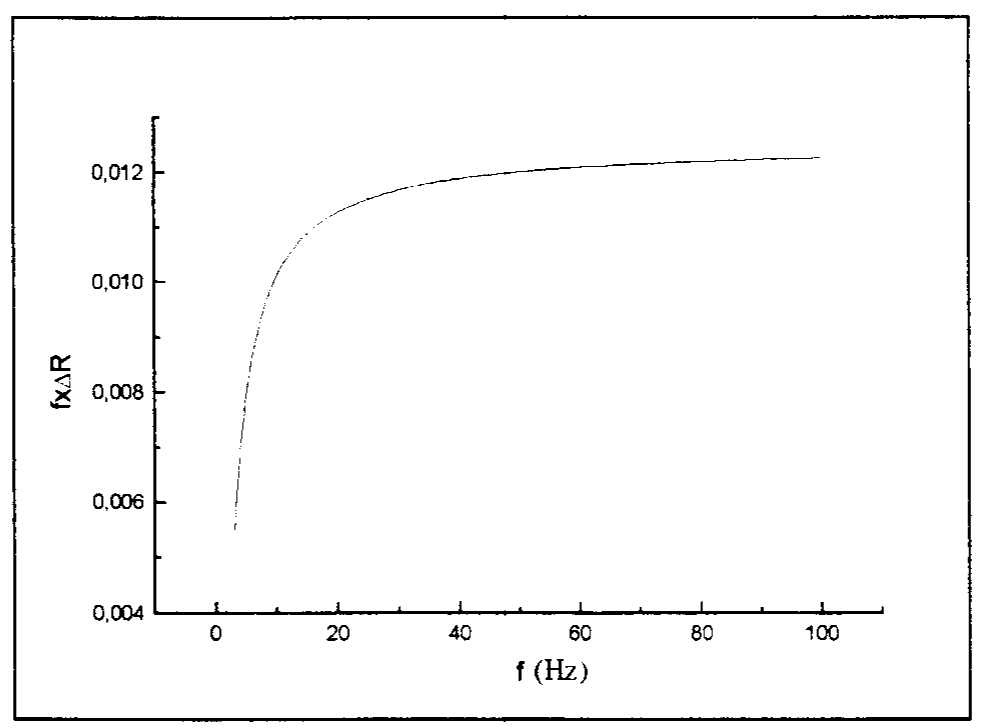

Figura 2.9: Representação de f. $\Delta \boldsymbol{R}(\mathrm{f})$ em função de $f$.

Podemos classificar a frequência como suficientemente alta na região onde f. $\Delta R$ estabiliza. Na região onde o sinal for não menos que $70 \%$ do sinal estabilizado, a frequência pode ser tida como moderadamente alta.

Há circunstâncias em que não é possível aumentar a frequência até o sinal estabilizar, por duas razões: em frequências muito altas o sinal $\Delta \boldsymbol{R}$ fica muito pequeno e nem sempre pode-se compensar isto aumentando a potência do laser. Em materiais com alta difusividade é preciso frequências muito grandes para se chegar ao regime estacionário e nem sempre o modulador alcança este regime. A figura 2.10 mostra uma curva medida para o vidro RG-715 de f. $\Delta \mathcal{Z}$ versus $\mathrm{f}$ em que o regime estacionário não é obtido. 


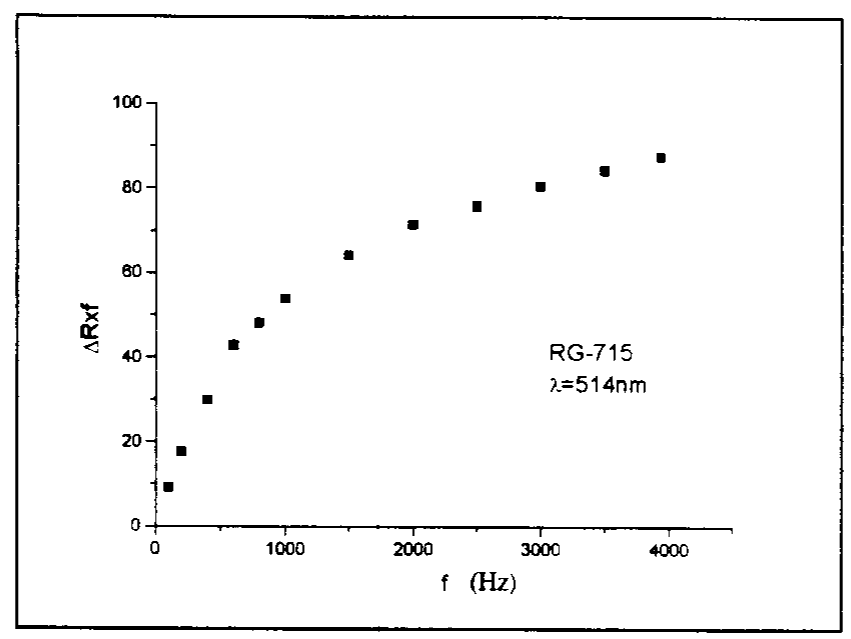

Figura 2.10: f. $\Delta R$ em função de f para o vidro dopado com semicondutor RG-715

Nestes casos não é possível obter isoladamente os parâmetros térmicos relacionados a $T^{(1)}(Z)$, pois há sempre uma contribuição do termo com $T^{(2)}(Z)$. $O$ que fazemos é um ajuste simultâneo de duas ou mais curvas de varredura-z com diferentes frequências.

Se a frequência máxima que se obtém não for suficiente para que possamos representar o sinal com série de potências até o termo quadrático, devemos incluir mais termos na equação (2.23). No apêndice $C$ mostramos $\mathbb{Z}(Z)$ com termos até quinta ordem. O tratamento teórico com mais termos em $\mathbb{Z}(Z)$ pode ser necessário em metais que possuem altas difusividades térmicas.

\subsubsection{Efeitos residuais}

Efeitos residuais ocorrem sempre que o "chopper" inicia um novo periodo antes que a amostra tenha relaxado completamente. Neste caso, a evolução temporal de periodos anteriores misturam-se ao sinal que se observa no tempo $t$ As equações (2.17) e (2.23) não levam em conta estes efeitos residuais. Quando considerados, as expressões matemáticas se tornam extremamente grandes e complexas inviabilizando 
em alguns casos o tratamento teórico. O objetivo de trabalharmos com expressões que evitem os efeitos residuais é obtermos relações simples entre os parâmetros térmicos e os dados experimentais. Quando apresentarmos os resultados no capitulo IV, discutiremos como evitar estes efeitos na técnica RT ou como corrigi-los de forma aproximada nas medidas com a técnica RF

Dedicaremos o próximo capitulo para descrever a técnica de varredura-z por reflexão por ser o ponto central deste trabalho. 


\section{Capítulo III}

A Técnica de Varredura-Z

por Reflexão 


\subsection{Introdução}

A técnica de varredura-z por reflexão é o ponto central deste trabalho. Desenvolvemos e aplicamos esta técnica para medir materiais opacos e também para separar efeitos de deformação superficial e de variação de índice de refração no "bulk" da amostra. Uma técnica muito semelhante já havia sido proposta por D. V Petrov et al. [5], porém nela tem-se o inconveniente da linha de base da transmissão variar segundo a função $1 / z^{2}$ devido à montagem experimental, e a teoria utilizada é demasiada simples para descrevermos os efeitos de absorção e difusão de calor que se observa. Aqui demonstraremos uma montagem na qual a linha de base permanece constante. Também estendemos a teoria para podermos observar e entender a difusão de calor nas amostras.

\subsection{Descrição experimental da técnica de varredura-z por} reflexão

$\mathrm{O}$ aparato experimental consiste de um feixe modulado e focalizado que atravessa um divisor de feixe (DF) e atinge a amostra. A luz, depois de refletida, é desviada do eixo óptico pelo DF. Este é fixado perpendicularmente a um espelho que desvia a luz para um detetor. A junção perpendicular entre o DF e o espelho garante que o feixe refletido pela amostra e o que segue até o detetor estejam paralelos, o que facilita o alinhamento do sistema. A amostra, o DF e o espelho se deslocam juntos sobre um estágio de translação. Com este deslocamento conjunto, a imagem do foco não se move em relação ao detetor. Isto garante o valor unitário da linha de base da transmitância para sinais normalizados (figura 3.1). 


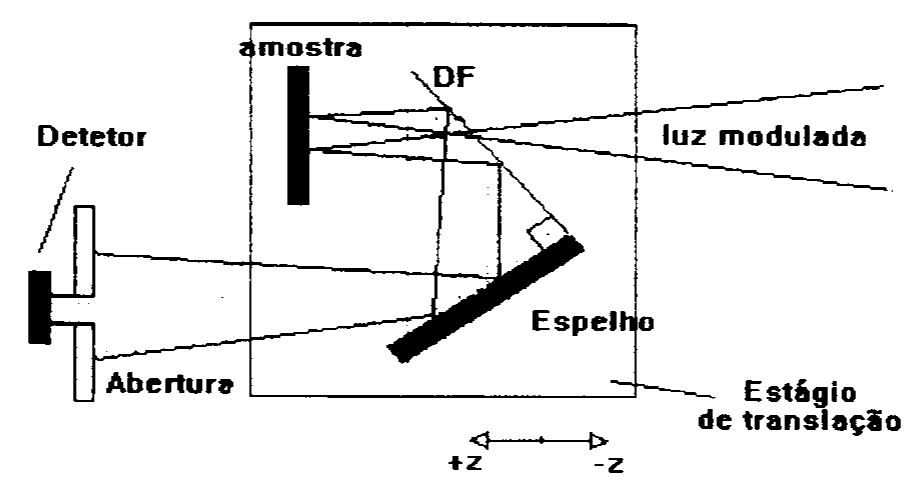

Figura 3.1: Montagem experimental da técnica de varredura-z por reflexão.

\subsection{Transmitância pela abertura para amostras grossas}

$(\mathbf{L} \rightarrow \infty)$

A transmitância pela abertura é a quantidade que se mede num experimento de varredura-z. Buscamos uma expressão teórica com a qual possamos ajustar os dados experimentais e extrair deles as propriedades do meio. Substituindo as equações (1.12) em (1.6) e esta em (2.15) temos para a transmitância na aproximação de amostra grossa a expressão:

$$
\begin{aligned}
& T(Z)=1-\frac{k P_{a b} \alpha_{t e r}(1+v)}{\pi k_{t e r}} \int_{0}^{\infty} A K e^{-K^{2}\left(\frac{1}{8}+\frac{1}{4\left(1+Z^{2}\right)}\right)} \operatorname{sen}\left(\frac{K^{2}}{4} \frac{Z}{1+Z^{2}}\right) \times \\
& {\left[\int_{0}^{\frac{D t}{w(Z)^{2}}} \frac{e^{\left(A^{2}-K^{2}\right) f i} \operatorname{erfd}(A \sqrt{f i})+e r f d(K \sqrt{f i})}{A+K}-\right.} \\
& \left.\frac{e^{\left(A^{2}-K^{2}\right) f i} \operatorname{erfd}(A \sqrt{f i})-\operatorname{erfd}(K \sqrt{f i})}{A-K} d f i\right] d K
\end{aligned}
$$


onde $\mathrm{A}$ ( coeficiente de absorção em unidades de $\mathrm{w}^{-1}$ ) é função de $\mathrm{Z}$ (pois w é função de Z) dada por $A=A_{0} \sqrt{1+Z^{2}}$, com $\mathrm{A}_{0}=\mathrm{w}_{0} \times \alpha_{\mathrm{ab}}$, e $\alpha_{\mathrm{ab}}$ o coeficiente de absorção. A e $A_{0}$ são adimensionais. Observe que não é prático utilizar a expressão (3.1) para ajustar os parâmetros teóricos com os dados experimentais, devido à integral dupla. Apesar da integral em fi ser solúvel analiticamente, a solução é uma soma de vários termos com funções erro e exponenciais, todos envolvendo a difusividade $D$, que nos interessa determinar. Mais uma vez deveremos obter os dados experimentais numa condição que simplifica a análise teórica. A expressão (3.1) vale para qualquer tempo. Expandindo as funções que envolvem a variável fi em série de potências, podemos obter uma expressão mais simples para a transmissão, válida nos primeiros instantes da evolução temporal. A partir do coeficiente dos termos linear e quadrático no tempo, já é possivel obter todos os parâmetros de interesse. Os dois primeiros termos da expansão da integral em fi são:

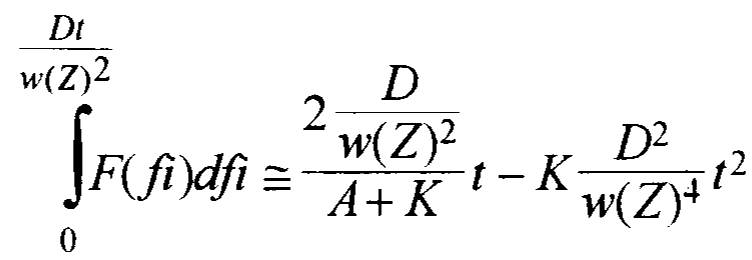

onde $\mathrm{F}(\mathrm{fi})$ é o integrando de $f i$ que aparece em (3.1). Os três primeiros termos da transmitância normalizada são: 


$$
\begin{aligned}
& T(Z)=1-\frac{2 k P_{a b} \alpha_{t e r}(1+v) D}{\pi k_{t e r} w(Z)^{2}} t \int_{0}^{\infty} \frac{A K}{A+K^{2}} e^{-K^{2}\left(\frac{1}{8}+\frac{1}{4\left(1+Z^{2}\right)}\right)} \operatorname{sen}\left(\frac{K^{2}}{4} \frac{Z}{1+Z^{2}}\right) d K+ \\
& \frac{k P \alpha_{t e r}(1+v) D^{2}}{\pi k_{t e r} w(Z)^{4}} t^{2} \int_{0}^{\infty} A K^{2} e^{-K^{2}\left(\frac{1}{8}+\frac{1}{4\left(1+Z^{2}\right)}\right)} \operatorname{sen}\left(\frac{K^{2}}{4} \frac{Z}{1+Z^{2}}\right) d K
\end{aligned}
$$

que pode ser escrita como:

$$
T(Z)=1+T^{(1)}(Z) t+T^{(2)}(Z) t^{2}
$$

onde definimos os coeficientes de primeira, $T^{(1)}(Z)$, e segunda ordem, $T^{(2)}(Z)$, da evolução temporal da transmitância como:

$$
T^{(1)}(Z)=\frac{-2 k P_{a b}}{\pi w(Z)^{2}} \frac{\alpha_{t e r}(1+v)}{\rho C_{p}} \int_{0}^{\infty} \frac{A K}{A+K} e^{-K^{2}\left(\frac{1}{8}+\frac{1}{4\left(1+Z^{2}\right)}\right)} \operatorname{sen}\left(\frac{K^{2}}{4} \frac{Z}{1+Z^{2}}\right) d K
$$

e

$$
T^{(2)}(Z)=\frac{k P_{a b}}{\pi w(Z)^{4}} \frac{\alpha_{t e r}(1+v) D}{\rho C_{p}} \int_{0}^{\infty} A K^{2} e^{-K^{2}\left(\frac{1}{8}+\frac{1}{4\left(1+Z^{2}\right)}\right)} \operatorname{sen}\left(\frac{K^{2}}{4} \frac{Z}{1+Z^{2}}\right) d K
$$

A expressão (3.3) é a mais simples que se pode obter para a transmitância na aproximação de amostra grossa. Nas seções seguintes vamos analisar que informações podem ser obtidas dela. No apêndice B está mostrada a expansão da integral de (3.2) com mais termos, caso sejam necessários para descrever adequadamente os dados experimentais 


\subsubsection{Propriedades da transmitância para amostras grossas}

\section{devido ao termo linear no tempo}

As propriedades da transmissão que pretendemos investigar estão relacionadas com a amplitude da variação de transmissão $\left(\Delta \mathrm{T}_{\mathrm{pv}}\right)$ e da distância entre o pico e o vale $\left(\Delta Z_{\mathrm{pv}}\right)$, mostradas na figura 2.3. Estas grandezas são convenientes pois não dependem da variável $\mathrm{Z}$ e se relacionam de forma simples com os parâmetros térmicos. Os valores do pico e vale são obtidos como usualmente se obtém extremos de funções: igualando a derivada da transmitância a zero e resolvendo a equação resultante para $Z$, substituindo as soluções $Z_{p}$ e $Z_{v}$ na transmitância para obtermos $T_{p}$ e $T_{v}$. O ajuste teórico de $\Delta \mathrm{T}_{\mathrm{pv}}$ e $\Delta \mathrm{Z}_{\mathrm{pv}}$ com os valores experimentais nos dá prontamente os parâmetros térmicos. Escreveremos estas grandezas com o supra-índice "(1)" $\left(\Delta \mathrm{T}_{\mathrm{pv}}{ }^{\left({ }^{1)}\right.}\right.$ e $\left.\Delta Z_{p v}{ }^{(1)}\right)$ para indicar que se referem ao coeficiente $T^{(1)}(Z)$.

Vamos inicialmente observar o que pode ser obtido de $\Delta Z_{p v}{ }^{(1)}$. Para tanto, observamos que a função que dá a forma da curva de $T^{(1)}(Z)$, é dada pela expressão:

$$
T^{(1)}(Z) \propto \frac{1}{\sqrt{1+Z^{2}}} \int_{0}^{\infty} \frac{K}{A(Z)+K} e^{-K^{2}\left(\frac{1}{8}+\frac{1}{4\left(1+Z^{2}\right)}\right)} \operatorname{sen}\left(\frac{K^{2}}{4} \frac{Z}{1+Z^{2}}\right) d K
$$

Os coeficientes que foram absorvidos pela proporcionalidade não dependem de $Z$, portanto só contribuem para a amplitude de $\mathrm{T}^{(1)}(Z)$ e não para sua forma. Assim, podemos calcular numericamente $\Delta Z_{\mathrm{pv}}{ }^{(1)}$ da expressão (3.7) em função de $\mathrm{A}_{0}$, lembrando que $A=A_{0} \sqrt{1+Z^{2}}$. A tabela 2.1 mostra alguns valores de $\mathrm{A}_{0}$ em função de $\Delta Z_{p v}$. Observamos nesta tabela que $\Delta Z_{p v}{ }^{(1)}$ é pouco sensivel em relação a 
$A_{0}$, o que implica num erro experimental grande. Extrair $A_{0}$ por meio de $\Delta Z_{\mathrm{pv}}{ }^{(1)}$ só é viável se a precisão da medida for muito boa. Se não, convém medi-lo de outra forma.

\begin{tabular}{|cccc|}
\hline$A_{0}$ & $\Delta Z_{p v}^{(1)}$ & $A_{0}$ & $\Delta Z_{p v}^{(1)}$ \\
& & & \\
0.05 & 2.217 & 1.55 & 1.940 \\
0.30 & 2.120 & 1.80 & 1.923 \\
0.55 & 2.060 & 2.50 & 1.887 \\
0.80 & 2.018 & 4.00 & 1.841 \\
1.05 & 1.986 & 10.0 & 1.777 \\
1.30 & 1.961 & $\infty$ & 1.717 \\
\hline
\end{tabular}

Tabela 3.1: $\Delta Z_{p v}{ }^{(1)}$ em função de $A_{0}$.

Nas amostras com que trabalhamos obtivemos $\alpha_{\mathrm{ab}}$ de forma direta, através da medida das potências incidente e transmitida na amostra. As amostras opacas foram afinadas até ficarem semitransparentes. Tendo o valor de $\alpha_{\mathrm{ab}}$ extraímos da curva de $T^{(1)}(Z)$ o parâmetro $\alpha_{t e r}(1+v) / \rho C_{p}$.

\subsubsection{Propriedades da transmitância para amostras grossas}

\section{devido ao termo quadrático no tempo}

A integral de (3.6) é analitica, sendo função apenas de $Z$. O valor de $\Delta Z_{\mathrm{pv}}{ }^{\left({ }^{2}\right)}$ é constante e igual a $1.4 \mathrm{z}_{0}$. Tendo determinado o parâmetro $\alpha_{\text {ter }}(1+v) / \rho C_{p}$ determinamos a difusividade, $\mathrm{D}$, relacionada $\operatorname{com} \Delta \mathrm{T}_{\mathrm{pv}}{ }^{(2)}$, da seguinte forma:

$$
\Delta T_{p v}{ }^{(2)}=\frac{1,5 P_{a b} A_{0}}{\pi w_{0}^{4}} \frac{\alpha_{t e r}(1+v) D}{\rho C_{p}}
$$


onde o fator 1,5 é a contribuição da integral da expressão (3.6) para a variação da transmissão.

Outra observação importante é que a razão entre as componentes linear e quadrática só tem dependência dos parâmetros $\mathrm{D}$ (difusividade) e $\mathrm{A}_{0}$. A difusividade em si é um parâmetro importante, mesmo que os fatores que o definem $\left(k_{\text {ter }}\right.$ e $\left.\rho \mathrm{Cp}\right)$ fiquem indeterminados. A razão entre as transmitâncias de primeira e segunda ordem nos dá:

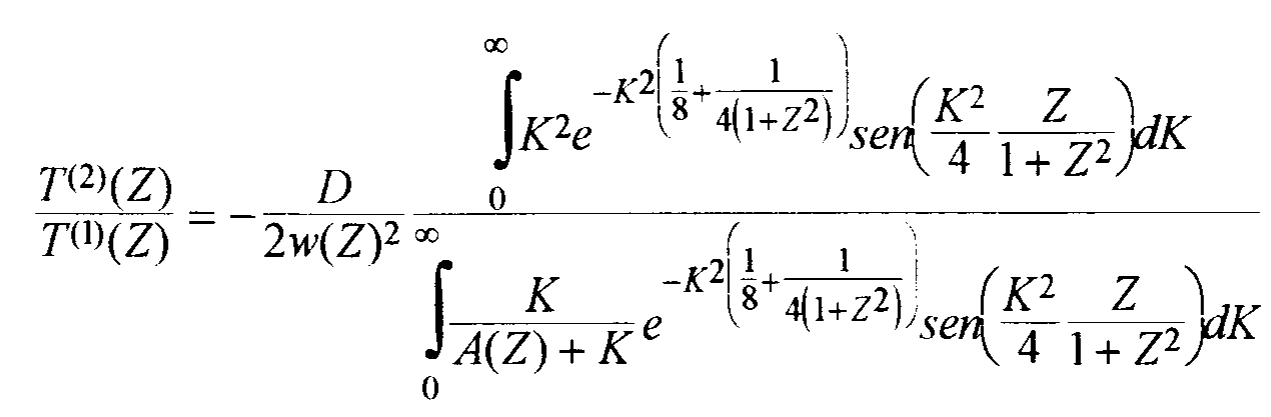

de onde determinamos $\mathrm{D}$.

\subsection{Transmitância pela abertura para amostras finas $(\mathrm{L} \rightarrow 0)$}

Substituindo as equações (1.16) em (1.6) e esta em (2.15) temos para a transmitância na abertura na aproximação de amostra fina a expressão:

$$
T(Z)=\mid-i \frac{k P \alpha_{a b} \alpha_{t e r} L}{2 \pi k_{t e r}}(1+v) \int_{0}^{\infty} \frac{e^{\frac{-K^{2}}{8}}}{K} e^{\frac{-K^{-2}}{4(1+i Z)}}\left(1-e^{\frac{-K^{2} D t}{w(Z)^{2}}}\right)_{d K}^{2}
$$

Felizmente a integral de (3.10) é analítica e a transmitância pode ser escrita como: 


$$
T(Z)=1+i \Gamma^{*}\left\{\ln \left[1+\frac{8 D t / w(Z)^{2}}{1 / 8+1 / 4(1+i Z)}\right]-\ln \left[1+\frac{8 D t}{1 / 8+1 / 4(1-i Z)}\right]\right\}
$$

com

$$
\Gamma^{*}=\frac{k P \alpha_{a b} \alpha_{t e r} L(1+v)}{4 \pi k_{t e r}}
$$

Apesar de envolver números complexos, a transmissão dada pela equação (3.11) é real. Nela desprezamos o termo com $\Gamma^{* 2}$. Observe também que (3.11) é relativamente simples comparada com as expressões para amostras grossas, pois não envolve integrais. Mesmo assim, ainda podemos simplificar a transmitância adotando o mesmo procedimento para amostras grossas. Expandindo as funções logaritmo de (3.11) em potências do tempo obtemos:

$$
\begin{aligned}
& T(Z)=1-\frac{64 k P \alpha_{a b} L}{\pi w_{0}^{2}} \frac{\alpha_{t e r}(1+v)}{\rho C_{p}} \frac{Z}{\left(1+Z^{2}\right)\left(9+Z^{2}\right)} t+ \\
& \frac{4096 k P \alpha_{a b} L}{\pi w_{0}{ }^{4}} \frac{\alpha_{t e r}(1+v) D}{\rho C_{p}} \frac{Z\left(3+Z^{2}\right)}{\left(1+Z^{2}\right)^{2}\left(9+Z^{2}\right)^{2}} t^{2}
\end{aligned}
$$

A expressão (3.13) é consideravelmente mais simples que a (3.3), tornando evidente a vantagem de medir amostras finas, sempre que possivel.

\subsubsection{Propriedades da transmitância devido aos termos linear e}

\section{quadrático no tempo para amostras finas}

O cálculo dos pontos de pico e vale neste caso é igual ao feito na seção $\mathbf{3 . 3}$, onde deriva-se a transmitância igualando a expressão resultante a zero. Tanto o termo linear no tempo quanto o quadrático de (3.13) não possuem termos cruzados de $\mathrm{Z}$ 
com $\mathrm{A}_{0}$ como acontece nas amostras grossas. Isto implica que $\Delta Z_{\mathrm{pv}}$ é constante em ambos os casos e que $\Delta T_{p v}$ é proporcional aos coeficientes do tempo. O valor de $\Delta Z_{p v}$ para os termos linear e quadrático no tempo valem $1.7 \mathrm{z}_{0}$ e $1.2 \mathrm{z}_{0}$ respectivamente. Estes valores podem ser usados para determinação de $\mathrm{z}_{0}$, e consequentemente, da cintura, $\mathrm{w}_{0}$, do feixe. $\Delta \mathrm{T}_{\mathrm{pv}}{ }^{(1)}$ fica:

$$
\Delta T_{p v}^{(1)}=\frac{6.4 k P \alpha_{a b} L}{\pi w_{0}^{2}} \frac{\alpha_{t e r}(1+v)}{\rho C_{p}}
$$

enquanto que para o coeficiente do termo quadrático temos:

$$
\Delta T_{p v}^{(2)}=\frac{102 k P \alpha_{a b} L}{\pi w_{0}^{4}} \frac{\alpha_{t e r}(1+v) D}{\rho C_{p}}
$$

Podemos obter diretamente a difusividade pela razão entre as amplitudes dos coeficientes linear e quadrático, obtendo:

$$
\frac{\Delta T_{p v}^{(2)}}{\Delta T_{p v}^{(1)}}=-15.9 \frac{D}{w_{0}^{2}}
$$

Lembramos que as equações (3.3) e (3.11) não levam em conta os efeitos residuais discutidas na seção 2.4.3. Quando apresentarmos os resultados referentes as medidas por reflexão discutiremos as implicações dos efeitos residuais.

No próximo capítulo aplicaremos os casos citados para encontrar os parâmetros térmicos da água, de vidros dopados com semicondutores e filmes de poliestireno 
Capítulo IV

Resultados 


\subsection{Introdução}

Neste capítulo vamos utilizar a teoria e as técnicas descritas nos capítulos anteriores para medirmos diversas classes de materiais. Entre eles, a água, que por ser bem conhecida nos possibilita demonstrar a validade das técnicas e da teoria.

Nos vidros dopados com semicondutores (VDS), nem todos os parâmetros eram conhecidos tal que pudéssemos fazer uma comparação. No entanto, os valores obtidos são coerentes com o que se espera para estes materiais. Nestes vidros, assim como na água, fizemos medidas com a técnica de varredura- $z$ resolvida no tempo (RT), descrita na seção 2.4.1, e resolvida em frequência (RF), descrita na seção 2.4.2 No poliestireno fizemos medidas RT apenas. Em todas as medidas que apresentamos a detecção do sinal é feita por um detetor rápido EGG modelo HFD-1100. Nas medidas RT na água e no poliestireno a aquisiçâo da evolução temporal para uma dada posição é feita através de um osciloscópio de memória modelo Tektronics TDS 360 que faz uma média sobre 256 períodos. Nos VDS's esta aquisição é feita com um osciloscópio de memória LeCroy 9400A que faz médias sobre 1000 periodos. Nas medidas RF a aquisição é feita com dois lock-ins digitais EGG modelo 5209. Os sinais dos lock-ins são convertidos em sinais digitais sobe os quais o microcomputador faz a razão entre as componentes de frequência em $\mathrm{f}$ e $2 \mathrm{f}$.

\subsection{Medidas por transmissão na água}

A água pura quase não absorve luz dificultando a observação de efeitos térmicos. Misturando-se uma pequena quantidade de corante aumentamos muito o coeficiente de absorção e observamos estes efeitos com clareza. Esperamos que o corante adicionado, por ser muito pouco, não altere nenhum dos paràmetros térmicos. 
Nestas circunstâncias podemos comparar os valores obtidos com os tabelados para verificação da validade da teoria que trata da transmissão em. A figura 4.1 mostra a evolução temporal da transmitância para uma dada posição, na qual fazemos um ajuste dos pontos experimentais com um polinômio de terceiro grau, cujos coeficientes estão relacionados aos parâmetros térmicos pela expressão (2.19) Repetindo este procedimento para várias outras posições, obtemos uma varredura-z dos coeficientes linear e quadrático, de onde extraímos os parâmetros térmicos.

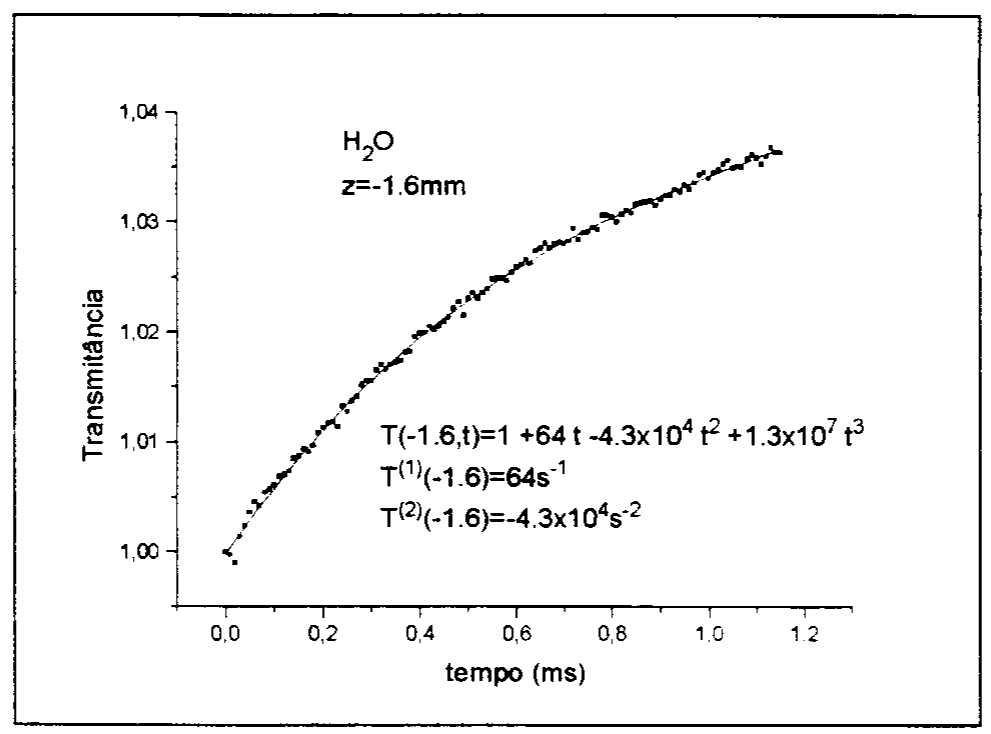

Figura 4.1: Evolução temporal da transmitância para a água numa dada posição

Nas medidas RT usamos o "chopper" com "duty cycle" de $92 \%$ para garantir que a amostra tivesse tempo de relaxar completamente antes do início do próximo período. Isto foi feito permitindo-se que a luz passasse por apenas um dos furos do "chopper". Todos os outros furos ficam bloqueados gerando uma modulação mostrada na figura 4.2 . 


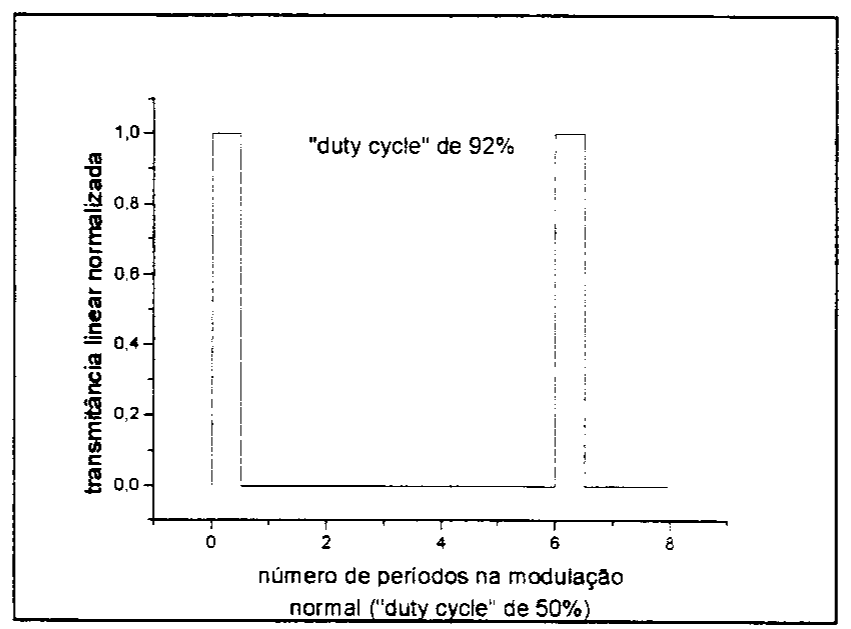

Figura 4.2: Representação da modulação da luz com "duty cỵcle" de $92 \%$ utilizada na técnica de varredura-z resolvida no tempo.

A figura 4.3 mostra os sinais obtidos para os coeficientes linear, $T^{(1)}(Z)$, e quadrático, $\mathrm{T}^{(2)}(\mathrm{Z})$, do tempo. O ajuste teórico é feito com a expressão (2.19), sendo que nela $T^{(1)}(Z)$ é o coeficiente do termo linear e $T^{(2)}(Z)$ é o coeficiente do termo quadrático no tempo. Tiramos do ajuste simultâneo das curvas o valor da difusividade, $D$, e do coeficiente $(\mathrm{dn} / \mathrm{d} \theta) / \rho \mathrm{C}_{\mathrm{p}}$.

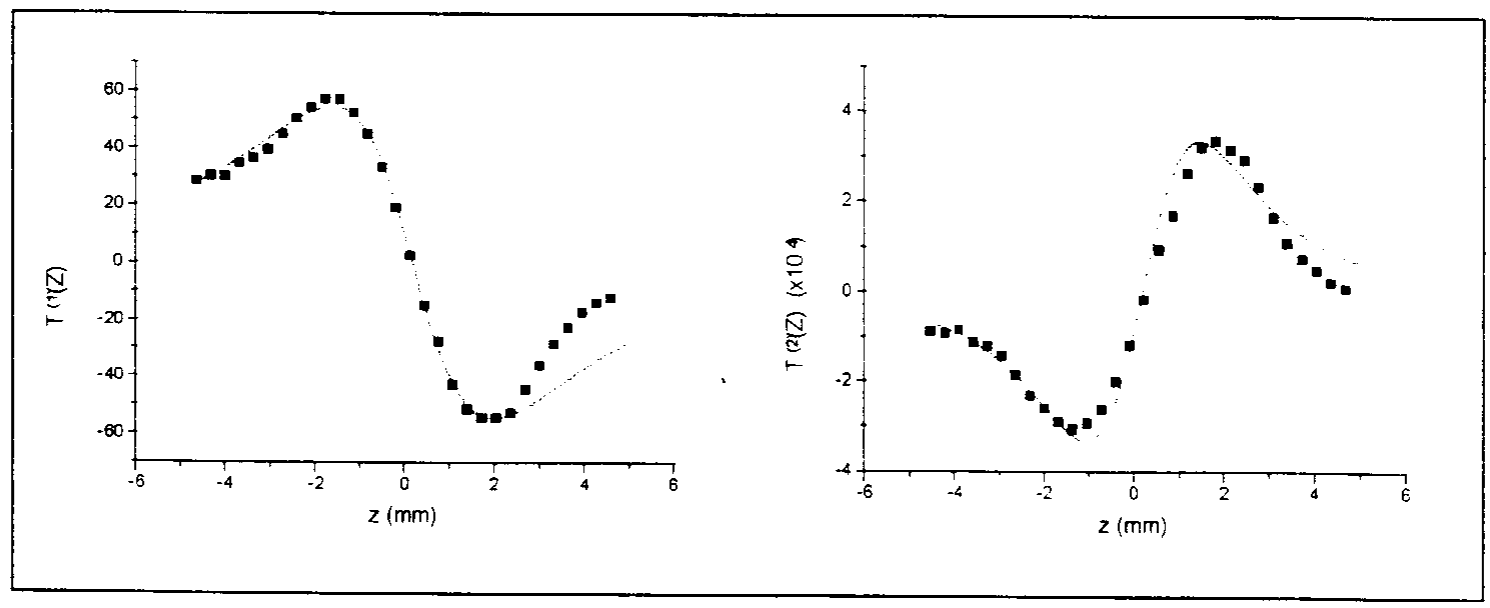

Figuras 4.3: Medidas resolvidas no tempo na água. Com os coeficientes linear e quadrático da evolução temporal é possível determinar os valores de $z_{0},(d n / d \theta) / \rho C_{p}$ e $D$.

As medidas foram feitas com $\mathrm{P}=7 \mathrm{~mW}, \lambda=532 \mathrm{~nm}$, que corresponde ao segundo harmônico de um laser de Nd-YAG continuo, $\alpha_{\mathrm{ab}}=0.86 \mathrm{~cm}^{-1}$ e L=0.11 cm. Os 
valores obtidos estão mostrados na tabela 4.1 juntamente com os valores tabelados para a água. $\mathrm{O}$ parâmetro confocal, $\mathrm{z}_{0}$, é obtido a partir da distância pico-vale da curva de $T^{(1)}(Z)$, onde temos que $\Delta Z_{p v}{ }^{(1)}=1.7 z_{0}$ e obtivemos $Z_{0}=2.1 \mathrm{~mm}$. A temperatura de $25^{\circ} \mathrm{C}$ com que comparamos nossos resultados experimentais aos tabelados é a temperatura aproximada do laboratório $\left(24^{\circ} \mathrm{C}\right)$. O laser esquenta a água apenas alguns décimos de ${ }^{\circ} \mathrm{C}$ na pior das hipóteses. A estimativa da variação de temperatura pode ser feita utilizando a equação (1.15), onde substituindo os parâmetros medidos obtemos uma variação de temperatura no centro do feixe de no máximo $0.75^{\circ} \mathrm{C}$.

Assim, as temperaturas da amostra e do laboratório são praticamente as mesmas.

\begin{tabular}{|c|c|c|}
\hline & Medido & Tabelado \\
\hline$\frac{d n}{d} \frac{1}{\rho} c_{p}\left(\times 10^{-11} m^{3}\right)$ & -1.94 & -2.27 \\
\hline$D\left(\times 10^{-7} \frac{m^{2}}{s}\right)$ & 1.24 & 1.43 \\
\hline
\end{tabular}

Tabela 4.1: Comparação entre valores medidos pela técnica de varredura-z resolvida no tempo e valores tabelados para a água.

A dependência dos parâmetros térmicos relevantes no experimento com a temperatura [23] é mostrada na tabela 4.2.

\begin{tabular}{|c|c|c|c|}
\hline $\mathbf{T}\left({ }^{\circ} \mathbf{C}\right)$ & $\mathbf{d n} / \mathbf{d} \theta\left(\times \mathbf{1 0}^{-6}{ }^{\circ} \mathbf{C}^{-1}\right)$ & $\mathbf{k}_{\text {ter }}\left(\mathbf{W} / \mathbf{m}^{\circ} \mathbf{C}\right)$ & $\mathrm{D}\left(\times 10^{-7} \mathbf{m}^{2} / \mathbf{s}\right)$ \\
\hline $\mathbf{0}$ & 7.47 & 0.561 & 1.34 \\
\hline $\mathbf{2 5}$ & -95.0 & 0.608 & 1.45 \\
\hline $\mathbf{5 0}$ & -174 & 0.643 & 1.54 \\
\hline 75 & -230 & 0.667 & 1.60 \\
\hline $\mathbf{1 0 0}$ & -262 & 0.679 & 1.62 \\
\hline
\end{tabular}

Tabela 4.2: Parâmetros térmicos tabelados para a água.

A diferença de $15 \%$ que se observa entre os valores medidos e tabelados na tabela 4.1 pode ser justificado devido ao modo do feixe não ser perfeitamente gaussiano, à correntes de convecçâo que ocorre em meios fluidos e que podem 
provocar deformações na lente térmica e ao contato térmico com a cubeta onde a amostra fica, pois, havendo difusão de calor uma parte dele é transferida para o vidro o que não é levado em conta na teoria.

As medidas resolvidas em frequência na água deram bastante assimétricas e por esta razão as curvas teóricas não se ajustam bem aos pontos experimentais como mostrado na figura 4.4 abaixo:

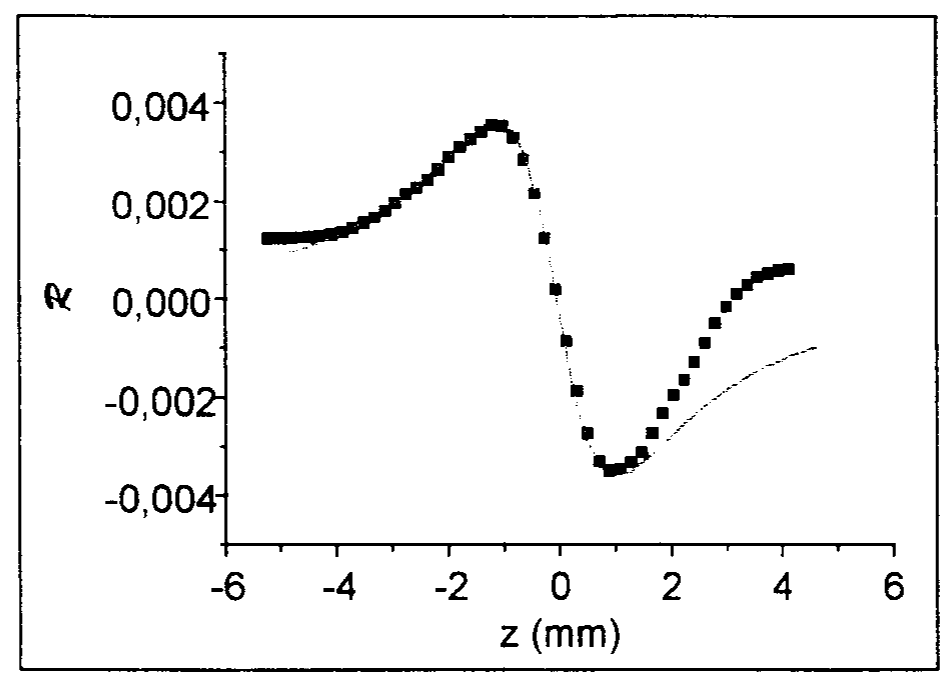

Figura 4.4: Medida resolvida em frequência na água

A assimetria, que não aparece nas medidas resolvidas no tempo, pode ser devida à correntes de convecção maiores, pois com um "duty-cycle" de $50 \%$ a potência média é maior e o contato térmico com a cubeta, assim como as correntes de convecção, permanecem atuando sobre as lentes térmicas residuais que ainda manifestam efeito. Na técnica resolvida no tempo com "duty-cycle" de $92 \%$ não há lentes térmicas residuais tornando estas medidas mais confiáveis neste caso. Ainda assim, as medidas RF são válidas para termos uma estimativa e a julgar pela variação da curva, $\Delta \mathrm{R}_{\mathrm{pv}}$ temos uma diferença de apenas $25 \%$ em relação a curva que utiliza os valores tabelados, o que reforça nossa teoria. 


\subsection{Medidas por transmissão no poliestireno}

No poliestireno fizemos medidas opor transmissão com amostras finas e obtivemos das medidas RT os gráficos mostrados na figura 4.5. O procedimento para obtermos estes gráficos é o mesmo descrito na seção 4.2 para a água. Devido ao baixo coeficiente de absorção deste material, foi feito uma dopagem com corante DR1. Espera-se que a dopagem não altere os parâmetros térmicos da amostra. As medidas foram feitas com $P=0.8 \mathrm{~mW}, \lambda=514 \mathrm{~nm}, \alpha_{\mathrm{ab}}=42 \mathrm{~cm}^{-1}, \mathrm{~L}=0.11 \mathrm{~mm}$

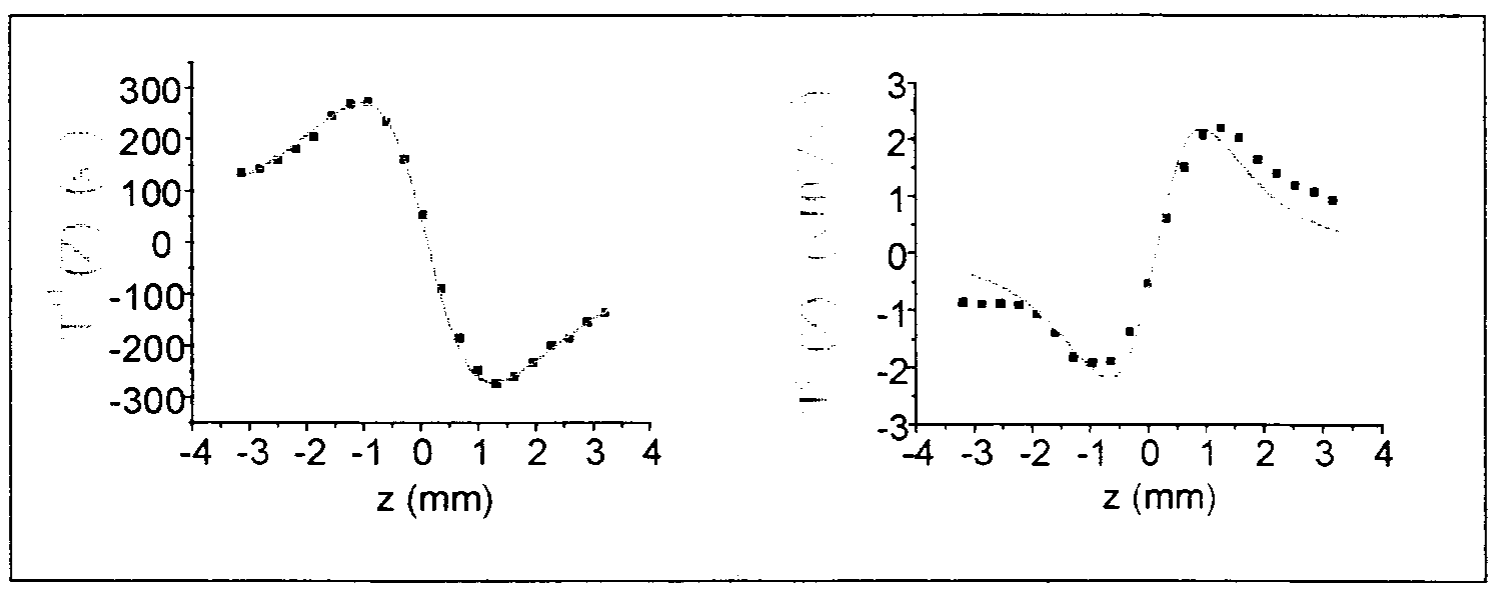

Figura 4.5: Medidas resolvidas no tempo no poliestireno dopado com DR1.

Na tabela 4.3 está mostrada uma comparação entre os valores obtidos e os tabelados [24] para o poliestireno.

\begin{tabular}{|c|c|c|}
\hline & Medido & Tabelado \\
\hline$\frac{d n}{d \theta} \frac{1}{\rho C_{p}}\left(\times 10^{-11} \stackrel{m}{j}^{3}\right)$ & -2.53 & -11.4 \\
\hline$D\left(\times 10^{-7} \frac{m^{2}}{s}\right)$ & 0.9 & 0.9 \\
\hline
\end{tabular}

Tabc 4.3: Comparação entre valores medidos pela técnica de varredura- $z$ resolvida no tempo e valores tabelados para o poliestireno.

A discrepância entre os valores do parâmetro $(\mathrm{dn} / \mathrm{d} \theta) / \rho \mathrm{C}_{\mathrm{p}}$ pode ser justificada por três razões principais: (i) variação radial de temperatura no interior do feixe: 
Usando a equação (1.15), estimamos que a temperatura no centro do feixe é $\approx 10^{\circ} \mathrm{C}$ maior do que nas bordas. Esta variação de temperatura pode implicar numa variação significativa do parâmetro $\mathrm{dn} / \mathrm{d} \theta$ como ocorre na água (figura 2.6) e que não é levado em conta no cálculo de $T^{(1)}(Z)$. (ii) Saturação da absorção: Observamos que o coeficiente de absorção diminui devido a saturação. As curvas mostradas na figura 4.5 só são simétricas pois subtraimos a curva de saturação, curva esta obtida fazendo-se a varredura-z sem a abertura, coletando-se toda a luz que passa pela amostra [6]. (iii)

Ressonância do DR1: Por trabalharmos com uma frequência muito próxima da ressonância do DR1 é possível que ele altere o valor de $\mathrm{dn} / \mathrm{d} \theta$. É interessante notar que usando o valor tabelado da difusividade para ajustar a curva $T^{(2)}(Z)$ obtemos uma excelente concordância apesar da discrepância na curva $T^{(1)}(Z)$. Isto demonstra que a difusividade pode ser obtida independentemente apesar de estar vinculado ao parâmetro $(\mathrm{dn} / \mathrm{d} \theta) / \rho C_{\mathrm{p}}$ [expressão (2.19)]. Isto é possivel pois os fatores que influem na formação da lente térmica citados anteriormente não alteram a difusão de calor no meio, ou em outras palavras, não alteram o alargamento da lente térmica e consequentemente a curvatura da evolução temporal

\subsection{Medidas em vidros dopados com semicondutor (VDS)}

Os VDS's medidos foram os filtros OG-590 e RG-715 da Schott. Nestas amostras pudemos trabalhar com vários valores para o coeficiente de absorção que varia desde $85 \mathrm{~cm}^{-1}$ até $210 \mathrm{~cm}^{-1}$, dependendo do vidro e do comprimento de onda. Utilizamos as linhas $514 \mathrm{~nm}$ e $476.5 \mathrm{~nm}$ do laser de argônio. A absorção é medida diretamente afinando os filtros a $\sim 0.3 \mathrm{~mm}$, espessura suficientemente fina, tal que, uma 
parte mensurável da luz é transmitida. O coeficiente de absorção é obtido pela fórmula:

$$
\alpha_{a b}=\ln \left(\frac{P_{0}-P_{R}}{P_{T}}\right)
$$

onde $\mathrm{P}_{0}, \mathrm{P}_{\mathrm{R}}$ e $\mathrm{P}_{\mathrm{T}}$ são as potências incidente, refletida e transmitida, respectivamente. Os valores de $\alpha_{a b}$ em função do comprimento de onda que medimos para os vidros OG-590 e RG-715 estão mostrados na tabela 4.4.

\begin{tabular}{ccc|}
\hline$\lambda(\mathrm{nm})$ & $\begin{array}{c}O G-590 \\
\alpha_{a b}\left(\mathrm{~cm}^{-1}\right)\end{array}$ & $\begin{array}{c}R G-715 \\
\alpha_{a b}\left(\mathrm{~cm}^{-1}\right)\end{array}$ \\
514 & 85,5 & 169 \\
501.7 & 114 & 183 \\
496.5 & 124,5 & 189 \\
488 & 136,5 & 199 \\
476.5 & 144,5 & 213 \\
\hline
\end{tabular}

Tabela 4.4: $\alpha_{a b}$ em função do comprimento de onda para os vidros OG-590 e RG-715.

Devido ao alto coeficiente de absorção destes vidros, utilizamos o aparato de varredura-z por reflexão descrita na seção 3.2 do capítulo III. combinada ou com a técnica de varredura-z RT ou com a técnica RF. As varreduras-z com a técnica RT é obtida como descrito na seção 4.2 para a água. Nas medidas RF obtivemos curvas de varredura-z com a mais alta frequência que o "chopper" atinge $(4 \mathrm{KHz})$. Nestas medidas, supomos que, devida a alta frequência a evolução temporal fosse linear no tempo. Quando apresentarmos os resultados destas medidas nas subseçōes seguintes, discutiremos a validade desta aproximação. 


\subsubsection{Medidas no vidro OG-590}

Das medidas RT obtemos para o vidro OG-590 os gráficos mostrados na figura 4.6.

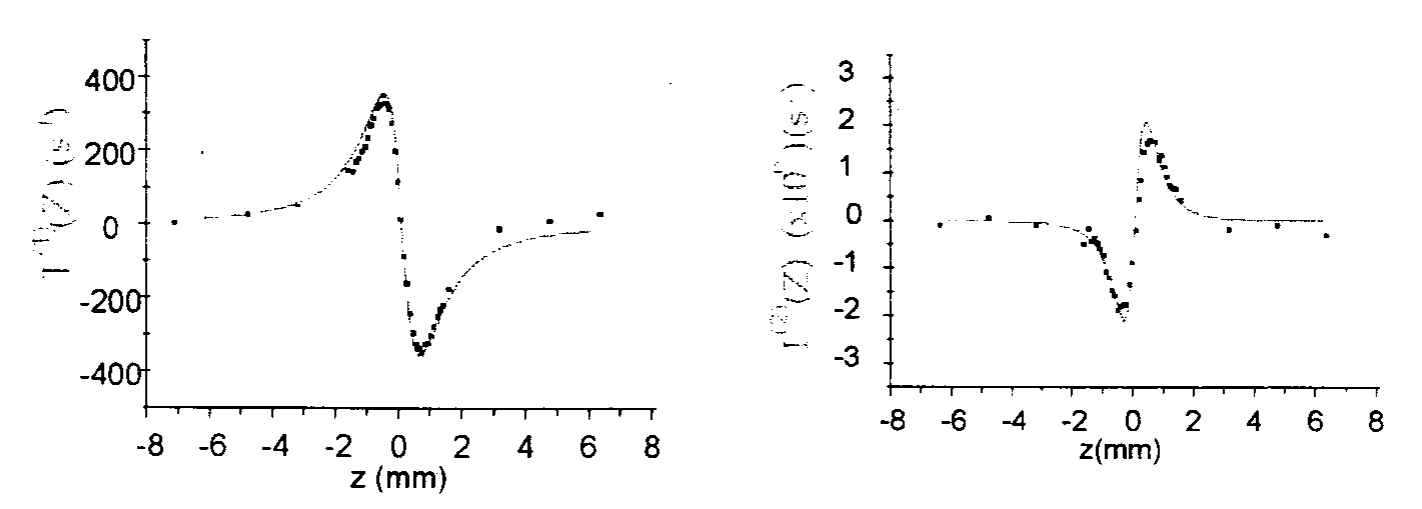

Figura 4.6: Variação dos coeficientes linear e quadrático no tempo medidos para o filtro OG590 com a técnica RT.

Os parâmetros que melhor ajustam os gráficos da figura 4.5 com $\mathrm{P}=15.8 \mathrm{~mW}$, $\alpha_{\mathrm{ab}}=85,5 \mathrm{~cm}^{-1}, \lambda=514 \mathrm{~nm}$, estão mostrados na tabela 4.5 .

\begin{tabular}{|cc|}
\hline Parâmetros & Valores Medidos \\
$\frac{\alpha_{t e r}(1+v)}{\rho C_{p}}$ & $(12.0 \pm 0.2) \times 10^{-12} \frac{\mathrm{m}^{3}}{J}$ \\
$D$ & $(3.3 \pm 0.4) \times 10^{-7} \frac{\mathrm{m}^{2}}{\mathrm{~s}}$ \\
$z_{0}$ & $(0.5 \pm 0.05) \mathrm{mm}$ \\
\hline
\end{tabular}

Tabela 4.5: Valores obtidos para o vidro OG-590 pela técnica RT

Nas medidas deste vidro com a técnica $\mathrm{RF}$, com $\mathrm{f}=3937 \mathrm{~Hz}, \lambda=514 \mathrm{~nm}, \mathrm{P}=30 \mathrm{~mW}$, $\alpha_{\mathrm{ab}}=85.50 \mathrm{~cm}^{-1}$ obtemos a curva mostrada na figura 4.7 . 


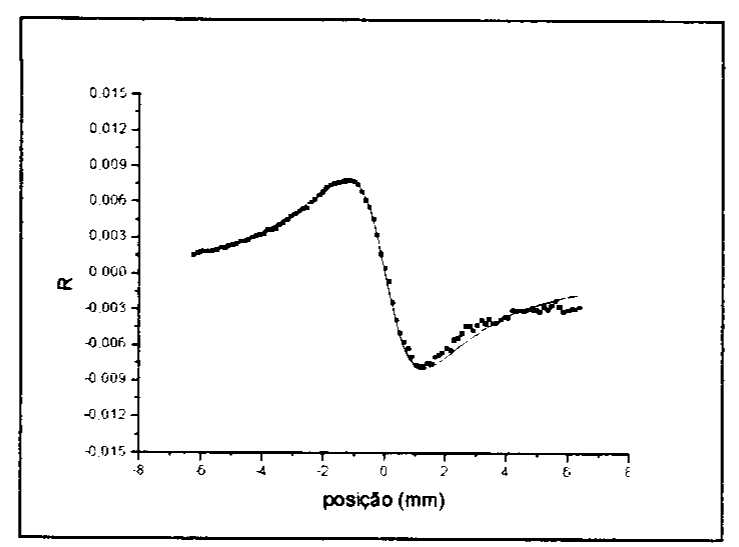

Figura 4.7: Medida no vidro OG-590 com a técnica de varredura-z resolvida em frequência.

A técnica resolvida em frequência impõe um "duty-cycle" de $50 \%$ e a amostra não tem tempo de relaxar completamente antes do início do próximo período. $\mathrm{O}$ cálculo do efeito residual para o caso da reflexão resulta em expressões demasiadamente complexas para podermos ajustar os pontos experimentais. Então, fizemos um ajuste com uma expressão que leva em conta efeitos residuais em meios eletrônicos $[7,25]$ como uma forma de obtermos uma estimativa para o parâmetro $\alpha_{\text {ter }}(1+v) / \rho C_{p}$. Como estamos interessados apenas numa estimativa não levaremos em conta a pequena difusão de calor que ainda se verifica nestes vidros nesta frequência (figura 2.10). Corrigindo o valor de $R$ por:

$$
\boldsymbol{R}_{\text {corrigido }}=\frac{1-\exp \left[\frac{D}{2 f w^{2}(Z)}\right]}{1-\exp \left[\frac{D}{f w^{2}(Z)}\right]}
$$

obtemos $\alpha_{\text {ter }}(1+v) / \rho C_{\mathrm{p}}=13.6 \times 10^{-12} \mathrm{~m}^{3} / \mathrm{J}$, que é próximo do valor obtido com a técnica RT $\left(12.0 \times 10^{-12} \mathrm{~m}^{3} / \mathrm{J}\right)$ o que reforça nossa teoria. 


\subsubsection{Medidas no vidro RG-715}

Das medidas resolvidas no tempo, obtivemos para amostra grossa os gráficos da figura 4.8. $O$ primeiro correspondendo ao termo linear $\mathrm{T}^{(1)}(Z)$ e o segundo correspondendo ao termo quadrático $\mathrm{T}^{(2)}(\mathrm{Z})$. As medidas foram feitas com $\mathrm{P}=15.8 \mathrm{~mW}, \alpha_{\mathrm{ab}}=169 \mathrm{~cm}^{-1}$ e $\lambda=514 \mathrm{~nm}$.

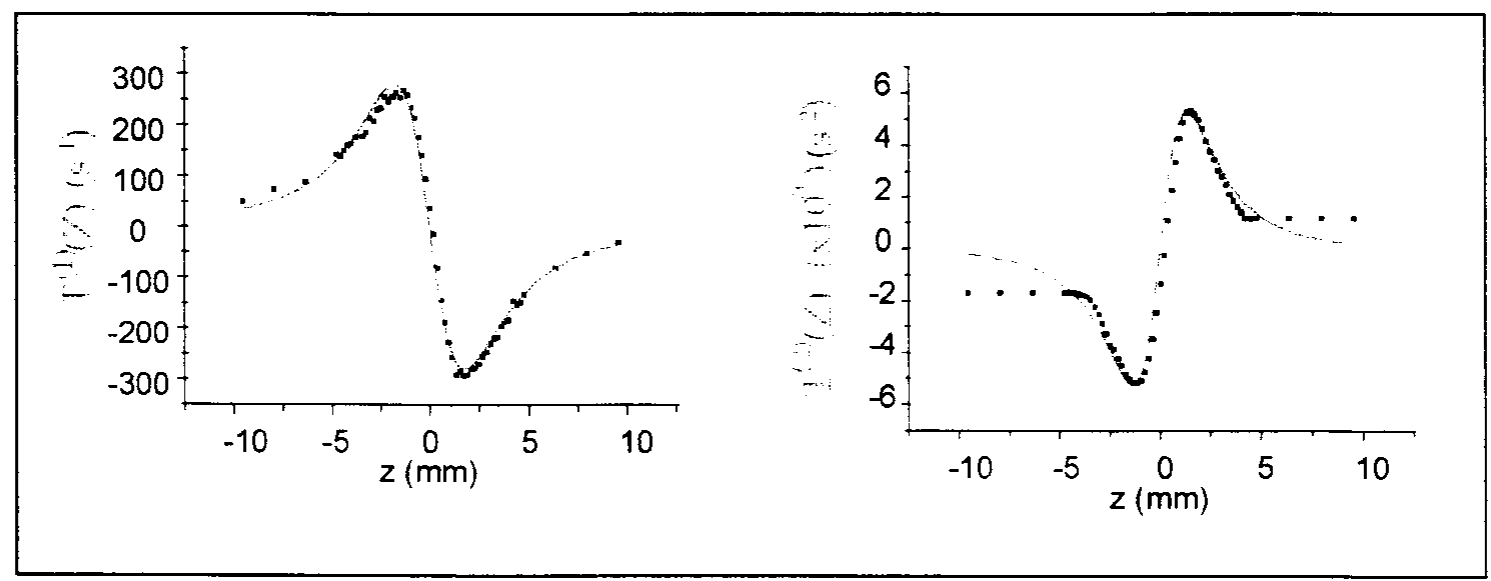

Figura 4.8: Gráficos de $T^{(1)}(Z)$ e $T^{(2)}(Z)$ para medidas resolvidas no tempo no vidro $R G-715$.

Do ajuste teórico das curvas acima obtemos os valores mostrados na tabela 4.6 .

\begin{tabular}{|cc|}
\hline Parâmetros & Valores Medidos \\
$\frac{\alpha_{\text {ter }}(1+v)}{\rho C_{p}}$ & $(12.7 \pm 0.3) \times 10^{-12} \frac{\mathrm{m}^{3}}{J}$ \\
$D$ & $(2.9 \pm 0.3) \times 10^{-7} \frac{\mathrm{m}^{2}}{\mathrm{~s}}$ \\
$z_{0}$ & $(1.9 \pm 0.1) \mathrm{mm}$ \\
\hline
\end{tabular}

Tabela 4.6: Valores obtidos para o vidro RG-715 pela técnica resolvida no tempo

Comparando as tabelas 4.6 e 4.5 vemos que os parâmetros térmicos dos vidros RG-715 e OG-590 são quase iguais dentro do erro experimental. Isto indica que ambos são feitos do mesmo material com diferentes dopagens. $O$ parâmetro confocal, $\mathrm{z}_{0}$, apesar de não ser um parâmetro da amostra e sim do experimento, 
incluímo-o na tabela dos resultados por ser obtido do ajuste teórico assim como as constantes térmicas. A diferença entre os valores de $z_{0}$ nestas duas tabelas, assim como em outras medidas se deve à utilização de diferentes lentes e diâmetros de feixe no experimento.

Da medida resolvida em frequência com $\mathrm{f}=3936 \mathrm{~Hz}, \lambda=514 \mathrm{~nm}, \mathrm{P}=30 \mathrm{~mW}$, $\alpha_{\mathrm{ab}}=169 \mathrm{~cm}^{-1}$, obtivemos o gráfico mostrado na figura 4.9 ,

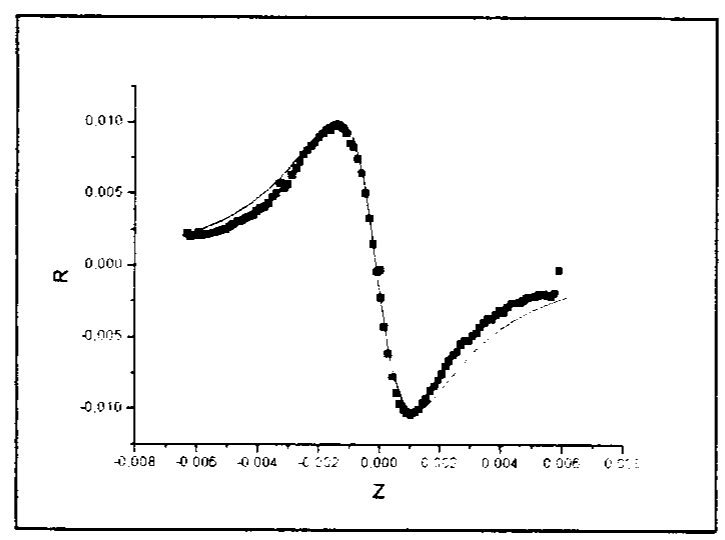

Figura 4.9: Medida resolvida em frequência no RG-715.

Fazendo o ajuste teórico com a expressão (4.1) obtemos e $\alpha_{\text {ter }}(1+v) /\left(\rho C_{p}\right)=$ $9.8 \times 10^{-12} \mathrm{~m}^{3} / \mathrm{J}$. A tabela 4.7 compara o parâmetro $\alpha_{\text {ter }}(1+v) /\left(\rho \mathrm{C}_{\mathrm{p}}\right)$ dos vidros OG-590 e RG-715 utilizando as técnicas RT e RF. Na técnica RT evitamos a fase não-linear residual com um "duty-cycle" de $92 \%$ de forma que estas medidas são mais confiáveis. Por RF obtemos uma estimativa que è próxima dos valores obtidos por RT o que reforça nossa teoria. 


\begin{tabular}{|lll|}
\hline & $\frac{\alpha_{\text {ter }}(1+v)}{\rho C_{p}}$ \\
& $O G-590 R G-715$ \\
RT & $12.0 \pm 0.2$ & $12.7 \pm 0.3$ \\
RF & 13.6 & 9.8
\end{tabular}

Tabela 4.7: Comparação entre os valores de $\alpha_{\text {ter }}(1+v) /\left(\rho C_{p}\right)$ para os vidros OG-590 e RG-715 usando as técnicas de varredura-z RT e RF. A unidade é dada $e m 10^{-12} \mathrm{~m}^{3} / \mathrm{J}$. 
Conclusão 
As técnicas e a teoria apresentadas permitem medir parâmetros térmicos de forma simples e rápida em relação a outras técnicas de medição de parâmetros térmicos. Os parâmetros que as técnicas apresentadas permitem medir são a difusividade, D, e a capacidade térmica por unidade de volume, que no caso da reflexão é dada por $\left[\alpha_{\text {ter }}(1+v) / \rho C_{p}\right]^{-1}$ e no caso da trasmissão é dado por $[(\mathrm{dn} / \mathrm{dT}) /$ $\left.\rho C_{p}\right]^{-1}$

A técnica resolvida no tempo foi aplicada com sucesso em todos os materiais medidos, sendo que a discrepânica no valor de $(\mathrm{dn} / \mathrm{dT}) / \rho \mathrm{C}_{\mathrm{p}}$ do poliestirno é justificável pela saturação da absorção, pelo gradiente radial de temperatura na amostra, e pela proximidade da frequência do laser com a ressonância do DR 1 como discutimos na seção 4.3. A técnica RF mostrou boa concordânica com a técnica RT, porém, requer um tratamento matemático complicado e induz em algumas amostras efeitos que não podem ser controlados como o contato térmico com suporte e correntes de convecção em amostras líquidas, discutidos na seção 4.2. Assim a técnica RT se mostrou mais confiável por permitir que se evite os efeitos térmicos residuais.

Nas medias com VDS's obtivemos valores que são coerentes com os valores esperados para vidros silicatos e os resultados com as técnicas RT e RF concordam entre si. No entanto, uma comparação precisa é dificil de ser feita pois não se conhece todos os parâmetros térmicos destes vidros. Na continuação deste trabalho pretendemos fazer medições por reflexão em materiais já bem caracterizados, para então testarmos melhorias em caso de discordância. Também pretendemos automatizar o sistema para aquisição resolvida no tempo, tal que não seja necessário adquerir a evolução temporal em diversas posições para então obter as curvas de 
varredura- $Z$ dos coeficientes $T^{(1)}(Z)$ e $T^{(2)}(Z)$, possibilitando-se fazer medidas mais rápidas e com mais pontos. Pretendemos ainda medir por reflexão amostras finas, visando discriminar nas medidas por transmissão os efeitos de auto-modulação de fase devido a deformação superficial daqueles gerados no "bulk" da amostra. Repitiremos as medidas no poliestireno com outro dopante para evitar os problemas citados acima. Pretendemos observar e medir efeitos térmicos e de interface em filmes finos e separar efeitos térmicos e eletrônicos nas amostras que apresentam os dois. 
Apêndice A

\section{Cálculo da Temperatura nas}

\section{Amostras}


Neste apêndice calcularemos a distribuição de temperatura nas amostras aquecidas por uma fonte de calor gaussiana de um laser. As equações que obteremos trata desta distribuição para amostras grossas e finas. As integrais que aparecem em várias equações são resolvidas no "software" Mathematica.

\section{A1. Distribuição de temperatura em meios semi-infinitos}

Em três dimensões, a variação de temperatura num ponto $(R, Z)$ devido a um incremento diferencial de calor depositado num volume em torno do ponto $\left(X^{\prime}, Y^{\prime}, Z^{\prime}\right)$ é dada por [13]:

$$
d \Delta \theta(R, Z, t)=\frac{d Q\left(X, Y^{\prime}, Z^{\prime}\right)}{8 \rho C p\left[\pi D\left(t-t^{\prime}\right)\right]^{3 / 2}} e^{\frac{w^{2},}{4 D\left(t-t^{\prime}\right)}\left[\left(R-X^{\prime}\right)^{2}+Y^{\prime 2}+\left(Z-Z^{\prime}\right)^{2}\right]}
$$

onde as variáveis adimensionais $\mathrm{X}^{\prime}, \mathrm{Y}^{\prime}$ e $\mathrm{Z}^{\prime}$ são as coordenadas $\mathrm{x}, \mathrm{y}, \mathrm{z}$ em unidades do raio do feixe gaussiano $(w)$ discutidas no capítulo I. e definidas na figura A1. A equação (A1) só é válida se o meio for infinito.

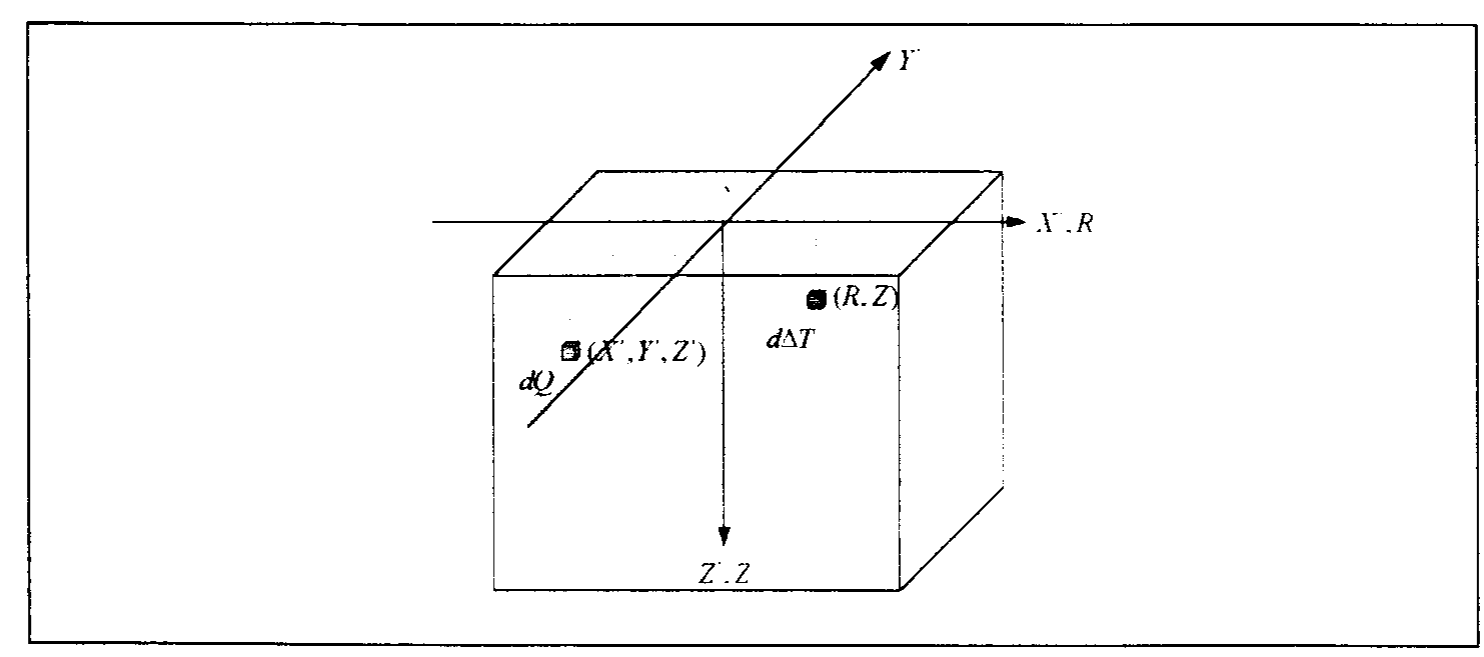

Figura A1: Representação da variação de temperatura em torno (R,Z) devido a uma quantidade dQ de calor depositada no volume $d X^{\prime} \times d Y^{\prime} \times d Z^{\prime}$ em $\left(X^{\prime}, Y^{\prime}, Z^{\prime}\right)$. 
A quantidade de calor dQ da equação (A1) é calculada levando-se em conta o perfil gaussiano do feixe atenuado exponencialmente na profundidade. Esta situação é representada na figura A2. A Intensidade absorvida no elemento de volume mostrado é dada por:

$$
\begin{aligned}
& I_{\text {fica }}=I_{\text {entra }}-I_{\text {sai }}=I_{0} e^{-2 X^{\prime 2}-2 Y^{2}}\left[e^{-A Z^{\prime}}-e^{-A Z^{\prime}}(1-A d Z)\right] \\
& I_{\text {fica }}=I_{0} e^{-2 X^{\prime 2}-2 Y^{2}} e^{-A Z^{\prime}} A d Z
\end{aligned}
$$

onde $I_{0}$ é a intensidade no centro do feixe, dado por $I_{0}=2 P_{a b} /\left(\pi w^{2}\right)$. Na equação (A2) também fizemos exp(-AdZ')=1-AdZ'.

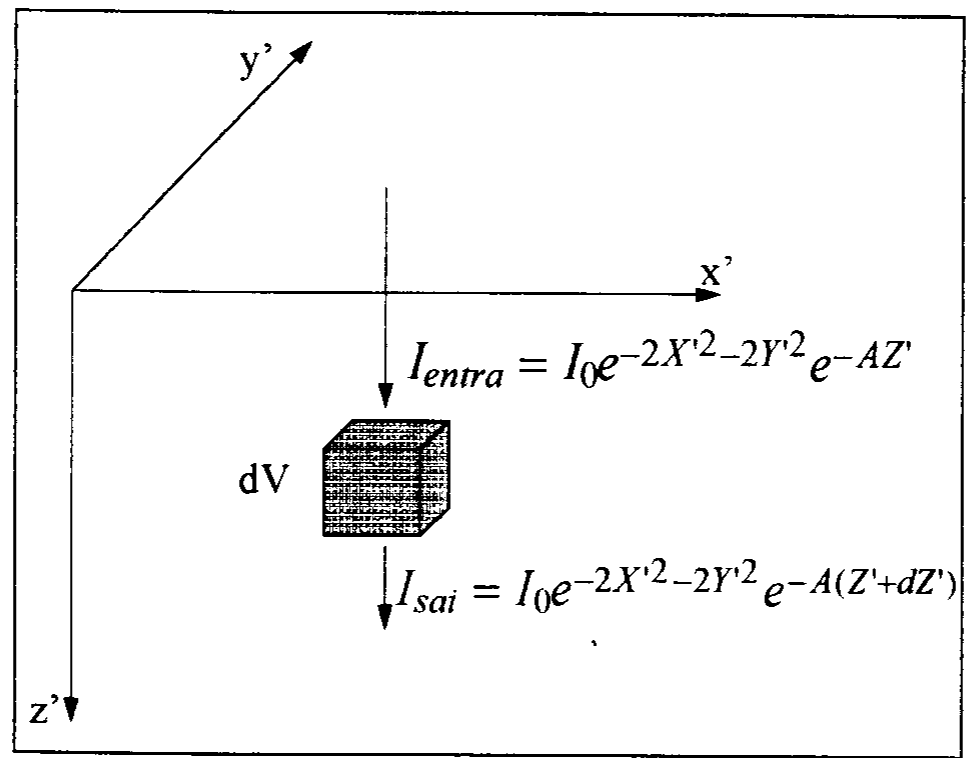

Figura A2: Representação da variação da intensidade com a profundidade de um elemento de volume devido a um feixe gaussiano atenuado exponencialmente.

$\mathrm{O}$ calor infinitesimal absorvido em $\mathrm{dV}$ é dada pela variação de intensidade vezes elemento de área perpendicular ao feixe vezes o instante de tempo que o meio fica exposto a luz, o que resulta em: 


$$
d Q=\frac{2 P_{a b} A}{\pi} d t \exp \left[-2\left(X^{\prime 2}+Y^{\prime 2}\right)-A Z^{\prime}\right] d X^{\prime} d Y^{\prime} d Z^{\prime}
$$

Precisamos ainda levar em conta que as amostras grossas são meios semiinfinitos. Neste caso a equação (A1) não é válida, pois, a interface bloqueia a difusão de calor modificando seu comportamento. No entanto, nestes meios, tudo se passa como se houvesse outra fonte de calor, dQ', idêntica a dQ, situada numa posição simétrica em relação ao plano da interface. Em outras palavras, é como se a interface fosse um espelho através do qual um suposto detetor na amostra sentisse o calor vindo de duas fontes: uma real, gerado pelo feixe dentro do meio e outra virtual, que nada mais é do que a imagem da primeira situada fora do meio [13]. Este efeito de reflexão de calor é representada na figura $\mathrm{A} 3$.
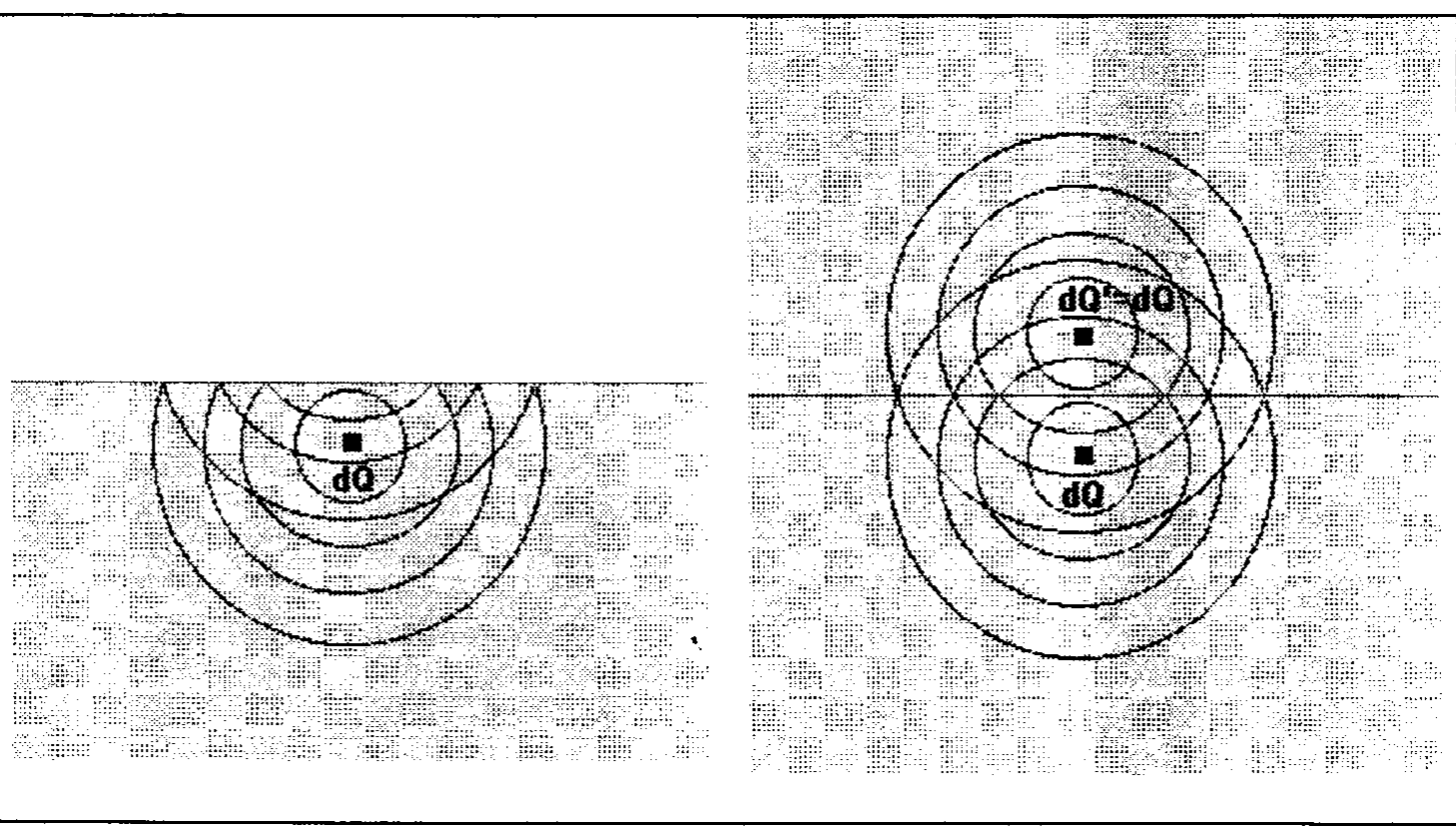

Figura A3: $O$ comportamento da difusão de calor num meio semi-infinito a partir de uma fonte puntual é idêntico ao de um meio infinito com duas fontes puntuais simétricas em relação à interface.

Assim, podemos calcular a temperatura na amostra usando a equação (A1), levando em conta duas fontes de calor. 
Apêndice A

Cálculo da Temperatura nas Amostras

69

Inicialmente calcularemos a temperatura em $(\mathrm{R}, \mathrm{Z})$ devido a um pulso infinitesimal de duração dt' integrando a equação (A1) sobre todos os elementos dQ e dQ' gerados no volume. Assim obtemos:

$$
\begin{aligned}
& d \theta(R, Z)=\frac{P_{a b} A}{4 \pi \rho C_{p}\left(\pi D\left(t-t^{\prime}\right)\right)^{\frac{3}{2}}} \int_{-\infty}^{\infty} e^{-X^{2}} e^{-2 f^{\prime}\left(R-X^{\prime}\right)^{2}} d X^{\prime} \int_{-\infty}^{\infty} e^{-Y^{2}} e^{-2 f^{\prime} Y^{2}} d Y^{\prime} \times \\
& \left(\int_{-\infty}^{0} e^{A Z^{\prime}} e^{-2 f^{\prime}\left(Z-Z^{\prime}\right)^{2}} d Z^{\prime}+\int_{0}^{\infty} e^{-A Z^{\prime}} e^{-2 f^{\prime}\left(Z-Z^{\prime}\right)^{2}} d Z^{\prime}\right)
\end{aligned}
$$

onde $\mathrm{f}^{\prime}=\mathrm{w}^{2} /\left[8 \mathrm{D}\left(\mathrm{t}-\mathrm{t}^{\prime}\right)\right]$, o que resulta $\mathrm{em}$ :

$$
\begin{aligned}
& d \Delta \theta=\frac{P_{a b} A}{\pi \rho C_{p} w^{3}} d t^{\prime} \frac{f^{\prime}}{1+f^{\prime}} e^{\frac{-2 f^{\prime}}{1+f^{\prime}} R^{2}-2 f^{\prime} Z} \times \\
& {\left[e^{-\frac{A-4 f^{\prime} Z}{\sqrt{8 f^{\prime}}}} \operatorname{erfc}\left(\frac{A-4 f^{\prime} Z}{\sqrt{8 f^{\prime}}}\right)+e^{\frac{A+4 f^{\prime} Z}{\sqrt{8 f^{\prime}}}} \operatorname{erfc}\left(\frac{A+4 f^{\prime} Z}{\sqrt{8 f^{\prime}}}\right)\right]}
\end{aligned}
$$

Integrando no tempo de duração do feixe, obtemos:

$$
\begin{aligned}
& \Delta \theta=\frac{P_{a b} A}{\pi \rho C_{p} w^{3}} \int_{0}^{t_{1}} \frac{f^{\prime}}{1+f^{\prime}} e^{\frac{-2 f^{\prime}}{1+f^{\prime}} R^{2}-2 f^{\prime} Z} \times \\
& {\left[e^{\frac{A-4 f^{\prime} Z}{\sqrt{8 f^{\prime}}}} \operatorname{erfc}\left(\frac{A-4 f^{\prime} Z}{\sqrt{8 f^{\prime}}}\right)+e^{\frac{A+4 f^{\prime} Z}{\sqrt{8 f^{\prime}}}} \operatorname{erfc}\left(\frac{A+4 f^{\prime} Z}{\sqrt{8 f^{\prime}}}\right)\right] d t^{\prime}}
\end{aligned}
$$


onde $t_{1}$ é o tempo de duração do feixe. Mudando a variável de integração de t' para $\mathrm{f}^{\prime}$, observando que $\mathrm{t}^{\prime}=\mathrm{t}-\mathrm{w}^{2} /(8 \mathrm{Df})$, obtemos a variação de temperatura dada por:

$$
\begin{gathered}
\Delta \theta=\frac{P_{a b} A}{8 \pi k_{t e r} w} \int_{w^{2}}^{\frac{w^{2}}{8 D(t-t)}} \frac{1}{f^{\prime}\left(1+f^{\prime}\right)} e^{\frac{-2 f^{\prime}}{1+f^{\prime}} R^{2}-2 f^{\prime} Z} \times \\
{\left[e^{\frac{A-4 f^{\prime} Z}{\sqrt{8 f^{\prime}}}} \operatorname{erfd}\left(\frac{A-4 f^{\prime} Z}{\sqrt{8 f^{\prime}}}\right)+e^{\frac{A+4 f^{\prime} Z}{\sqrt{8 f^{\prime}}}} \operatorname{erfd}\left(\frac{A+4 f^{\prime} Z}{\sqrt{8 f^{\prime}}}\right)\right] d f^{\prime}}
\end{gathered}
$$

A expressão (A7) é a mais simples que se pode obter para temperatura em função da posição e do tempo para meios semi-infinitos. Se estivermos observando a temperatura ao final da duração do feixe, a integral da equação (A7) se estende a infinito

\section{A2. Distribuição de temperatura em duas dimensões para}

\section{meios infinitos}

Para o cálculo da temperatura em duas dimensões, partiremos da solução de um elemento de calor depositado no meio, como fizemos na seção anterior. Esta solução é dada por [13]

$$
d \Delta \theta=\frac{d Q\left(X^{\prime}, Y^{\prime}\right) / L}{4 \pi \rho C_{p} D\left(t-t^{\prime}\right)} e^{\frac{-w^{2}}{4 D\left(t-t^{\prime}\right)}\left[\left(X^{\prime}-R\right)^{2}+Y^{\prime} 2\right]}
$$

onde $\mathrm{dQ}\left(\mathrm{X}^{\prime}, \mathrm{Y}^{\prime}\right) / \mathrm{L}$ é a densidade linear de calor depositado sobre uma área $\mathrm{dX} \mathrm{X}^{\prime} \mathrm{Y}^{\prime}$ em $\left(X^{\prime}, Y^{\prime}\right)$, dado por: 


$$
\frac{d Q}{L}=\frac{2 P \alpha_{a b}}{\pi} d t^{\prime} e^{-2\left(X^{\prime} 2+Y^{\prime} 2\right)} d X^{\prime} d Y^{\prime}
$$

Integrando no espaço, obtemos a temperatura para um pulso:

$$
d \Delta \theta=\frac{P \alpha_{a b}}{2 \pi^{2} \rho C_{p} D\left(t-t^{\prime}\right)} d t^{\prime} \int_{-\infty}^{\infty} e^{-2 X^{\prime 2}-2 f^{\prime}\left(X^{\prime}-R\right)^{2}} d X^{\prime} \int_{-\infty}^{\infty} e^{-2 Y^{2}\left(1+f^{\prime}\right)} d Y^{\prime}
$$

Resolvendo as integrais em (A10) e integrando no tempo:

$$
d \Delta \theta(R)=\frac{P \alpha_{a b}}{4 \pi k_{t e r}} \int_{0}^{t_{1}} \frac{1}{\left(t-t^{\prime}\right)} \frac{1}{1+f^{\prime}} e^{-\frac{2 f}{1+f} R^{2}} d t^{\prime}
$$

Mudando a variável de integração de t' para f', lembrando que $t^{\prime}=t-w^{2} / 8 D f^{\prime}$ obtemos:

$$
\Delta \theta(R)=\frac{P \alpha_{a b}}{4 \pi k_{t e r}} \int_{\frac{w^{2}}{8 D t}}^{\frac{w^{2}}{8 D(t-t)}} \frac{1}{f^{\prime}\left(1+f^{\prime}\right)} e^{-\frac{2 f^{\prime}}{1+f^{\prime}} R^{2}} d f^{\prime}
$$

A integral em (A12) é solúvel resultando em:

$$
\Delta \theta(R)=\frac{P \alpha_{a b}}{4 \pi k_{t e r}}\left[E i\left(-\frac{2 R^{2}}{1+\frac{8 D\left(t-t_{1}\right)}{w^{2}}}\right)-E i\left(-\frac{2 R^{2}}{1+\frac{8 D t}{w^{2}}}\right)\right]
$$


Apêndice B

Cálculo da Deformação na Superfície 


\section{B1. Introdução}

Neste apêndice mostraremos o cálculo da deformação na superficie de um meio aquecido por uma fonte gaussiana. A solução da equação de Navier-Stokes para um meio de espessura L foi calculada por Olmstead et al.(1983) [26]. Nesta solução, tomaremos casos limites para espessura $(\mathrm{L} \rightarrow \infty$ e $\mathrm{L} \rightarrow 0)$ e então substituiremos as temperaturas obtidas no apêndice B para cada caso e, resolvendo as integrais passo a passo obteremos a deformação superficial.

A solução geral para deformação superficial calculada por Olmstead et al. [26] é dada por:

$$
\begin{gathered}
u_{z p}(r, z=0)=-\alpha_{t e r} \frac{1+v}{1-v} \int_{0}^{\infty} \int_{0}^{\infty} \int_{0} k \rho \theta(\rho, \zeta) J_{0}(k \rho) J_{0}(k r) \times \\
\frac{\operatorname{senh}(k L-k \zeta)}{\operatorname{senh}(k L)} d \zeta d \rho d k \\
u_{z h}(r, z=0)=(1-2 v)^{-1} \int_{0}^{\infty} k^{2} J_{0}(k r) \times \\
\left\{\operatorname{senh}\left(\frac{k L}{2}\right)\left[A-\frac{k L}{2} B-2 D(1-2 v)\right]+\cosh \left[-C+\frac{k L}{2} D+2 B(1-2 v)\right]\right\} d k \\
\operatorname{com}, \quad \\
A=I_{1} \frac{\left[(1-2 v) \cosh \left(\frac{k L}{2}\right)-\frac{k L}{2} \operatorname{senh}\left(\frac{k L}{2}\right)\right]}{\operatorname{senh}(k L)+k L} \\
B=I_{2} \frac{\operatorname{senh}\left(\frac{k L}{2}\right)}{\operatorname{senh}(k L)-k L}
\end{gathered}
$$




$$
\begin{aligned}
& C=I_{2} \frac{\left[(1-2 v) \operatorname{senh}\left(\frac{k L}{2}\right)-\frac{k L}{2} \cosh \left(\frac{k L}{2}\right)\right]}{\operatorname{senh}(k L)-k L} \\
& D=I_{1} \frac{\cosh \left(\frac{k L}{2}\right)}{\operatorname{senh}(k L)+k L}
\end{aligned}
$$

e com

$$
\begin{aligned}
& I_{1}=2 \alpha_{t e r}(1-2 v) \frac{1+v}{1-v} \int_{0}^{\infty} \int_{0}^{L} \rho J_{0}(k \rho) \theta(\rho, \zeta) \frac{\operatorname{senh}\left(\frac{k L}{2}\right) \cosh \left(k \zeta-\frac{k L}{2}\right)}{k \cdot \operatorname{senh}\left(\frac{k L}{2}\right)} d \zeta d \rho \\
& I_{2}=2 \alpha_{t e r}(1-2 v) \frac{1+v}{1-v} \int_{0}^{\infty} \int_{0}^{L} \rho J_{0}(k \rho) \theta(\rho, \zeta) \frac{\cosh \left(\frac{k L}{2}\right) \operatorname{senh}\left(k \zeta-\frac{k L}{2}\right)}{k \cdot \operatorname{senh}\left(\frac{k L}{2}\right)} d \zeta d \rho
\end{aligned}
$$

\section{B2. Deformação para amostras grossas $\mathbf{L} \rightarrow \infty$}

Nas equações acima, fazendo $\mathrm{L} \rightarrow \infty$, ficamos com:

$$
\begin{gathered}
A=-C=I^{\prime} e^{-\frac{k L}{2}}\left(1-2 v-\frac{k L}{2}\right) . \\
D=-B=I^{\prime} e^{-\frac{k L}{2}} \\
I^{\prime}=2 \alpha_{t e r}(1-2 v) \frac{1+v}{1-v} \int_{0}^{\infty} \int_{0}^{\infty} \rho J_{0}(k \rho) \theta(\rho, \zeta) e^{-k \zeta} d \zeta d k
\end{gathered}
$$

obtemos: 


$$
\begin{aligned}
& u_{z h}=-\alpha_{t e r}(1-2 v) \frac{1+v}{1-v} \int_{0}^{\infty} \int_{0}^{\infty} \int_{0}^{\infty} k \rho J_{0}(k \rho) J_{0}(k r) \theta(\rho, \zeta) e^{-k \zeta} d \rho d \zeta d k \\
& u_{z p}=-\alpha_{t e r} \frac{1+v}{1-v} \int_{0}^{\infty} \int_{0}^{\infty} \int_{0}^{\infty} k \rho J_{0}(k \rho) J_{0}(k r) \theta(\rho, \zeta) e^{-k \zeta} d \rho d \zeta d k
\end{aligned}
$$

Cuja solução geral é dada pela soma da particular e da homogênea:

$$
u_{z}(r, 0)=-2 \alpha_{t e r}(1+v) \iint_{0}^{\infty} \int_{0}^{\infty} \int_{0}^{\infty} k \rho J_{0}(k \rho) J_{0}(k r) e^{-k \zeta} \Delta \theta(\rho, \zeta) d \rho d \zeta d k
$$

Na equação (B14) convém transformar as variáveis $\rho, \zeta$ e r em unidades de $w$, e a variável $\mathrm{k}$ em unidades de $\mathrm{w}^{-1}$. Tal que, $\rho=w P, \zeta=w Z, r=w R, k=w^{-1} K$. Assim ficamos com (B14) da forma:

$$
u_{z}(R, 0)=-2 \alpha_{t e r}(1+v) w \iint_{0}^{\infty} \int_{0}^{\infty} \int_{0}^{\infty} K P J_{0}(K P) J_{0}(K R) e^{-K Z} \Delta \theta(P, Z) d P d Z d K
$$

Assim podemos substituir a temperatura dada pela equação (1.10), cujas variáveis também estão em unidades de $\mathrm{w}$, mostrada abaixo:

$$
\begin{aligned}
& \Delta \theta(P, Z)=\frac{P_{a h} A}{8 \pi k_{t e r} w} \int_{\frac{w^{2}}{8 D t}}^{\infty} \frac{e^{\frac{-2 f}{1+f} P^{2}-2 f Z^{2}}}{f(1+f)} \times \\
& {\left[e^{\frac{A-4 f Z}{\sqrt{8 f}}} \operatorname{erf}\left(\frac{A-4 f Z}{\sqrt{8 f}}\right)+e^{\frac{A+4 f Z}{\sqrt{8 f}}} \operatorname{erf}\left(\frac{A+4 f Z}{\sqrt{8 f}}\right)\right] d f}
\end{aligned}
$$


teremos que calcular as seguintes integrais para $\mathrm{P}$ e Z:

$$
\begin{aligned}
& \int_{0}^{\infty} P J_{0}(K P) e^{\frac{-2 f}{1+f} P^{2}} d P=\frac{1+f}{4 f} e^{\frac{-(1+f)}{8 f} K^{2}} \\
& \int_{0}^{\infty} e^{-2 f Z^{2}-K Z}\left[e^{\left(\frac{A-4 f Z}{\sqrt{8 f}}\right)^{2}} \operatorname{erfc}\left(\frac{A-4 f Z}{\sqrt{8 f}}\right)+e^{\left(\frac{A+4 f Z}{\sqrt{8 f}}\right)^{2}} \operatorname{erf}\left(\frac{A+4 f Z}{\sqrt{8 f}}\right)\right] d Z= \\
& e^{\frac{A^{2}}{8 f}} \int_{0}^{\infty} e^{-(A+K) Z} \operatorname{erfd}\left(\frac{A-4 f Z}{\sqrt{8 f}}\right)+e^{(A-K) Z} \operatorname{erfc}\left(\frac{A+4 f Z}{\sqrt{8 f}}\right) d Z= \\
& \frac{e^{\frac{A^{2}}{8 f}} \operatorname{erf}\left(\frac{A}{\sqrt{8 f}}\right)+e^{\frac{K^{2}}{8 f}} \operatorname{erfd}\left(\frac{K}{\sqrt{8 f}}\right)}{A+K}-\frac{e^{\frac{A^{2}}{8 f}} \operatorname{erfd}\left(-\frac{A}{\overline{8 f}}\right)-e^{\frac{K^{2}}{8 f}} \operatorname{erfd}\left(\frac{K}{\sqrt{8 f}}\right)}{A-K}
\end{aligned}
$$

As integrais de (B17) e (B18) foram resolvidas com a ajuda do "software" Mathematica. Em (B18), na integral que aparece depois da primeira igualdade, fazemos uma integração por partes sobre cada termo para que o computador consiga resolvê-la a partir do resultado desta operação

Substituindo as soluções dadas em (B17) e (B18) em (B15), ficamos com:

$$
u(R)=\frac{-P_{a h} A \alpha_{t e r}(1+v)}{16 \pi k_{t e r}} \int_{0}^{\infty} K e^{-\frac{K^{2}}{8}} J_{0}(K R) \int_{\frac{w^{2}}{8 D t}}^{\infty} \frac{1}{f^{2}} \times
$$

$$
\frac{e^{\frac{A^{2}-K^{2}}{8 f}} \operatorname{erfc}\left(\frac{A}{\sqrt{8 f}}\right)+\operatorname{erfc}\left(\frac{K}{\sqrt{8 f}}\right)}{A+K}-\frac{e^{\frac{A^{2}-K^{2}}{8 f}} \operatorname{erf}\left(\frac{A}{\sqrt{8 f}}\right)-\operatorname{erfc}\left(\frac{K}{\sqrt{8 f}}\right)}{A-K} d f d K
$$


Mudando a variável de integração de (B19) de $f$ para fi tal que fi=1/8f, simplificamos esta equação obtendo:

$$
\begin{aligned}
& u(R)=\frac{-P_{a b} A \alpha_{t e r}(1+v)}{2 \pi k_{t e r}} \int_{0}^{\infty} K e^{-\frac{K^{2}}{8}} J_{0}(K R) \times \\
& {\left[\int_{0}^{\frac{D t}{w^{2}} \frac{e^{\left(A^{2}-K^{2}\right) f i}}{\operatorname{erfd}(A \sqrt{f i})+e r f d(K \sqrt{f i})}}-\right.} \\
& {\left[\frac{e^{\left(A^{2}-K^{2}\right) f i} \operatorname{erfc}(A \sqrt{f i})-\operatorname{erfd}(K \sqrt{f i})}{A-K} d f i\right] d K}
\end{aligned}
$$

Para tempos curtos podemos expandir a integral em fi da equação (B20):

$$
\begin{aligned}
& \int_{0}^{f i} F(f i) d f i=\frac{2 f i}{A+K}-K . f i^{2}+0.602 A . K . f i^{5 / 2}+ \\
& 0.333\left(K^{2}+\mathrm{A}^{2}\right) f i^{3}+0.086 A \cdot K\left(2 A^{2}+3 K^{2}\right) f i^{7 / 2}- \\
& 0.0833 K\left(K^{2}-A^{2}\right)^{2} f i^{4}+ \\
& 0.00478 A \cdot K\left(8 A^{4}-20 A^{2} K^{2}+15 K^{4}\right) f i^{9 / 2}+ \\
& 0.0167 K\left(K^{2}-A^{2}\right)^{3} f i^{5}
\end{aligned}
$$

\section{B3. Deformação para amostras finas $(L \rightarrow 0)$}

Nas equações de (B1) a (B8) fazendo $L \rightarrow 0$, obtemos 


$$
\begin{aligned}
& A=\frac{I^{\prime}(1-2 v)}{2 k L} \\
& D=\frac{I^{\prime}}{2 k L} \\
& B=C=0
\end{aligned}
$$

com

$$
I^{\prime}=\alpha_{t e r}(1-2 v) \frac{1+v}{1-v} L \int_{0}^{\infty} \frac{\rho}{k} J_{0}(k \rho) T(\rho) d \rho
$$

Substituindo (B22) e (B23) em (B1) e (B2) ficamos com:

$$
u_{z h}=\frac{v}{2} \alpha_{t e r} \frac{1+v}{1-v} L \int_{0}^{\infty} \int_{0}^{\infty} k \rho J_{0}(k \rho) J_{0}(k r) T(\rho) d \rho d k
$$

e

$$
u_{z p}=-\frac{1}{2} \alpha_{t e r} \frac{1+v}{1-v} L \int_{0}^{\infty} \int_{0}^{\infty} k \rho J_{0}(k \rho) J_{0}(k r) T(\rho) d \rho d k
$$

A soma de (B24) com (B25) dá o deslocamento na superficie. Transformando $\rho$ e $\mathrm{k}$ em $\mathrm{P}$ e $\mathrm{K}$ como feito no cálculo do deslocamento superficial em amostras grossas, obtemos:

$$
u_{z}(R)=-\frac{1}{2} \alpha_{t e r}(1+v) L \int_{0}^{\infty} \int_{0}^{\infty} K P J_{0}(K P) J_{0}(K R) \theta(P) d P d K
$$

Substituindo a temperatura dada pela expressão (1.15), obtemos: 


$$
\begin{aligned}
& u_{z}(R)=-\frac{1}{2} \alpha_{t e r}(1+v) L \times \frac{P \alpha_{a b}}{4 \pi k_{t e r}} \int_{0}^{\infty} \int_{0}^{\infty} K P J_{0}(K P) J_{0}(K R) \times \\
& {\left[E_{i}\left(-2 R^{2}\right)-E_{i}\left(-\frac{2 R^{2}}{1+\frac{8 D t}{w^{2}}}\right)\right] d P d K}
\end{aligned}
$$

Resolvendo a integral em P:

$$
\int_{0}^{\infty} P J_{0}(K P)\left[E_{i}\left(-2 P^{2}\right)-E_{i}\left(\frac{-2 P^{2}}{1+\frac{8 D t}{w^{2}}}\right)\right] d P=\frac{2 e^{-\frac{K^{2}}{8}}}{K^{2}}\left(1-e^{-\frac{K^{2} D t}{u^{2}}}\right)
$$

obtemos:

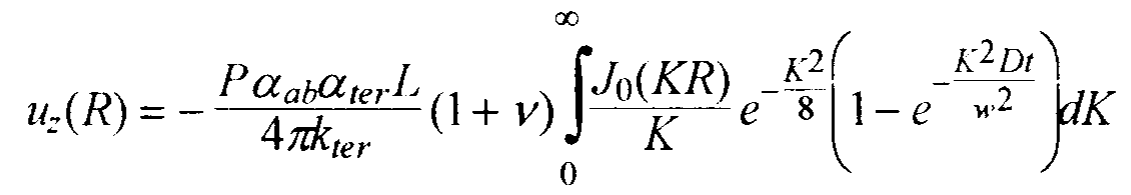

A integral de (B28) é resolvida no Mathematica. As expressões (B20) e (B29) aparecem negativas por que definimos a região positiva de $z$ da superficie da amostra para dentro, enquanto a deformação acontece da superficie para fora. 
Apêndice C

Decomposição Espectral

\author{
do Sinal
}




\section{C1. Introdução}

Neste apêndice aplicaremos as equações gerais da teoria das séries de Fourier sobre o sinal do detector para tratarmos matematicamente os sinais dos lock-ins em dois casos: (i) análise do sinal para frequências suficientemente altas e (ii) análise do sinal para frequências moderadamente altas. A diferença entre eles está relacionada à difusão de calor na amostra. Para frequências suficientemente altas do chopper o período é tão curto que a difusão de calor neste período é desprezivel, e portanto, o sinal é linear no tempo. Definimos frequências moderadamente altas como aquelas em cujo periodo apenas uma pequena difusão possa ocorrer. Desta forma, a evolução temporal do sinal pode ser representada por apenas três termos: um constante, um linear e um quadrático no tempo. Frequências muito baixas requerem termos de ordem maior para representar a evolução temporal, complicando muito a análise teórica.

\section{C2. Análise espectral do sinal para frequências suficientemente}

altas

Da teoria das séries de Fourier [27] temos que toda função periódica pode ser representada por uma série infinita de senos e cosenos dada por:

$$
f(t)=a_{0}+\sum_{n=1}^{\infty}\left(a_{n} \cos \left(2 \pi n \frac{t}{T}\right)+b_{n} \operatorname{sen}\left(2 \pi n \frac{t}{T}\right)\right)
$$

onde T é o período da função, e com 


$$
\begin{aligned}
& a_{0}=\frac{1}{T} \int_{0}^{T} f(t) d t \\
& a_{n}=\frac{2}{T} \int_{0}^{T} f(t) \cos \left(2 n \pi \frac{t}{T}\right) d t \\
& b_{n}=\frac{2}{T} \int_{0}^{T} f(t) \operatorname{sen}\left(2 n \pi \frac{t}{T}\right) d t
\end{aligned}
$$

A função que representa o sinal em um período com frequência suficientemente alta é dada por:

$$
\begin{array}{cc}
S=0 & p / \frac{-1}{2 f}<t<0 \\
S=S_{0}\left(1+T^{(1)}(Z) t\right) & p / 0<t<\frac{1}{2 f}
\end{array}
$$

onde $\mathrm{f}$ é a frequência ( $\mathrm{f}=1 / \mathrm{T}$ ) e cujo gráfico tem a forma mostrada na figura $\mathrm{Cl}$

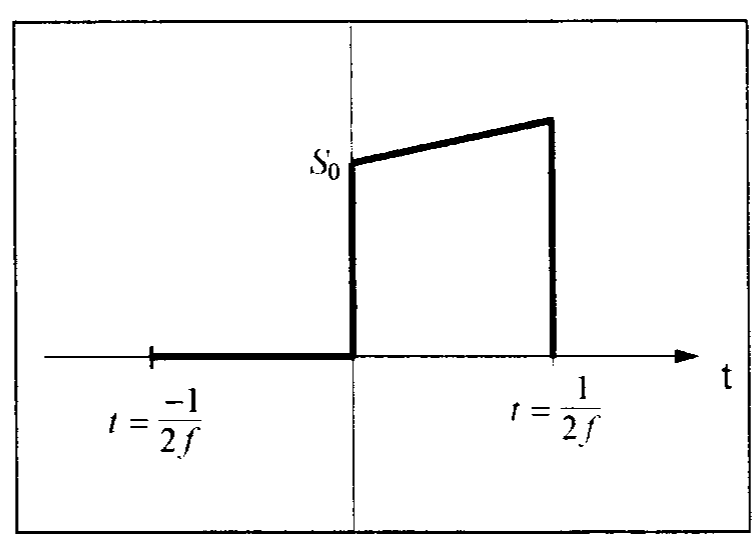

Figura C1: Representação esquemática de um período do sinal visto no osciloscópio.

Substituindo a função definida por (C5) nas expressões para $a_{1}, a_{n}$ e $b_{n}$, obtemos: 


$$
\begin{gathered}
a_{0}=\frac{S_{0}}{2}+\frac{S_{0} T^{(1)}(Z)}{8 f} \\
a_{n}=\frac{-S_{0} T^{(1)}(Z)}{f n^{2} \pi^{2}} \operatorname{sen}\left(\frac{n \pi}{2}\right)^{2} \\
b_{n}=\frac{S_{0}}{n \pi}\left(1-\cos (n \pi)-\frac{T^{(1)}(Z)}{2 f} \cos (n \pi)+\frac{T^{(1)}(Z)}{2 f n \pi} \operatorname{sen}(n \pi)\right)
\end{gathered}
$$

Substituindo as expressões acima na equação (C1) obtemos a representação em série de Fourier da função $S(t)$ como:

$$
\begin{aligned}
& S(t)=\frac{S_{0}}{2}+\frac{S_{0} T^{(1)}(Z)}{8 f}+ \\
& \sum_{n=1}^{\infty}\left\{\frac{-S_{0} T^{(1)}(Z)}{f n^{2} \pi^{2}} \operatorname{sen}\left(\frac{n \pi}{2}\right)^{2} \cos (2 n \pi f t)+\right. \\
& \left.\frac{S_{0}}{n \pi}\left(1-\cos (n \pi)-\frac{T^{(1)}(Z)}{2 f} \cos (n \pi)+\frac{T^{(1)}(Z)}{2 f n \pi} \operatorname{sen}(n \pi)\right) \operatorname{sen}(2 n \pi f t)\right\}
\end{aligned}
$$

A figura C2 mostra a expressão (C9), com a somatória truncada para alguns valores de $n$. Cada termo da somatória, ligado a um valor de $n$, representa um modo normal de oscilação. O que o sistema de aquisição faz por meio dos lock-ins é discriminar estas componentes. No caso, as componentes com $n=1$ e $n=2$. 


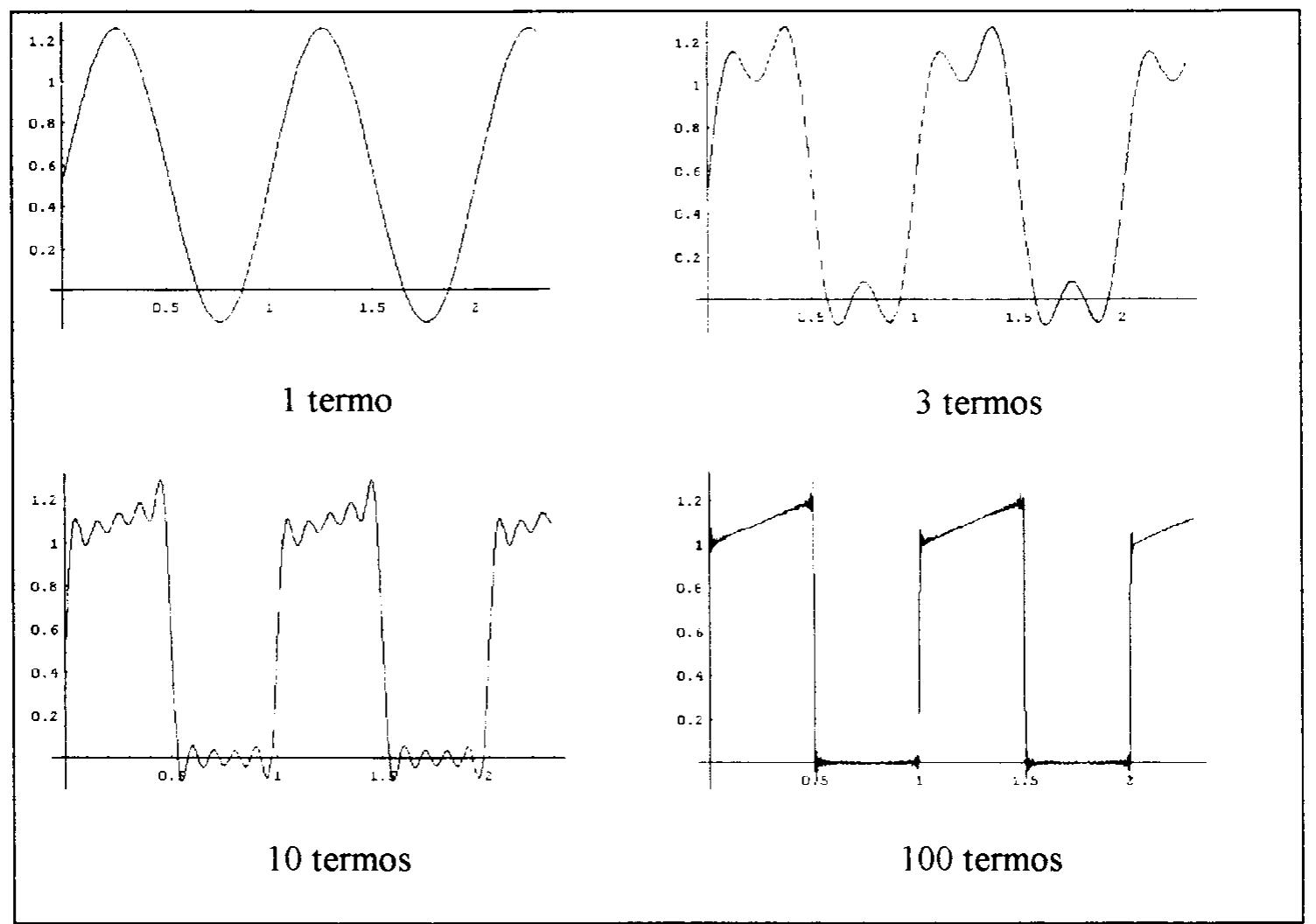

Figura C2: Gráfico da expressão (C9) conforme acrescentamos termos a somatória.

As duas primeiras componentes oscilatórias no tempo obtidas fazendo $n=1 \mathrm{e}$ $\mathrm{n}=2$ são dadas respectivamente por:

$$
\begin{gathered}
c_{1}=\frac{2 S_{0}}{\pi} \\
c_{2}=\frac{S_{0} T^{(1)}(Z)}{4 f \pi}
\end{gathered}
$$

onde levamos em conta que na prática $T^{(1)}(Z)<<1$ e a razão destas componentes nos dá uma função normalizada que chamaremos de $R(Z)$ relacionada com $T^{(1)}(Z)$ da forma:

$$
R(Z)=\frac{c_{2}}{c_{1}}=\frac{T^{(1)}(Z)}{8 f}
$$




\section{C3. Análise espectral do sinal para frequências}

\section{moderadamente altas}

Como discutimos na introdução deste apêndice, a condição de frequências moderadamente altas nos permite escrever a evolução temporal como

$$
\begin{array}{cc}
S=0 & p / \frac{-1}{2 f}<t<0 \\
S=S_{0}\left(1+T^{(1)}(Z) t+T^{(2)}(Z) t^{2}\right) & p / 0<t<\frac{1}{2 f}
\end{array}
$$

cuja série de Fourier é dada de forma geral por:

$$
S(t)=a_{0}+\sum_{n=1}^{\infty} a_{n} \cos (2 n \pi f t)+b_{n} \operatorname{sen}(2 n \pi f t)
$$

Substituindo a expressão (C12) nas fórmulas de $\mathrm{a}_{0}, \mathrm{a}_{\mathrm{n}}$ e $\mathrm{b}_{\mathrm{n}}$ obtermos:

$$
\begin{gathered}
a_{0}=S_{0}\left(\frac{1}{2}+\frac{T^{(1)}(Z)}{8 f}+\frac{T^{(2)}(Z)}{24 f^{2}}\right) \\
a_{n}=\frac{S_{0}}{2 f n^{2} \pi^{2}}\left[T^{(1)}(Z)(\cos (n \pi)-1)+\frac{T^{(2)}(Z)}{f} \cos (n \pi)\right] \\
b_{n}=\frac{S_{0}}{n \pi}\left[\begin{array}{l}
\left(1-\cos (n \pi)-\frac{T^{(1)}(Z)}{2 f} \cos (n \pi)-\right. \\
\frac{T^{(2)}(Z)}{2(f n \pi)^{2}}\left(1-\cos (n \pi)-\frac{T^{(2)}(Z)}{4 f^{2}} \cos (n \pi)\right.
\end{array}\right]
\end{gathered}
$$

que determinam completamente a série de Fourier para $S(t)$.

A figura C3 mostra o gráfico da equação (C13) com 100 termos. 


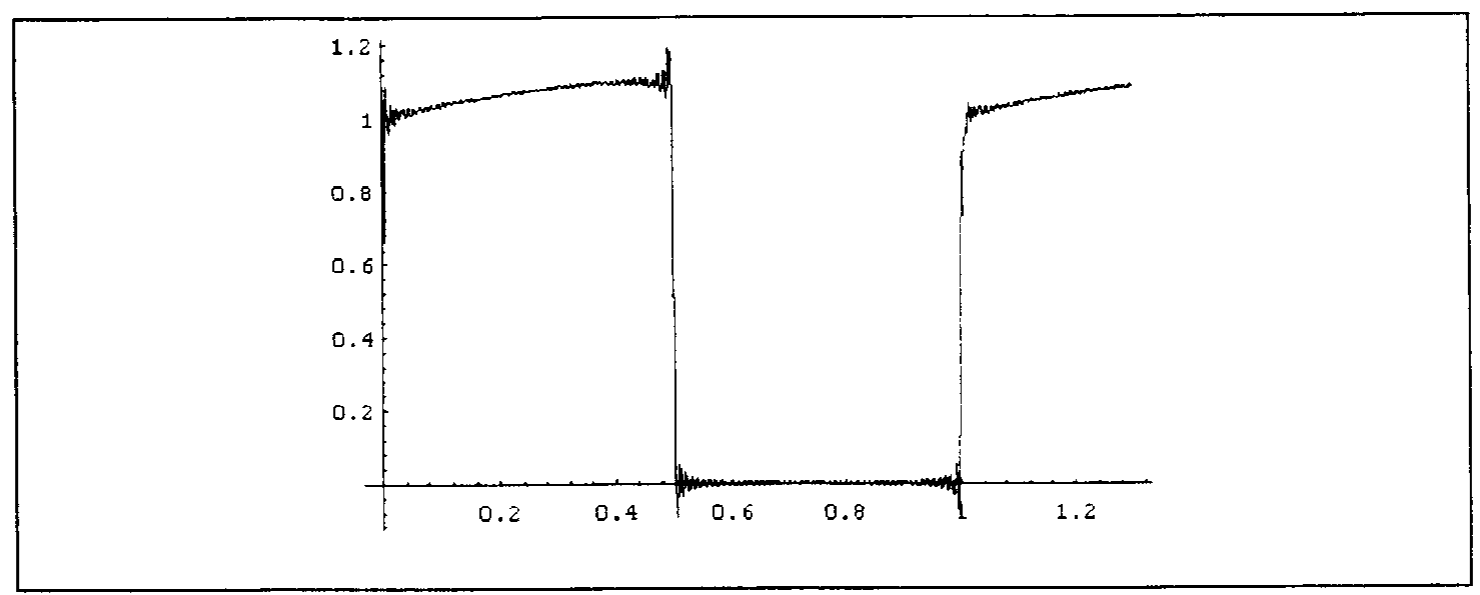

Figura C3: Gráfico da função (C13) com 100 termos. A curvatura da evolução temporal é devida ao termo com $\mathrm{T}^{(2)}(\mathrm{Z})$ que leva em conta a difusão de calor.

As expressões teóricas das componentes com $n=1$ e $n=2$ são dadas respectivamente por:

$$
\begin{gathered}
c_{1}=\frac{2 S_{0}}{\pi} \\
c_{2}=\frac{S_{0}}{8 f^{2} \pi} \sqrt{\frac{T^{(2)}(Z)^{2}}{\pi^{2}}+\left[2 f T^{(1)}(Z)+T^{(2)}(Z)\right]^{2}}
\end{gathered}
$$

onde consideramos que $T^{(1)}(Z)$ e $T^{(2)}(Z) \ll 1$. Esta consideração se verifica na prática. Experimentalmente, estas componentes são obtidas pelos lock-ins que as discriminam do sinal. A razâo entre elas dá a transmitância normalizada $T(Z)$ :

$$
R(Z)=\frac{c_{2}}{c_{1}}=\frac{1}{16 f^{2}} \sqrt{\frac{T^{(2)}(Z)^{2}}{\pi^{2}}+\left[2 f T^{(1)}(Z)+T^{(2)}(Z)\right]^{2}}
$$

Observem na equação (C18) que para frequências altas a contribuição dos termos com $T^{(2)}(Z)$ é desprezivel, recaindo no caso da seção 2 


\section{C4. Análise espectral para frequências baixas}

Se a evolução temporal do sinal tiver que ser descrita por termos de ordem superior ao quadrático, a função $\mathbb{R}(Z)$ com termos até quinta ordem fica:

$$
R(Z)=\left(\begin{array}{l}
\left.0.125 \frac{T^{(1)}}{f}+0.0625 \frac{T^{(2)}}{f^{2}}+0.0265 \frac{T^{(3)}}{f^{3}}+0.0109 \frac{T^{(4)}}{f^{4}}+\right)^{2} \\
\left.0.0045 \frac{T^{(5)}}{f^{5}}+0.041 \frac{T^{(5 / 2)}}{f^{(5 / 2)}}+0.017 \frac{T^{(7 / 2)}}{f^{(7 / 2)}}+0.007 \frac{T^{(9 / 2)}}{f^{(9 / 2)}}\right)^{2}
\end{array}\right.
$$

Uma possível aplicação da função $\mathbb{R}(Z)$ com tantos termos seria na análise de metais que possuem difusividades muito altas. Na analise por transmissão, a equação (C19) só possui os termos inteiros. Os semi-inteiros aparecem na análise por reflexão. 


\section{Referências}


[1] Y. R. Shen, "Principles of Nonlinear Optics", John Wiley \& Sons (1984).

[2] P. A. Franken, A. E. Hill, C. W. Petters and G. Weinreich, Phys. Rev. Lett. 7, 118, (1961).

[3] M. Sheik-Bahae, A. A. Said and E. W. Van Stryland, Opt. Lett. 14, 995 (1989)

[4] M. Sheik-Bahae, A. A. Said, T. Wei, D. Hagan and E. W. Van Stryland, IEEE J. Quantum Electronics QE-26, 760 (1990)

[5] D. V. Petrov, A. S. L. Gomes and C. B. Araújo, Appl. Phys. Lett. 65, 29 (1994)

[6] L. C. Oliveira and S. C. Zilio, Appl. Phys. Lett., 65, 2121, (1994).

[7] C. R. Mendonça L. Misoguti and S. C. Zilio, Appl. Phys. Lett. 71, 2094 (1997)

[8] R. W. Boyd, "Nonlinear Optics", Academic Press, (1992).

[9] B. E. A. Saleh and M. C. Teich, "Fundamentals of Photonics" Jonh Wiley \& Sons (1991)

[10] A. Yariv "Optical Eletronics", Sounders College Publishing, $4^{\text {th }}$ edition, 45 (1991)

[11] D. V. Petrov, A. S. L. Gomes, and C. B. Araújo. Opt. Commun. 123, 637 (1996).

[12] W. Nowacki, "Thermoelasticity", Pergamon Press, Oxford, (1962).

[13] J. Crank, "The Mathematics of Diffusion", Oxford University Press, $2^{\text {nd }}$ edition, (1975)

[14] M. J. Weber, D. Milan and W. L. Smith, Opt. Eng. 17. 463 (1978).

[15] S. R. Friberg and P. W. Smith, IEEE J.Quantum Electronics. QE-23, 2098, (1986).

[16] R. Aidar, L. L. Chase and S. A. Payne, J. Opt. Soc. Am. B4, 875 (1987)

[17] A. Owyoung, IEEE J. Quantum Electronics. QE-9, 1064 (1973).

[18] W. E. Williams, M. J. Soileau and E. W. Van Stryland, Opt. Commun, 50, 256 (1984)

[19] Miles V. Klein, "Optics", John Wiley \& Sons, $2^{\text {nd }}$ edition (1975)

[20] H. Ma, A. S. L. Gomes and C. B. Araújo, Appl. Phys. Lett. 59 (21). 2666 (1991).

[21] D. F. Grosz and H. L. Fragnito (Unicamp, IFGW, Campinas, SP, Brazil) and E. Palange (Univeritá degli Studi, Roma, Italy), Comunicação pessoal 
[22] T. Xia, D. J. Hagan, M. Sheik-Bahae, and E. W. Van Stryland, Opt. Lett 19 , 317 (1994).

[23] Handbook of Chemestry and Physics, CRC Press, $73^{\text {rd }}$ edition, (1992).

[24] Polymer Handbook, John Wiley \&Sons, New York $2^{\text {nd }}$ edition.

[25] C. R. Mendonça, M. M. Costa, J. A. Giacometti, F. D. Nunes e S. C. Zilio, Elet. Lett. 34, 116, (1998).

[26] M. A. Olmstead, N. M. Amer, S. Kohn, D. Fournier and A. C. Boccara, Appl. Phys. A, 32141 (1983).

[27] E. Butkov, "Física Matemática", Guanabara Koogan, 156 (1988). 